\author{
UNIVERSIDADE DE SÃO PAULO \\ ESCOLA DE ENGENHARIA DE SÃO CARLOS \\ DEPARTAMENTO DE ENGENHARIA ELÉTRICA \\ PROGRAMA DE PÓS -GRADUAÇÃO EM ENGENHARIA ELÉTRICA
}

\author{
WILLIAN DARWIN JUNIOR \\ Mestre em Ciências, Programa de Engenharia Elétrica
}

\title{
Agrupamento de textos utilizando Divergência Kullback-Leibler
}

Trata-se da versão corrigida da dissertação. A versão original se encontra disponível na EESC/USP que aloja o Programa de Pós-Graduação de Engenharia Elétrica

São Carlos

2016 



\section{WILLIAN DARWIN JUNIOR}

Mestre em Ciências, Programa de Engenharia Elétrica

\section{Agrupamento de Textos Utilizando Divergência Kullback-Leibler}

Dissertação de Mestrado apresentada ao Programa de Engenharia Elétrica da Escola de Engenharia de São Carlos como parte dos requisitos para a obtenção do título de Mestre em Ciências.

Área de Concentração: Sistemas Dinâmicos Orientador: Prof. Dr. Carlos Dias Maciel

Trata-se da versão corrigida da dissertação. A versão original se encontra disponível na EESC/USP que aloja o Programa de Pós-Graduação de Engennharia Elétrica

São Carlos

2016 
AUTORIZO A REPRODUÇÃO E DIVULGAÇÃO TOTAL OU PARCIAL DESTE TRABALHO, POR QUALQUER MEIO CONVENCIONAL OU ELETRÔNICO, PARA FINS DE ESTUDO E PESQUISA, DESDE QUE CITADA A FONTE.

DARWIN JUNIOR, Willian

D228a Agrupamento de textos utilizando Divergência Kullback-Leibler / Willian DARWIN JUNIOR; orientador Carlos Dias MACIEL. São Carlos, 2016.

Dissertação (Mestrado) - Programa de Pós-Graduação em Engenharia Elétrica e Área de Concentração em Sistemas Dinămicos -- Escola de Engenharia de São Carlos da Universidade de São Paulo, 2016.

1. agrupamento de textos. 2. divergência Kullback-Leibler. 3. algoritmo k-means. 4. informação mútua. I. Título. 


\section{FOLHA DE JULGAMENTO}

Candidato: Engenheiro WILLIAN DARWIN JUNIOR.

Título da dissertação: "Agrupamento de textos utilizando divergência Kullback-Leibler".

Data da defesa: 22/02/2015

Comissão Julgadora:

$\underline{\text { Resultado: }}$

Prof. Associado Alexandre Cláudio Bołazzo Delbem (Presidente Designado)

APROVADO

(Instituto de Ciências Matemáticas e de Computação/ICMC)

Prof. Dr. Ailton Akira Shinoda

(Universidade Estadual Paulista "Júlio de Mesquita Filho"/UNESP - Ilha

Solteira)

Prof. Dr. Anderson da Silva Soares

APROVADO

(Universidade Federal de Goiás/UFG)

Coordenador do Programa de Pós-Graduação em Engenharia Elétrica: Prof. Associado Luis Fernando Costa Alberto

Presidente da Comissão de Pós-Graduação:

Prof. Associado Paulo César Lima Segantine 

A meu pai e maior amigo, Willian Darwin, que ainda estava aqui conosco quando essa trajetória se iniciou, mas cuja referência permaneceu me acompanhando por todo o tempo. 



\section{Agradecimentos}

Ao meu orientador e amigo Prof. Dr. Carlos Dias Maciel, por acreditar em mim, por me conceder essa oportunidade única e por proporcionar tudo o que foi necessário para esse trabalho.

Às minhas filhas Ana Carolina e Flávia, pela compreensão pelo tempo indisponível e pela extrema colaboração no cumprimento das suas responsabilidades.

À minha esposa Giselda, com amor, pelo incansável apoio e pelo carinho alentador.

À minha chefe e colega de trabalho, Ana Paula Gervásio Silveira, pelo incentivo e por colaborar na viabilização de parte das condições necessárias para o desenvolvimento da presente pesquisa.

Aos colegas do Laboratório de Processamento de Sinais, pelo inigualável espírito de equipe, pela ajuda, pelas informações, pelo companheirismo e pelas inestimáveis trocas de conhecimento. 

"Wyrd bið ful arced".

"O destino é inexorável".

Bernard Cornwell 



\section{Resumo}

\section{DARWIN JUNIOR, Willian Agrupamento de textos utilizando Divergência}

Kullback-Leibler. 101 p. Tese de mestrado - Escola de Engenharia de São Carlos, Universidade de São Paulo, 2016.

O presente trabalho propõe uma metodologia para agrupamento de textos que possa ser utilizada tanto em busca textual em geral como mais especificamente na distribuição de processos jurídicos para fins de redução do tempo de resolução de conflitos judiciais. A metodologia proposta utiliza a divergência Kullback-Leibler aplicada às distribuições de frequência dos radicais (semantemas) das palavras presentes nos textos. Diversos grupos de radicais são considerados, formados a partir da frequência com que ocorrem entre os textos, e as distribuições são tomadas em relação a cada um desses grupos. Para cada grupo, as divergências são calculadas em relação à distribuição de um texto de referência formado pela agregação de todos os textos da amostra, resultando em um valor para cada texto em relação a cada grupo de radicais. Ao final, esses valores são utilizados como atributos de cada texto em um processo de clusterização utilizando uma implementação do algoritmo K-Means, resultando no agrupamento dos textos. A metodologia é testada em exemplos simples de bancada e aplicada a casos concretos de registros de falhas elétricas, de textos com temas em comum e de textos jurídicos e o resultado é comparado com uma classificação realizada por um especialista. Como subprodutos da pesquisa realizada, foram gerados um ambiente gráfico de desenvolvimento de modelos baseados em Reconhecimento de Padrões e Redes Bayesianas e um estudo das possibilidades de utilização de processamento paralelo na aprendizagem de Redes Bayesianas.

Palavras-chave: agrupamento de textos, Divergência Kullback-Leibler, algoritmo KMeans, informação mútua. 



\section{Abstract}

\section{DARWIN JUNIOR, Willian Texts Grouping using Kullback-Leibler Diver-}

gence. 101 p. Master Thesis - São Carlos School of Engineering, University of São Paulo, 2016.

This work proposes a methodology for grouping texts for the purposes of textual searching in general but also specifically for aiding in distributing law processes in order to reduce time applied in solving judicial conflicts. The proposed methodology uses the Kullback-Leibler divergence applied to frequency distributions of word stems occurring in the texts. Several groups of stems are considered, built up on their occurrence frequency among the texts and the resulting distributions are taken regarding each one of those groups. For each group, divergences are computed based on the distribution taken from a reference text originated from the assembling of all sample texts, yelding one value for each text in relation to each group of stems. Finally, those values are taken as attributes of each text in a clusterization process driven by a K-Means algorithm implementation providing a grouping for the texts. The methodology is tested for simple toy examples and applied to cases of electrical failure registering, texts with similar issues and law texts and compared to an expert's classification. As byproducts from the conducted research, a graphical development environment for Pattern Recognition and Bayesian Networks based models and a study on the possibilities of using parallel processing in Bayesian Networks learning have also been obtained.

Keywords: text clustering, Kullback-Leibler divergence, K-Means algorithm, mutual information. 



\section{Lista de ilustrações}

Figura 1 Ambiente de Trabalho - Terminal de acesso e cluster de computadores, composto por 8 máquinas, LPS01 a LPS08, sendo LPS01 também o controlador do cluster. . . . . . . . . . . . . . . . . . . . . . 40

Figura 2 Fluxograma do algoritmo geral - as raias indicam as possibilidades de distribuição do processamento pelos diversos núcleos . . . . . . . . . . 43

Figura 3 Fluxograma do algoritmo de busca exaustiva da população de redes solução para os dados considerados . . . . . . . . . . . . . . . . . . . . 47

Figura 4 Distribuição de frequência (vocábulo x frequência) dos vocábulos do Supertexto (Texto 0) - cada vocábulo é representado por seu índice na ordem alfanumérica.

Figura 5 Distribuição de frequência dos vocábulos do Texto 3 (amostra 3), a título de exemplo - cada vocábulo é representado por seu índice na ordem alfanumérica. KL representa o valor da Divergência K-L entre esse Texto e o Supertexto. DKL $(3 ; 0)=0,323$. . . . . . . . . . . . 52

Figura 6 Distribuição de frequência dos vocábulos do Supertexto que pertencem ao Subvocabulário 2, a título de exemplo - cada vocábulo é representado por seu índice. Cada um dos seis vocábulos aparece uma vez em um dos dois dos textos, logo todas as frequências são iguais a 2/12 $=0.167 .54$

Figura 7 Distribuição de frequência dos vocábulos do Texto 3 (amostra 3) que pertencem ao Subvocabulário 2, a título de exemplo - cada vocábulo é representado por seu índice. DKL $(3 ; 0)=1,099$. . . . . . . . . . . . 54

Figura 8 Gráfico das distâncias intercluster e intracluster em função do número de clusters considerado (Distância x Número de Clusters). O cruzamento ocorre entre 1 e 2 clusters e, portanto, foi selecionado o maior desses números, caracterizando-se como solução o agrupamento em 2 clusters, conforme já apresentado na última coluna da Tabela 1 (cluster 0 e cluster 1$) \ldots \ldots \ldots \ldots \ldots$. . . . . . . . . . . . 56 
Figura 9 Gráfico do índice de Validação das distâncias intercluster e intracluster em função do número de clusters considerado (Razão de Validação x Número de Clusters). O mínimo ocorre para 2 clusters. . . . . . . . . . 56

Figura 10 Representação gráfica do agrupamento dos 3 textos em 2 clusters por meio de esferas coloridas, cada eixo representando uma das dimensões da representação em Componentes Principais (PCA). O número associado a cada esfera representa o número de amostras daquele cluster. $\quad 57$

Figura 11 Visão panorâmica da tela inicial do Ambiente de Desenvolvimento. . . 60

Figura 12 Quadro de configuração de parâmetros gerais e de acompanhamento da execução do Ambiente de Desenvolvimento. Aqui se determina se será utilizado processamento paralelo nos módulos em que essa opção está implementada e são mostradas as mensagens de andamento da execução. 61

Figura 13 Módulo de Aquisição de Dados, do Ambiente de Desenvolvimento, no qual os arquivos que contém as amostras do fenômeno a serem analisadas são lidos e processados. A tela mostrada apresenta a versão que implementa o fenômeno de Agrupamento de Textos. . . . . . . . . . . . 61

Figura 14 Quadro que mostra o resultado final da aquisição de dados na forma de uma tabela onde as linhas indicam cada amostra e as colunas os valores de cada variável característica (feature). . . . . . . . . . . . . 61

Figura 15 Módulo gráfico de Aprendizagem do Modelo, que corresponde aos módulos de processamento de Elicitação de Restrições, Apreensão de Superestrutura, Segmentação do Espaço de Busca e Seleção das Redes. Nessa versão inicial, a interface gráfica prevê os algoritmos de busca exaustiva e de Naïve Bayesian Network, associados a um algoritmo libpgm discreto para aprendizagem dos parâmetros da rede. . . . . . . . 62

Figura 16 Quadro de apresentação das Redes Bayesianas selecionadas por meio do modelo de representação utilizado pelo pacote "pebl". . . . . . . . . 62

Figura 17 Extrato do perfil de processamento das rotinas para o conjunto de dados Múltiplo-100 . . . . . . . . . . . . . . . . . . 64

Figura 18 Experimento 2 - Gráfico do agrupamento definido pelo algoritmo, onde os eixos representam as 3 dimensões dos Componentes Principais (PCA). A esfera representa o cluster, cada ponto representa uma amostra e o número anotado na lateral é o número de pontos do cluster correspondente à esfera. Nesse experimento, todas as amostras coincidem em um único ponto. . . . . . . . . . . . . . . . . . . . 6 . 68

Figura 19 Experimento 3 - Exemplos de distribuições de frequências dos radicais - Supertexto versus todos os radicais das amostras . . . . . . . . . . . .

Figura 20 Experimento 3 - Exemplos de distribuições de frequências dos radicais - Amostra 10 versus todos os radicais das amostras . . . . . . . . . . . 70 
Figura 21 Experimento 3 - Exemplos de distribuições de frequências dos radicais - Supertexto versus radicais presentes em até 10\% das amostra . . . . . 70

Figura 22 Experimento 3 - Distâncias intraclusters (em verde) e interclusters (em azul) em função do número de clusters. O equilíbrio entre essas distâncias ocorre próximo a $n=5 \ldots \ldots \ldots \ldots$

Figura 23 Experimento 3 - Representação gráfica da clusterização nos três Componentes Principais (eixos da figura). Cada cluster é representado por uma esfera. O agrupamento se mostra bem definido. . . . . . . . . . . 72

Figura 24 Experimento 4 - Distâncias Intraclusters e Interclusters em função do número de clusters. O equilíbrio entre essas distâncias ocorre próximo a $n=5$.

Figura 25 Experimento 4 - Gráfico da Razão de Validação entre as Distâncias Intracluster e Intercluster. O mínimo compensado pelo custo da complexidade $($ fator $(n+1) / n)$ ocorre em $n=14 \ldots \ldots \ldots$. . . . . . 74

Figura 26 Experimento 4 - Gráfico do agrupamento definido pelo algoritmo para $\mathrm{n}=14$, onde os eixos são as 3 dimensões dos Componentes Principais (PCA). As esferas representam os clusters, cada ponto representa uma amostra e o número anotado na lateral é o número de pontos do cluster correspondente à esfera.

Figura 27 Experimento 5 - Janela do Monitor de Texto após processamento do Experimento 5. . . . . . . . . . . . . . . . 78

Figura 28 Experimento 5 - Exemplos de amostras do Experimento 5 obtidas do Ambiente de Desenvolvimento. . . . . . . . . . . . . . . . . 78

Figura 29 Experimento 5 - Gráfico do número de radicais em cada "Subvocabulário". 80

Figura 30 Experimento 5 - Exemplos de distribuições de frequências dos radicais - Supertexto versus todos os radicais das amostras.

Figura 31 Experimento 5 - Exemplos de distribuições de frequências dos radicais - Amostra 1 versus todos os radicais das amostras.

Figura 32 Experimento 5 - Exemplos de distribuições de frequências dos radicais - Supertexto versus todos os radicais do "Subvocabulário" 1 . . . . . . 81

Figura 33 Experimento 5 - Exemplos de distribuições de frequências dos radicais - Amostra 1 versus todos os radicais do "Subvocabulário" 1 . . . . . . 82

Figura 34 Experimento 5 - Gráfico das Distâncias Intracluster e Intercluster. O ponto de inversão ocorre entre $n=18$ e $n=19 \ldots \ldots$. . . . . . . . . . 85

Figura 35 Experimento 5 - Gráfico da Razão de Validação entre as Distâncias Intracluster e Intercluster. O mínimo compensado pelo custo da complexidade (fator $(n+1) / n$ ) ocorre em $n=67$, porém nota-se um mínimo local relativamente acentuado em $\mathrm{n}=25$. 
Figura 36 Experimento 5 - Gráfico da Razão de Validação entre as Distâncias Intra e InterCluster a partir de $\mathrm{n}=5$ ampliado. O mínimo local em $\mathrm{n}=25$ fica mais evidente e a curva entra em relativo decaimento suave a partir daí. . . . . . . . . . . . . . . . . 86

Figura 37 Experimento 5 - Gráfico das Distâncias Intracluster e Intercluster a partir de $\mathrm{n}=5$ ampliado. Evidencia-se o ponto de inversão entre $\mathrm{n}=18$ $\mathrm{e} n=19 \ldots \ldots \ldots \ldots \ldots$

Figura 38 Experimento 5 - Gráfico do agrupamento definido pelo algoritmo para $\mathrm{n}=14$, onde os eixos são as 3 dimensões dos Componentes Principais (PCA). As esferas representam os clusters, cada ponto representa uma amostra e o número anotado na lateral é o número de pontos do cluster correspondente à esfera. . . . . . . . . . . . . . . . . . . . . . . 87 


\section{Lista de tabelas}

Tabela 1 Valores das Divergências K-L entre cada amostra e o "Supertexto" para cada grupo de vocábulos. "KLx" representa as Divergências K-L para o "Subvocabulario x" e "S_x" é a amostra "x". O valor "inf" significa divergência infinita, que ocorre quando a amostra não possui nenhuma palavra do grupo. A última coluna representa o agrupamento ótimo obtido como resultado final do processamento. . . . . . . . . . . . . 55

Tabela 2 Comparação dos resultados obtidos com o processamento dos diversos conjuntos de dados de teste e respectivos valores de aceleração (speed

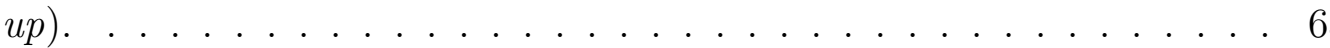

Tabela 3 Perfil de processamento do algoritmo processado em modo serial para o exemplo dos múltiplos com 4 variáveis (complementado com informações do processamento paralelo para as rotinas específicas do modo paralelo)

Tabela 4 Experimento 2 - Valores das variáveis (Divergências K-L) para cada amostra em relação a cada grupo de radicais e clusterização proposta. Cada coluna "KLn" representa o valor da Divergência em relação ao grupo "n", onde n=0 é o vocabulário completo e n de 1 a 10 são os grupos associados a cada decil. A coluna "Cluster" mostra o índice do cluster obtido pelo algoritmo. . . . . . . . . . . . . . . . . . . . 67

Tabela 5 Experimento 3 - Variáveis K-L para as 10 primeiras amostras. "KLn" é a Divergência K-L da amostra em relação ao Supertexto, onde "n" de 1 a 3 indica o percentil não vazio e 0 o diretório com todos os radicais. 71

Tabela 6 Experimento 3 - Acurácia do agrupamento proposto para $n=5$ em relação às classes indicadas pelo especialista. . . . . . . . . . . . . . . . . 72 
Tabela 7 Experimento 4 - Valores das variáveis (Divergências K-L) para cada amostra em relação a cada grupo de radicais e clusterização proposta para $n=5$ clusters. Cada coluna "KLn" representa o valor da divergência em relação ao grupo "n", onde n=0 é o vocabulário completo e n de 1 a 10 são os grupos associados a cada percentil. A coluna "Cluster" mostra o índice do cluster obtido pelo algoritmo. . . . . . . . . . . . 74

Tabela 8 Experimento 4 - Valores das variáveis (Divergências K-L) para cada amostra em relação a cada grupo de radicais e clusterização proposta para $\mathrm{n}=14$ clusters. Cada coluna "KLn" representa o valor da divergência em relação ao grupo " $\mathrm{n}$ ", onde $n=0$ é o vocabulário completo e $\mathrm{n}$ de 1 a 10 são os grupos associados a cada percentil. A coluna "Cluster" mostra o índice do cluster obtido pelo algoritmo. . . . . . . . . . . . . 75

Tabela 9 Experimento 4 - Acurácia do agrupamento em relação às classes indicadas pelo especialista para os agrupamentos de $n=5$ e $n=14$. A acurácia é medida pelo percentual de pontos corretamente agrupados para cada classe. . . . . . . . . . . . . . . . . . 76

Tabela 10 Experimento 5 - Classificação prévia das amostras em função do tema principal. . . . . . . . . . . . . . . . 77

Tabela 11 Experimento 5 - Valores das variáveis (Divergências K-L) para cada amostra em relação a cada "Subvocabulário" e clusterização proposta para n=14 clusters. Cada coluna "KLn" representa o valor da divergência em relação ao grupo "n", onde n=0 é o vocabulário completo e $n$ de 1 a 10 são os grupos associados a cada percentil. A coluna "Cluster" mostra o índice do cluster obtido pelo algoritmo. . . . . . . . . . . . . 83

Tabela 12 Experimento 5 (continuação) - Valores das variáveis (Divergências K-L) para cada amostra em relação a cada grupo de radicais e clusterização proposta para $\mathrm{n}=14$ clusters. Cada coluna "KLn" representa o valor da divergência em relação ao grupo "n", onde $n=0$ é o vocabulário completo e n de 1 a 10 são os grupos associados a cada percentil. A coluna "Cluster" mostra o índice do cluster obtido pelo algoritmo. . . . 84

Tabela 13 Experimento 5 - Acurácia do agrupamento em relação às classes indicadas pelo especialista para os agrupamentos de $n=14, n=19$ e $n=25$. A acurácia é medida pelo percentual de pontos corretamente agrupados para cada classe. . . . . . . . . . . . . . . . . . . . . . . 87 


\section{Lista de Símbolos}

$f_{1}$ distribuição de probabilidade de uma variável aleatória, p. 33

$f_{2}$ distribuição de probabilidade de uma variável aleatória, p. 33

$X$ variável aleatória, p. 33

$\lambda$ parâmetro de uma distribuição de probabilidade, p. 33

$\mu_{1}$ valor esperado da distribuição de probabilidade $f_{1}$, p. 33

$P(i)$ probabilidade de ocorrência da amostra elementar de índice i de uma variável aleatória de distribuição P, p. 34

$Q(i)$ probabilidade de ocorrência da amostra elementar de índice i de uma variável aleatória de distribuição Q, p. 34

$i$ índice de cada amostra em uma amostragem de uma variável aleatória, p. 34

$n$ número de amostras em uma amostragem de uma variável aleatória, p. 34

$d$ dimensão de uma variável aleatória ou número de características de cada amostra, p. 34

$K$ número de grupos de um agrupamento, p. 34

$d_{\text {intra }}$ distância intracluster, p. 35

$d_{\text {inter }}$ distância intercluster, p. 36

$V$ razão de validação entre distâncias intracluster e intercluster, p. 36

$U$ agrupamento inicial de amostras em determinado número de clusters, p. 37

$V$ agrupamento alternativo de amostras em determinado número de clusters, p. 37

$H(U)$ entropia de uma partição de objetos, p. 37

$M I(U, V)$ Informação Mútua, p. 37

$P(i, j)$ probabilidade de uma amostra ser simultaneamente da classe $U_{i}$ e da classe $V_{j}$, p. 38

EMI valor esperado da Informação Mútua, p. 38

AMI Informação Mútua Ajustada (Adjusted Mutual Information - AMI), p. 38 



\section{Sumário}

1 Introdução $\quad 25$

$2 \quad$ Justificativa e objetivos 29

2.1 Justificativa . . . . . . . . . . . . . . . . . . . . . . . . . . . 29

2.2 Objetivos . . . . . . . . . . . . . . . . . . . 30

2.3 Organização do Texto . . . . . . . . . . . . . . . . . . . . . 30

3 Teoria $\quad 33$

3.1 Divergência Kullback-Leibler (K-L) . . . . . . . . . . . . . . . . . 33

3.2 Algoritmo K-Means para Agrupamento de Dados . . . . . . . . . . . . . . 34

3.3 Índice para Comparação entre Agrupamento Proposto e Agrupamento Real 36

$4 \quad$ Materiais e Métodos $\quad 39$

4.1 Ambiente de Trabalho . . . . . . . . . . . . . . . . . . . . 39

4.2 Metodologia . . . . . . . . . . . . . . . . . . . . . 41

4.2.1 Ambiente de Desenvolvimento . . . . . . . . . . . . . . . . . . 41

4.2.2 Módulo de Seleção da Rede Bayesiana - Busca Exaustiva . . . . . 46

4.2.3 Módulo de Agrupamento de Textos . . . . . . . . . . . . . . . . . 47

5 Resultados $\quad 59$

5.1 Ambiente de Desenvolvimento . . . . . . . . . . . . . . . . . . . 59

5.2 Processamento Paralelo e Busca Exaustiva . . . . . . . . . . . . . . 63

5.3 Agrupamento de Textos . . . . . . . . . . . . . . . . . . 66

6 Discussão e Conclusão $\quad 89$

$\begin{array}{ll}\text { Referências } & 95\end{array}$ 



\section{Introdução}

Em inúmeros fenômenos, a participação humana resulta na produção de textos em algumas de suas etapas e os textos assim produzidos são uma relevante fonte de informação. No entanto, sua análise manual é dispendiosa em termos de tempo, havendo grande interesse em que esse tipo de análise possa ser simplificada por vias computacionais (GANDOMI; HAIDER, 2014).

Existem diversas formas de abordar o problema do tratamento do texto para transformálo em dados suscetíveis de análise por meio de processamento de Linguagem Natural: recuperação de informação (LI; LIAKATA; REBHOLZ-SCHUHMANN, 2013), análise léxica para estudo da distribuição da frequência das palavras (PARK; LEE; MOON, 2015), reconhecimento de padrões (STOMMEL; HERZOG; XU, 2015), marcas e anotações, extração de informação e técnicas de mineração de dados, incluindo análises de relações e associações, visualização e análise preditiva (BOSE, 2009).

São exemplos atuais de pesquisas nessa área e do estado-da-arte a análise de literatura sobre inovação em Tecnologia da Informação usando análise textual (BASOLE; SEUSS; ROUSE, 2013), a análise de conteúdo baseada em linguística computacional (Lía Chávez; YAMAMOTO, 2014), o uso de técnicas de processamento de linguagem a mensagens no Tweeter (PREVITALI; ARRIETA; ERMANNI, 2015) e a aprendizagem ativa para extração de emoções (PARK; LEE; MOON, 2015).

Um problema especificamente interessante é o agrupamento de textos. Essa é uma necessidade que surge naturalmente em aplicações de caráter geral, como os mecanismos de busca na Internet, mas também está presente em situações mais específicas, como no caso da distribuição de processos administrativos ou judiciais a julgadores, cujo agrupamento em lotes conforme o tema pode facilitar sobremaneira a adequação entre a matéria julgada e o perfil do julgador, agilizando o julgamento e produzindo decisões mais rápidas e uniformes (SILVA, 2006).

Há diversos trabalhos com foco no agrupamento de textos já desenvolvidos na literatura, como em (GUELPELI, 2012) e (GOMES; ALEXANDRE; PARDO, 2009). O objeto do presente trabalho segue nessa linha: estudar uma estrutura de processamento que per- 
mita realizar o agrupamento de textos sob o enfoque do Reconhecimento de Padrões e do Aprendizado de Máquina. Por questões de controle do escopo, a fim de não estender a necessidade de aquisição de conhecimento a áreas notadamente extensas, evitou-se adentrar o universo das pesquisas baseadas em Linguagem Natural além do estritamente necessário para viabilizar o presente trabalho, cujo foco é, conforme já mencionado, no uso de técnicas de Reconhecimento de Padrões.

O presente estudo tem por finalidade avaliar a viabilidade de agrupamento de textos de acordo com seus temas, por meio da aquisição de conhecimento a partir de estratégias de text mining (COHEN; HUNTER, 2008) e text analytics (KROEZE; MATTHEE; BOTHMA, 2003) (GRIMES, 2012), processos de extração de informação de alta qualidade a partir de textos. Tais técnicas permitem que, a partir de um conjunto de textos, sejam extraídas informações sobre eles que podem ser o insumo para uma classificação desses textos com suficiente grau de acurácia em relação à classificação realizada por especialistas e, consequentemente, esses resultados possam ser utilizados para melhorias nos processos aos quais estão associados e como uma fase preparatória ao uso de Redes Bayesianas.

De forma resumida, a metodologia adotada no presente estudo parte de um procedimento de amostragem que resulta em vários textos, cada um representando um registro de ocorrência do fenômeno observado, para extrair desses textos as ocorrências dos radicais das palavras neles contidas, previamente filtradas para desconsiderar variações menos relevantes, obtendo-se, assim, uma distribuição de frequência para cada amostra. Em seguida, são produzidas as distribuições de frequências considerando grupos de radicais de acordo com sua maior ou menor presença entre as diversas amostras.

Para cada distribuição de cada amostra é calculada a Divergência Kullback-Leibler, ou Divergência K-L, (KULLBACK; LEIBLER, 1951) em relação à distribuição de referência dentro de cada grupo e esses valores são usados como os atributos das amostras em um procedimento de agrupamento das mesmas por meio do algoritmo K-Means (JAIN, 2010) para o número de classes que apresenta o melhor agrupamento em termos de equilíbrio entre o raio médio dos clusters e a distância entre eles (ROKACH; MAIMON, 2005).

Adotou-se a Divergência K-L por ser uma medida simples da diferença de entropia entre duas distribuições de frequência. Para o presente estudo não foi necessário adotar uma medida simétrica, pois as medidas sempre foram tomadas em relação a uma referência fixa. Há outras medidas de distância entre distribuições de probabilidade ou frequência, tais como Distância Hellinger, Distância da Variância Total, Divergência Rényi, Divergência Jensen-Shannon, métrica Lévy-Prokhorov, Distância Bhattacharyya, métrica Wasserstein, Distância de Energia, Estatística Kolmogorov-Smirnov e Discrepância Média Máxima, mas qualquer uma delas não traria grandes ganhos em contrapartida às complexidades introduzidas nos cálculos, pois o objetivo é obter uma informação puramente unidimensional acerca da diferença entre as distribuições, o que é suprido pela Divergência K-L. 
Há outros trabalhos na literatura que usam a Divergência K-L em agrupamento de textos, mas não se verificou um uso idêntico ao que está sendo aqui proposto. (DHILLON; MALLELA; KUMAR, 2003) usa essa divergência como base para otimizar a clusterização das características features dos textos, mas não a aplica nas distribuições de frequências dos vocábulos, como aqui. Já (HUANG, 2008) usa essa divergência como base para uma distância entre as distribuições de frequência na forma de uma representação vetorial dos textos, porém usa a variante simétrica e não aplica isso a subdivisões do vocabulário.

A metodologia desenvolvida foi aplicada na forma de cinco experimentos, além de testes pontuais acessórios ao desenvolvimento dos algoritmos. Os dois primeiros foram experimentos simples controlados para verificação imediata dos efeitos do algoritmo e consistiram de amostras na forma de frases simples com pequenas variações entre elas. Os três experimentos subsequentes decorreram da aplicação do algoritmo a dados reais: um conjunto de registros de falhas em sistema de distribuição elétrica, um conjunto de textos de temática diversificada coletados na Internet e um conjunto de textos jurídicos.

As contribuições esperadas como resultado do presente trabalho são a proposição de uma técnica que permita obter resultados significativos preliminares sem a necessidade de um aprofundamento do processamento com ferramentas complexas de Linguagem Natural que representariam aumento da complexidade e do custo computacional.

Necessário acrescentar que o presente trabalho corresponde à etapa final do curso de Mestrado do autor e resultou de uma busca por um tema de interesse nas áreas de Reconhecimento de Padrões e Aprendizagem de Máquina ao longo do período de duração daquele curso. Nesse processo, partiu-se, inicialmente, de um foco mais abrangente, o qual foi se estreitando na medida em que o aprendizado ia avançando e as oportunidades iam surgindo. No primeiro momento, o trabalho voltou-se para o desenvolvimento de um ambiente gráfico de Aprendizagem de Máquina, fundamentado no paradigma de Redes Bayesianas (RB), o que resultou em uma versão embrionária de um Ambiente de Desenvolvimento. Em face da alta carga de processamento que esse paradigma exige, o trabalho evoluiu para a pesquisa da aplicação de Processamento Paralelo na aprendizagem de Redes Bayesianas e foram gerados resultados preliminares nessa área. A última evolução da linha de pesquisa voltou-se então para a implementação de um dos módulos do Ambiente de Desenvolvimento, o módulo de Aquisição de Dados, e foi então que surgiu a oportunidade e o interesse na aplicação de Agrupamento de Textos.

Portanto, o trabalho principal aqui descrito, além de uma pesquisa específica e autônoma, também é um módulo de um sistema maior voltado à Aprendizagem de Máquina por meio de Redes Bayesianas e, por esse motivo, esse sistema será também apresentado no presente texto, assim como os resultados associados. 


\section{Justificativa e objetivos}

\section{$2.1 \quad$ Justificativa}

A pesquisa científica busca compreender e atuar nos mais diversos fenômenos que se reproduzem no mundo real. Para tanto, o elemento essencial dessa pesquisa são os dados e registros associados a cada fenômeno estudado.

Com o desenvolvimento da tecnologia, cada vez mais informações ficam disponíveis por meio dos registros materializados pelos artefatos tecnológicos, desde os mais simples até os mais complexos, incluindo aí os mecanismos de armazenamento de dados, com a exponencial ampliação de suas capacidades. Dentre os inúmeros tipos de dados acumulados, há os registros textuais efetuados por meio da interação humana com os fenômenos estudados, que passam a ser relevante fonte de informação.

Isso considerado, resta evidente o interesse em mecanismos de análise de dados textuais. No entanto, a análise manual de grandes volumes de dados textuais é inviável e surge daí a necessidade de facilitar essa análise por meio de métodos computacionais (GANDOMI; HAIDER, 2014), seja simplificando etapas, seja efetuando toda a análise. Uma das formas de simplificar a análise de grandes volumes de textos é efetuando o seu agrupamento prévio.

As aplicações em que essa técnica pode ser empregada são as mais diversas. Podese vislumbrar de imediato aplicações de uso geral, como os mecanismos de busca na Internet, mas, com a mesma facilidade, podem ser elencadas situações bastante específicas, como no caso da distribuição de processos administrativos ou judiciais a julgadores, cujo agrupamento em lotes conforme o tema pode facilitar sobremaneira a adequação entre a matéria julgada e o perfil do julgador, agilizando o julgamento e produzindo decisões mais rápidas e uniformes (SILVA, 2006). Portanto, o desenvolvimento de uma metodologia eficaz pode contribuir para superação de questões de alto interesse para a sociedade, como é o caso da rapidez e eficiência no trâmite dos processos jurídicos (SILVA, 2006), no exemplo específico anteriormente citado. 


\subsection{Objetivos}

O principal objetivo do presente trabalho é a implementação de um algoritmo que utiliza a Divergência Kullback-Leibler entre as respectivas distribuições de frequência para agrupamento de textos.

No desenvolvimento da pesquisa para atingir essa meta, os seguintes objetivos específicos foram estabelecidos e concluídos:

1. implementação de um Ambiente de Desenvolvimento geral para Aprendizagem de Redes Bayesianas e Reconhecimento de Padrões, a fim de registrar progressivamente a pesquisa e integrá-la em um ambiente que permita a produção de resultados na análise de fenômenos diversos;

2. análise do potencial do uso de Processamento Paralelo na Aprendizagem de Redes Bayesianas;

3. implementação do módulo de Aquisição de Dados para o caso específico de Agrupamento de Textos;

4. realização de experimentos com dados de teste e com dados reais e avaliação do desempenho;

5. discussão e conclusão acerca da pesquisa realizada, com identificação do potencial de aplicação da metodologia estudada.

\subsection{Organização do Texto}

O presente trabalho está organizado nas seguintes seções: Introdução, Teoria, Materiais e Métodos, Resultados e Discussão e Conclusão.

A Introdução apresenta o trabalho, seu escopo, sua finalidade, o problema abordado e descreve seus principais objetivos. A seção Teoria expõe os princípios teóricos que fun-

damentam a pesquisa realizada. É uma seção de temas gerais, onde a preocupação é uma breve exposição dos fundamentos teóricos de interesse para o escopo do trabalho, sem aprofundamento dos pontos que não sejam relevantes para a compreensão das atividades desenvolvidas e das análises efetuadas. A seção Materiais e Métodos descreve tanto o ambiente de pesquisa em termos de infraestrutura, equipamentos e sistemas computacionais utilizados quanto a metodologia adotada e o planejamento e execução dos procedimentos da pesquisa. Em Resultados são apresentados os principais resultados obtidos nos experimentos, sua contextualização em relação ao projeto como um todo e a análise desses resultados, a fim de permitir uma comparação entre o desempenho projetado e o desempenho de fato obtido. Por último, a seção de Discussão e Conclusão reúne aspectos das expectativas presentes e futuras, no âmbito do trabalho e para além dele, sob a forma 
de uma discussão dos resultados obtidos frente às expectativas originais, da pontuação de nuances ou elementos que mereceriam uma futura prospecção ou aprofundamento, e das conclusões acerca da proposta do trabalho, do seu tema e da relação dele com os ambientes em que se insere. 


\section{Teoria}

O arcabouço teórico que fundamentou a pesquisa realizada tem dois elementos principais: a Divergência Kullback-Leibler (Divergência K-L) e o algoritmo de agrupamento (clustering) K-Means.

A Divergência K-L foi a métrica utilizada para estabelecer a distância entre distribuições de frequência representativas de cada instância do fenômeno específico observado, no caso os textos. O algoritmo K-Means foi usado para agrupar os textos a partir das distâncias entre eles e uma referência.

Com o objetivo de avaliar a qualidade do agrupamento nos casos mais complexos, em que a mera observação não permite conclusões mais imediatas, foi também utilizado o conceito de Informação Mútua Ajustada (AMI), que é um índice direcionado a avaliar a qualidade de um agrupamento em relação a uma classificação real das amostras previamente conhecida.

A seguir, cada um desses elementos teóricos será apresentado.

\subsection{Divergência Kullback-Leibler (K-L)}

A Divergência K-L foi originalmente proposta no artigo "On Information and Sufficiency", publicado pelos autores (KULLBACK; LEIBLER, 1951), sob a referência de "informação média para discriminação" (equação 2.4 daquele artigo) entre duas funções de distribuição de probabilidade e tem como base a definição de informação proposta por (SHANNON, 1948).

Sendo $f_{1}$ e $f_{2}$ distribuições de probabilidade de uma variável aleatória $X$ com parâmetro $\lambda$ determinado a partir da amostra $x$ dessa variável, e sendo $\mu_{1}$ o valor esperado da distribuição $f_{1}$, a Divergência K-L de $f_{1}$ em relação a $f_{2}$ é dada por:

$$
I(1: 2)=I_{1: 2}(X)=\int d \mu_{1}(x) \cdot \frac{f_{1}(x)}{f_{2}(x)}=\int f_{1}(x) \cdot \frac{f_{1}(x)}{f_{2}(x)} d \lambda(x)
$$


Essa divergência apresenta uma medida do erro de informação provocado ao se atribuir a distribuição $f_{2}$ a um experimento efetivamente regido pela distribuição $f_{1}$. Dessa forma, essa divergência também representa uma boa medida da distância entre instâncias de fenômenos da mesma natureza e, portanto, justifica-se sua aplicação para a apuração da distância entre amostras de textos, que são as instâncias do fenômeno estudado no presente trabalho, na forma de uma diferença de entropias.

No presente estudo, a Divergência K-L foi aplicada para distribuições de frequência discretas, portanto foi adaptada para sua forma discreta, onde $P(i)$ e $Q(i)$ são as probabilidades de ocorrência da amostra elementar de índice $i$ e $n$ é o número de amostras consideradas, medidas na forma de sua frequência relativa:

$$
D_{K L}(P \| Q)=\sum_{i=1}^{n} P(i) \cdot \log \left(\frac{P(i)}{Q(i)}\right)
$$

Essa divergência é assimétrica, depende da ordem dos operandos, porém essa característica não reflete negativamente no estudo, pois sempre se apura o valor tomando uma distribuição de referência (denominada "Supertexto") para todas as demais distribuições (amostras de textos).

Outro ponto importante a observar acerca dessa medida é que ela é comutativa em relação à ordem sequencial das amostras elementares, ou seja, qualquer que seja o ordenamento utilizado para as amostras elementares resultará sempre no mesmo valor da divergência.

\subsection{Algoritmo K-Means para Agrupamento de Dados}

Uma ferramenta muito presente na literatura para agrupamento de amostras ou ocorrências de um determinado fenômeno é o algoritmo K-Means.

Esse algoritmo foi proposto em publicações em diversas áreas do conhecimento desde 1955, mas ainda permanece popular e é bastante utilizado até hoje (JAIN, 2010).

Dado um conjunto de $n$ pontos de dimensão $d$ para serem agrupados em um conjunto de $K$ grupos, o algoritmo busca um agrupamento que associa cada ponto ao cluster cujo centro é mais próximo e minimiza o erro quadrático entre o centro de cada cluster e os pontos a ele associados.

A associação dos pontos aos clusters segue a seguinte regra (RAY; TURI, 1999):

$$
x \epsilon C_{j}(k) \text { se }\left|x-z_{j}(k)\right|<\left|x-z_{i}(k)\right|
$$

para todo $i, j=1,2, \ldots, K$; onde $C_{j}(k)$ representa o conjunto de amostras cujo cluster é o de centro $z_{j}(k)$. 
O erro quadrático entre o centro de um cluster e um ponto a ele pertencente é definido por (JAIN, 2010):

$$
J\left(C_{k}\right)=\sum_{x \in C_{k}}\left|x_{i}-\mu_{k}\right|^{2}
$$

onde $C_{k}$ é o $K$-ésimo cluster, $\mu_{k}$ seu centro e $x_{i}$ o ponto em relação ao qual o erro é calculado.

Portanto, o erro quadrático total de um determinado agrupamento em $K$ clusters é:

$$
J(C)=\sum_{k=1}^{K} \sum_{x \in C_{k}}\left|x_{i}-\mu_{k}\right|^{2}
$$

Logo, o objetivo do algoritmo é encontrar o agrupamento em $K$ clusters que minimize o valor de $J(C)$ dentre todos os agrupamentos possíveis.

Definidos esses valores, o algoritmo consiste nos seguintes passos (JAIN, 2010):

1. inicia-se com uma partição inicial qualquer dos pontos em $K$ clusters;

2. calculam-se os centros desses clusters;

3. reassocia-se cada ponto ao cluster cujo centro é o mais próximo dele;

4. repete-se 2 e 3 até que o particionamento se estabilize.

Há que se observar que esse algoritmo é do tipo greedy, ou seja, ele não garante a identificação de um mínimo global, podendo esbarrar em mínimos locais; no entanto, apesar disso, sua utilização apresenta resultados bastante satisfatórios em situações das mais diversas naturezas (JAIN, 2010).

Uma das limitações mais relevantes do algoritmo K-Means é a necessidade de conhecer a priori o número de clusters. Essa limitação pode ser superada por algoritmos que executam repetidamente o próprio algoritmo K-Means iniciando com um único cluster contendo todos os pontos até um número máximo de agrupamentos possível, selecionandose, então, o agrupamento que melhor atenda a um critério de validação pré-definido, conforme descrito em (RAY; TURI, 1999) e (ROKACH; MAIMON, 2005).

Adotou-se, na presente pesquisa, a abordagem que trabalha com as distâncias intracluster e intercluster, pois a consideração conjunta desses fatores permite obter agrupamentos com clusters concentrados e bem definidos.

A distância intracluster de um determinado cluster $d_{\text {intra }}$ foi definida em (RAY; TURI, 1999) como sendo a média da distância entre o seu centro e cada um dos seus pontos:

$$
d_{\text {intra }}=\frac{1}{n} \cdot \sum_{k=1}^{K} \sum_{x \in C_{k}}\left|x_{i}-\mu_{k}\right|^{2}
$$


Esses mesmos autores definem a distância intercluster $d_{\text {inter }}$ como o mínimo das distâncias entre os centros dos clusters tomados dois a dois:

$$
d_{\text {inter }}=\min \left(\left|\mu_{i}-\mu_{j}\right|^{2}\right)
$$

$\operatorname{com} i=1,2, \ldots, K-1 ; j=i+1, \ldots, K$

Essas medidas apresentam tendências distintas em relação à variação do número de clusters. A distância intracluster tende a diminuir, pois o aumento do número de clusters aumenta a probabilidade do centro do cluster mais próximo estar mais perto de cada ponto. Ao contrário, como o número de pontos de cada cluster tende a diminuir, o centro de cada cluster tende a se concentrar em regiões cada vez menores, portanto provocando uma dispersão entre eles.

A partir dessas duas medidas, há várias formas de serem construídos mecanismos para determinação do número mais adequado de clusters, alguns considerando apenas uma das medidas e outros combinando as duas.

Na presente pesquisa, monitoram-se dois mecanismos. O primeiro consiste em observar o comportamento das duas medidas, dando especial atenção ao ponto de inversão, o número de clusters a partir do qual a distância intercluster supera a distância intracluster. O segundo adota a razão de validação $V$ proposta por (RAY; TURI, 1999), a seguir expressa:

$$
V=\frac{d_{\text {intra }}}{d_{\text {inter }}}
$$

No caso da razão de validação, como essa medida tende a se estabilizar a partir de determinado ponto em valores muito próximos, acrescentou-se um fator de custo para determinação do número adequado de clusters, a fim de privilegiar soluções mais simples (menor número de clusters em detrimento de soluções mais complexas de mínimo ganho relativo). Esse fator consiste em somente adotar $\mathbf{n}+\mathbf{1}$ se o ganho em relação a $\mathbf{n}$ for maior do que $(\mathbf{n}+\mathbf{1}) / \mathbf{n}$.

\section{3 Índice para Comparação entre Agrupamento Pro- posto e Agrupamento Real}

Feito o agrupamento dos textos, torna-se necessário avaliar sua efetividade em relação ao agrupamento real previamente conhecido. No entanto, essa avaliação não é tão simples quanto se pode intuir, pois não deve ser influenciada pela nomenclatura atribuída aos clusters pelo algoritmo de agrupamento e deve tanto verificar a inclusão de amostras da mesma classe em um mesmo cluster como a não inclusão de amostras de classes distintas no mesmo cluster. 
Há várias técnicas propostas na literatura para avaliar a perfeição do agrupamento, tais como o Índice Rand Ajustado (HUBERT; ARABIE, 1985), medidas baseadas em Informação Mútua (Normalized Mutual Information - NMI e Adjusted Mutual Information - AMI) (GHOSH; STREHL, 2002); (VINH, 2010a); (VINH, 2010b), medidas baseadas em Homogeneidade e Completude (como a Medida-V) (ROSENBERG; HIRSCHBERG, 2007) e o Coeficiente de Silhueta (ROUSSEEuW, 1987).

O Coeficiente de Silhueta aplica-se aos casos em que a classificação real é desconhecida, portanto não é o caso em tela. As medidas baseadas em Homogeneidade e Completude não são as mais indicadas para um número de classes reduzido, como é o dos textos analisados no presente estudo, pois elas não são normalizadas em relação à classificação aleatória, ou seja, uma classificação totalmente aleatória não irá sempre resultar no mesmo valor de Homogeneidade, Completude e Medida-V e, em especial, poderá não resultar em zero. Portanto, das técnicas mais recentes, a mais indicada para os experimentos com número de amostras relativamente limitado (centenas) é a técnica baseada em Informação Mútua. A medida NMI não pode ser aplicada por não ser ajustada para compensar dependências da aleatoriedade da amostra, porém a medida AMI é ajustada para compensar essa deficiência. Logo, a medida adotada foi a Adjusted Mutual Information - AMI.

Dado o agrupamento real de um conjunto de amostras e o resultado de um algoritmo de clustering aplicado a esse conjunto, a Informação Mútua Ajustada é uma função que mede a concordância dos dois agrupamentos, desconsiderando permutações. É uma medida simétrica, não se altera comutando-se os argumentos.

Os pontos positivos são que a medida tende a zero para agrupamentos aleatórios (uniformes) para qualquer número de clusters ou de amostras. Os valores ficam restritos entre 0 e 1 , onde valores próximos de zero indicam dois agrupamentos altamente independentes e valores próximos de 1 indicam alta concordância entre eles, sendo que valores exatos correspondem a completa independência ou completa dependência (agrupamentos idênticos). Além disso, não se estabelece qualquer restrição a priori acerca da estrutura dos agrupamentos, sendo, portanto, uma medida compatível com o algoritmo K-Means.

A definição da AMI parte de dois agrupamentos, $U$ e $V$, dos mesmos $n$ objetos e do conceito de entropia de uma partição dos objetos $H(U)$ como sendo a incerteza dessa partição, matematicamente expressa por:

$$
H(U)=\sum_{i=1}^{\#(U)} P(i) \log (P(i))
$$

onde $P(i)$ é a probabilidade de um objeto de $U$ ser da classe $U_{i}$.

A Informação Mútua $M I(U, V)$ entre $\mathrm{U}$ e $\mathrm{V}$, duas partições possíveis das amostras, é:

$$
M I(U, V)=\sum_{i=1}^{\#(U)} \sum_{j=1}^{\#(V)} P(i) \cdot \log \left(\frac{P(i, j)}{P(i) \cdot P(j)}\right)
$$


onde $P(i, j)$ é a probabilidade de uma amostra ser simultaneamente das classes $U_{i}$ e $V_{j}$ :

$$
P(i, j)=\frac{\#\left(U_{i} \cap V_{j}\right)}{n}
$$

No entanto, a Informação Mútua não está ajustada para independer da partição instanciada e apresenta a tendência de aumentar na medida em que aumente o número de grupos, independente da real dimensão de informação mútua entre os agrupamentos. Uma forma de compensar isso é trabalhar com o valor esperado.

O valor esperado da informação mútua $E M I$ é obtido a partir da equação a seguir, proposta por (VINH, 2010a):

$$
E[M I(U, V)]=\sum_{i=1}^{\#(U)} \sum_{j=1}^{\#(V)} \sum_{n_{i j}=\left(a_{i}+b_{j}-n\right)}^{\min \left(a_{i}, b_{j}\right)} \frac{n_{i j}}{n} \cdot \log \left(\frac{n \cdot n_{i j}}{a_{i} \cdot b_{j}}\right) \cdot F_{i j}
$$

onde $a_{i}=\#\left(U_{i}\right)$ é o número de elementos em $U_{i}, b_{j}=\#\left(V_{j}\right)$ é o número de elementos em $V_{j}$ e $F_{i j}$ é calculado conforme a seguir:

$$
F_{i j}=\frac{a_{i} ! \cdot b_{j} ! \cdot\left(n-a_{i}\right) ! \cdot\left(n-b_{j}\right) !}{n ! . n_{i j} ! .\left(a_{i}-n_{i j}\right) \cdot\left(b_{j}-n_{i j}\right) ! \cdot\left(n-a_{i}-b_{j}+n_{i j}\right) !}
$$

Finalmente, a Informação Mútua Ajustada $A M I$ é calculada a partir desse valor esperado como:

$$
A M I=\frac{M I-E[M I]}{\max (H(U), H(V))-E[M I]}
$$

Esse valor da $A M I$ pode, então, ser usado como uma medida da divergência entre os agrupamentos $\mathrm{U}$ e $\mathrm{V}$. 


\section{Materiais e Métodos}

\subsection{Ambiente de Trabalho}

O ambiente de trabalho utilizado é o do Laboratório de Processamento de Sinais do Departamento de Engenharia Elétrica da Escola de Engenharia da USP São Carlos SP. Recentemente a configuração do ambiente do Laboratório foi modificada, inclusive com acréscimo de novas máquinas, porém todos os experimentos usaram a configuração anterior, conforme aqui descrita. O ambiente inclui recursos de processamento paralelo que não foram utilizados diretamente no Agrupamento de Textos, mas que serviram no desenvolvimento do Ambiente de Desenvolvimento, especificamente na aplicação de processamento paralelo no módulo de Aprendizagem da Rede Bayesiana.

Esse ambiente consiste dos seguintes elementos:

1. um computador portátil HP G42-415DX AMD Athlon II P340 Dual-core 2.200MHZ 3GB, com sistema operacional Ubuntu 12.04 LTS, onde são desenvolvidos os algoritmos e realizados os testes de consistência, é feito todo o processamento serial e o acesso cliente ao ambiente de processamento paralelo, bem como são anotados os registros de todo o trabalho;

2. um cluster de computadores para processamento paralelo utilizando Python 2.7.6 e IPython 1.2.1 sobre um sistema operacional Ubuntu Server 14.04.1 LTS, interligado em um segmento de rede local Ethernet 1Gbps estabelecido por meio de um Switch que conecta esse segmento ao backbone da rede local do Departamento, consistindo de 8 máquinas com as seguintes denominações e configurações:

a) LPS01: Intel(R) Core(TM) i7-4770 CPU @ 3.40GHz RAM: 8Gb , com GPU;

b) LPS02: Intel(R) Core(TM) i7-3770 CPU @ 3.40GHz RAM: 4Gb, com GPU;

c) LPS03: Intel(R) Core(TM) i7 CPU 920 @ 2.67GHzRAM: 6Gb, com GPU;

d) LPS04: Intel(R) Core(TM) i7-4820K CPU @ 3.70GHz RAM: 16Gb, com GPU; 
e) LPS05: Intel(R) Core(TM) i7-4820K CPU @ 3.70GHz RAM: 16Gb, com GPU;

f) LPS06: Intel(R) Core(TM) i7-4820K CPU @ 3.70GHz RAM: 16Gb;

g) LPS07: Intel(R) Core(TM) i7-4820K CPU @ 3.70GHz RAM: 16Gb;

h) LPS08: Intel(R) Core(TM) i7 CPU 950 @ 3.07GHz RAM: 16Gb, com GPU.

Figura 1: Ambiente de Trabalho - Terminal de acesso e cluster de computadores, composto por 8 máquinas, LPS01 a LPS08, sendo LPS01 também o controlador do cluster.

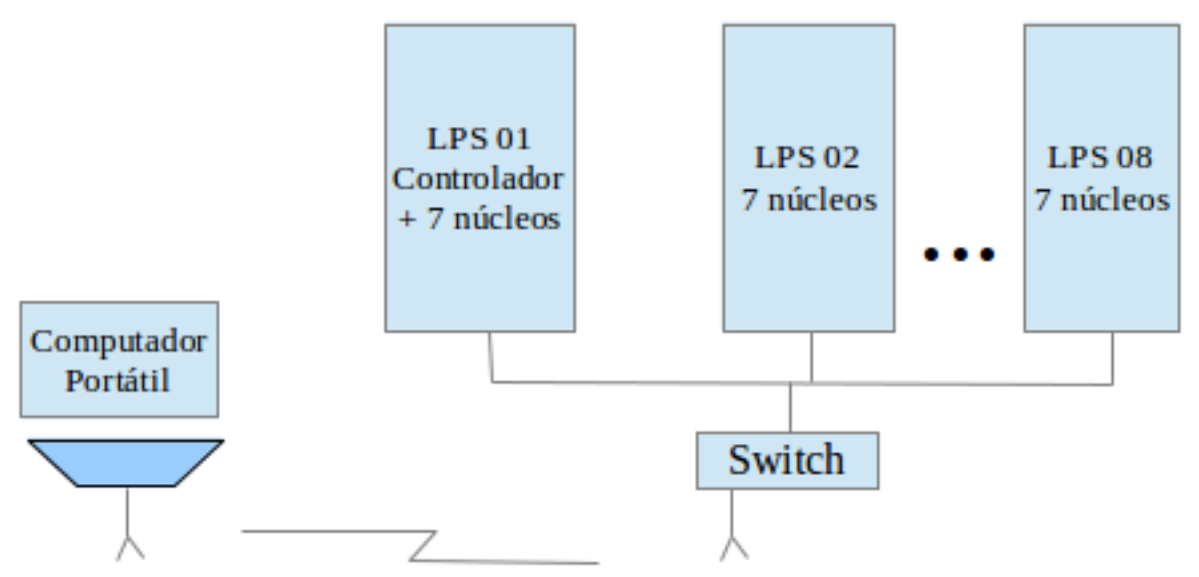

Fonte: elaborado pelo próprio autor

Os elementos de software específicos utilizados, além dos sistemas operacionais e plataformas já descritos, são a linguagem Python versão 2.7.3 com as bibliotecas SciPy e NumPy obtidos da SciPy.org (JONES et al., 2001), Matplotlib versão 1.4.0 obtido da matplotlib.org (HUNTER, 2007), o ambiente de computação interativa IPython versão 2.1.0 (IPYTHON; TEAM, 2011) e o pacote pebl - "Python Environment For Bayesian Learning" versão 1.0.2, desenvolvido no Systems Biology Lab da University of Michigan e disponibilizado publicamente por meio uma licença MIT (RADENSKI, 2006).

Foram também utilizados os seguintes pacotes em Python:

1. Tk/Tcl Graphical User Interface (GUI) toolkit - parte integral do Python que fornece um conjunto de ferramentas para uso de janelas que é robusto e independente de plataforma (OUSTERHOUT, 1993);

2. módulo Tkinter - a interface padrão do Python para o Tk GUI toolkit (GRAYSON, 2000);

3. pickle - mecanismo padrão para serialização de objetos que usa uma máquina virtual baseada em empilhamento (single stack) que grava as instruções usadas para reconstruir os objetos (ABRAHAMS; GROSSE-KUNSTLEVE, 2003); 
4. sklearn - pacote de ferramentas para data mining e data analysis desenvolvido sobre NumPy, SciPy e Matplotlib, aberto e disponível sob licença BSD (BRUNING, 2013);

5. NLTK (Natural Language Toll Kit) - plataforma para desenvolvimento de programas para trabalhar com Linguagem Natural (BIRD, 2006).

\subsection{Metodologia}

O presente trabalho representa, no seu núcleo, a implementação de um algoritmo de Agrupamento de Textos. No entanto, a metodologia de pesquisa ao longo do curso teve como uma das diretrizes o desenvolvimento de estruturas e algoritmos de Aprendizagem de Máquina que atendessem aos critérios de modularidade e progressividade, de forma que cada etapa do trabalho pudesse estreitar ou aprofundar o foco de acordo com a necessidade e a permanente atualização da pesquisa desenvolvida. Assim, caso uma alternativa de abordagem se mostrasse especialmente promissora, como ocorreu com o Agrupamento de Textos, o trabalho poderia ser intensificado de forma focada, sem prejuízo para a consistência do todo ou da geração de resultados efetivos mensuráveis. Essa metodologia resultou na elaboração do Ambiente de Desenvolvimento, um ambiente gráfico que integra todas as subestruturas de Aprendizagem de Máquina por meio de Redes Bayesianas, e de uma aplicação básica do módulo de Aprendizagem da Rede com uso de processamento paralelo.

Sob essa diretriz e considerando as oportunidades mais imediatas para melhor aproveitamento trabalho, optou-se pela concentração do foco no desenvolvimento do módulo de tratamento e pré-processamento do fenômeno de Agrupamento de Textos, conforme será descrito no item correspondente.

A fim de obter ao final do trabalho uma implementação minimamente funcional, foram implementadas versões básicas de cada um dos módulos do Ambiente de Desenvolvimento baseadas em uma abordagem de busca exaustiva para identificação da Rede Bayesiana mais representativa do fenômeno estudado. Esses produtos e subprodutos da presente pesquisa são apresentados a seguir.

\subsubsection{Ambiente de Desenvolvimento}

A preocupação inicial foi em desenvolver uma estrutura arcabouço que permitisse sua utilização em todo o trabalho e tendo por diretrizes a reutilização do código e a reprodutividade dos resultados obtidos. Esse arcabouço basicamente consiste em um programa que adquire os dados disponíveis decorrentes da materialização de determinado fenômeno, realiza um pré-processamento desse fenômeno em estado natural para transformar cada amostra em um conjunto de valores de determinadas variáveis escolhidas como as ca- 
racterísticas ou dimensões relevantes do fenômeno, considera as condições e restrições $a$ priori conhecidas desse fenômeno traduzidas como grau de probabilidade de arestas na Rede Bayesiana representativa, por exemplo as derivadas do conhecimento de especialistas, e processa essas informações para obter um resultado na forma das melhores Redes Bayesianas que descrevem o fenômeno, hierarquizadas de acordo com uma determinada função de ranqueamento. Ao final, pode ser incluído um módulo que permita prever a classificação de novas amostras a partir da rede aprendida. Ou seja, a partir dos dados e do conhecimento prévio apresentam-se as Redes Bayesianas que melhor descrevem o fenômeno e que podem efetuar predições sobre ele.

Com essa abordagem, foi elaborada uma estrutura geral em camadas, definidas a partir do grau de especificidade. A camada mais geral ou externa buscou refletir os macroprocessos envolvidos na obtenção de Redes Bayesianas sem considerar, dentro do possível, qualquer especificidade do algoritmo utilizado. Portanto, essa primeira camada implementa macrorrotinas gerais dos seguintes blocos: aquisição dos dados (que inclui préprocessamento e reconhecimento de padrões), condições a priori da rede, determinação do espaço de busca, segmentação do espaço de busca em subespaços, seleção de redes em cada subespaço, agregação dos resultados dos subespaços, registro dos resultados e predição.

A partir dessa camada e do desenvolvimento do trabalho, as camadas inferiores (mais específicas) irão sendo desenvolvidas para implementar os algoritmos mais específicos que forem de interesse do trabalho. No entanto, o programa será desenvolvido de forma a possibilitar evoluções posteriores e introdução de outros algoritmos específicos, a fim de permitir a reutilização do seu código como ponto de partida para outros trabalhos, contribuindo assim para maior efetividade do meio acadêmico.

A estrutura geral do algoritmo utilizado foi a da Figura 2, a qual já prevê a possibilidade de utilização de processamento paralelo para alguns módulos, representada na forma de raias distintas para cada grupo de núcleos de processamento, conforme será descrito posteriormente no item correspondente do presente texto. 
Figura 2: Fluxograma do algoritmo geral - as raias indicam as possibilidades de distribuição do processamento pelos diversos núcleos

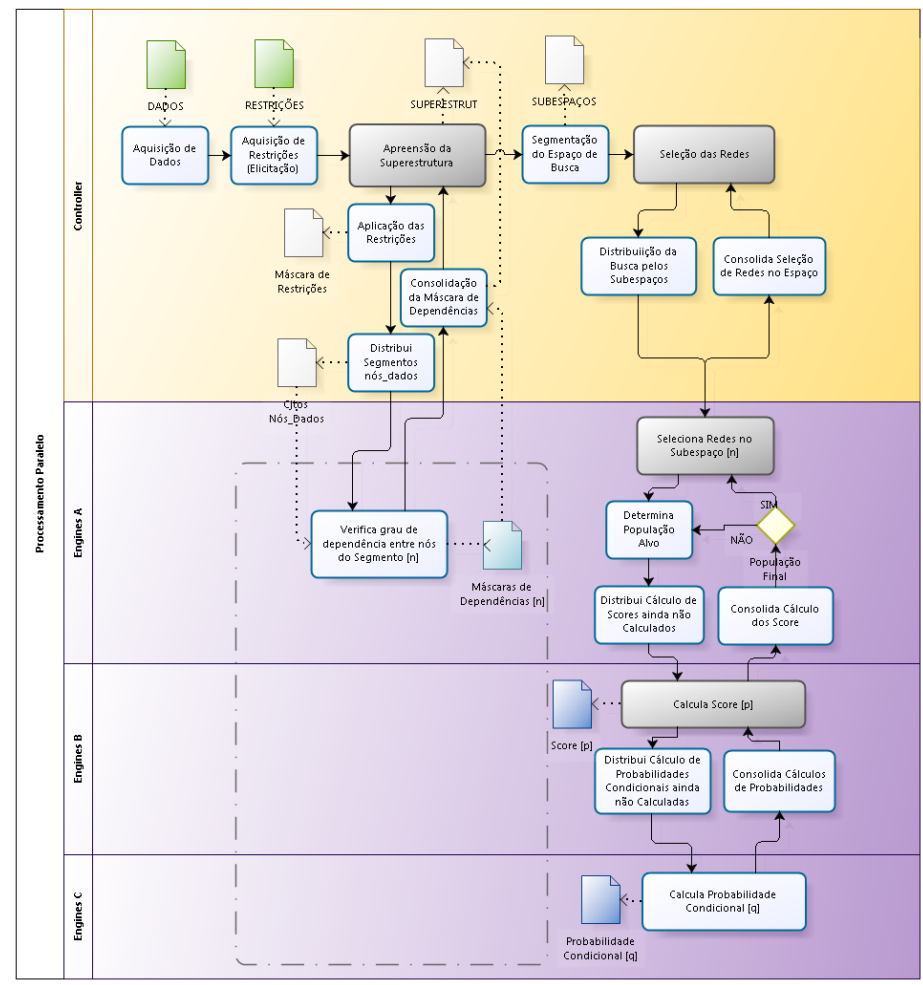

Fonte: elaborado pelo próprio autor

A lógica do algoritmo é a descrita a seguir. Trata-se de uma estrutura geral que pretende implementar mais de uma abordagem de aprendizado de Redes Bayesianas, portanto prevê blocos ou etapas que podem ser desnecessárias em determinadas abordagens.

A estrutura compõe-se de seis grandes blocos: Aquisição de Dados, Elicitação de Restrições, Apreensão de Superestrutura, Segmentação do Espaço de Busca, Seleção das Redes e Registro do Resultado.

A Aquisição de Dados consiste na importação pelo algoritmo dos dados relativos ao fenômeno e na sua conversão em uma tabela com os diversos valores das variáveis do sistema para cada amostra, podendo incluir fases de pré-processamento e de Reconhecimento de Padrões, de acordo com o fenômeno objeto da análise. A Elicitação de Restrições corresponde à etapa de introdução do conhecimento prévio acerca do fenômeno quanto ao relacionamento entre as variáveis refletido na forma de restrições ou condições na estrutura da Rede Bayesiana representativa. Essa é uma das etapas que pode não ser processada, por exemplo quando a abordagem utilizada seja totalmente não supervisionada, sem a possibilidade de introdução de conhecimento prévio oriundo de especialistas.

A etapa seguinte é a de Apreensão de Superestrutura, que também pode ser desnecessária para determinadas abordagens, como é o caso da busca exaustiva utilizada nos testes efetuados com processamento paralelo. Essa etapa corresponde a uma análise pré- 
via das relações de dependência entre as diversas variáveis a partir dos dados disponíveis com a finalidade de identificar fortes relações de dependência ou independência entre as variáveis e convertê-las em condicionantes da existência ou ausência de arestas na Rede Bayesiana procurada. Esses condicionantes são então representados na forma de uma Superestrutura que funciona como uma máscara para a validação de possíveis candidatos a estrutura da rede procurada.

Em seguida, passa-se à Segmentação do Espaço de Busca em subespaços, a fim de possibilitar uma utilização do processamento paralelo já no nível mais alto do algoritmo, caso isso se mostre possível dentro da abordagem adotada numa determinada implementação. A título de exemplo, a segmentação em subespaços surge como uma etapa natural na abordagem de busca exaustiva, porém não é de aplicação imediata na busca por meio de algoritmos genéticos.

A etapa de Seleção das Redes Bayesianas é a etapa principal e irá estar presente em qualquer abordagem, em que pese seu formato variar bastante de acordo com aquela. É nessa etapa que será implementada a busca da rede adequada, seja por meio de uma simples busca exaustiva para redes de pouca complexidade, seja por meio de algoritmos complexos, como, por exemplo, o de um algoritmo genético.

A fase de Registro do Resultado também é uma etapa que estará presente em qualquer abordagem e consiste na etapa de apresentação dos resultados com todas as informações que sejam de interesse além das soluções de rede, tais como tempo de processamento e dados acerca do procedimento de busca utilizado.

Além da apresentação desses grandes blocos, o algoritmo geral já apresenta algumas alternativas para utilização do recurso de processamento paralelo em diversos níveis do algoritmo. No nível mais alto, conforme já mencionado, a segmentação do espaço de busca em subespaços disjuntos de cobertura completa permite a paralelização total do processamento da busca, gerando resultados parciais independentes que são agregados ao final por uma seleção simples dos melhores resultados.

Outra possibilidade de paralelização do processamento é a que corresponde ao cálculo da pontuação para cada rede de uma população alvo. Nesse caso, a população pode ser segmentada em grupos para que o cálculo da pontuação dos indivíduos de cada grupo seja efetuado por uma máquina distinta, multiplicando a velocidade de processamento para o cálculo de toda a população.

Também é possível paralelizar o cálculo das relações de dependência ou independência entre as variáveis, por meio da segmentação dos possíveis conjuntos de interesse da variável objeto e das variáveis condicionantes.

Mais uma possibilidade, essa já em um nível muito menos agregado, é a paralelização do processamento dos cálculos das probabilidades condicionais de uma determinada rede dentro do processo de pontuação dessa rede, que pode ser materializado pela distribuição do cálculo por nós ou grupos de nós. 
A literatura recente aponta também a possibilidade de efetuar cálculos MCMC com uso de paralelização, como em (JOSEPH; GUILLAUME, 2013). Esses autores apresentam um algoritmo que afirmam ter excelentes resultados na redução no tempo de processamento a partir da avaliação em paralelo dos parâmetros, especialmente em modelos com grande número de entradas, e o algoritmo teria portabilidade para o uso no desenvolvimento de funções de verossimilhança apropriadas a cada situação.

Cabe ressaltar que todo esse processamento paralelo deve considerar o reaproveitamento de cálculos já efetuados, sem deixar de observar os custos associados às trocas de mensagens entre máquinas e controlador necessárias ao longo do processo, que aumenta quando da opção pelo aproveitamento de resultados parciais de menor granularidade. Esse reaproveitamento é feito por meio da utilização de cache de memória, com os resultados parciais passíveis de reaproveitamento nos diversos níveis do algoritmo sendo armazenados em memória de tal forma que seu registro e reutilização impliquem no menor custo possível em termos de troca de informações entre os núcleos de processamento e o controlador.

Um ponto importante e norteador nessa parcela do trabalho é a forma de representação das Redes Bayesianas e do espaço de busca. Em face da estratégia de utilizar soluções já existentes a fim de focar esforços no cerne do trabalho, uma condição de contorno inicial foi a necessidade da representação a ser adotada ser compatível com o pacote pebl (PEBL - Python Environment For Bayesian Learning versão 1.0.2). Esse pacote utiliza classes de objetos pré-definidas para os objetos variável (variable), nó (node), aresta (edge), rede (network) e assim por diante. Tais representações foram totalmente absorvidas no presente projeto e determinaram parte da representação a ser usada.

O atributo utilizado como chave na representação das Redes Bayesianas foi a matriz de adjacências (adjacency_matrix), que consiste de uma matriz na qual as linhas representam os nós de origem e as colunas os nós de destino e o valor de cada entrada uma variável lógica que indica se existe ou não a aresta que sai do nó correspondente à linha e chega ao nó correspondente à coluna. Essa representação não garante que o grafo representado seja acíclico, portanto toda vez que uma nova representação é criada há a necessidade de sua validação, que é feita a partir de sub-rotinas específicas. Apesar desse inconveniente, essa representação se mostrou eficiente por sua simplicidade de manipulação. Uma das vantagens dessa representação é a possibilidade de criar uma rede a partir do número inteiro que pode ser associado à linearização das entradas da matriz de adjacências tomada como um número na base 2 .

A implementação desses módulos no código em Python seguiu o mesmo critério de modularização, subdividindo o código em pacotes. Assim, foi elaborado um pacote principal BNSystem que representa a interface gráfica principal e carrega todos os pacotes responsáveis pelos módulos específicos. Esses são o BNS_Phenom_Text, que implementa o tratamento do fenômeno de amostras de textos, o BNS_Learning_Structure, 
da aprendizagem da estrutura da rede, o BNS_Learning_Parameters, de aprendizagem dos parâmetros da rede, o BNS_Predict, para predição dos resultados do fenômeno para novas amostras, o BNS_Parallel, que concentra as rotinas de interface com a estrutura de processamento paralelo, o BNS_Graph, para elaboração de gráficos de apresentação de alguns resultados do processamento, e o TextMonitor, que é um pacote apenas para apresentação gráfica de todo o processamento dos textos.

Estabelecida a metodologia e desenvolvida a estrutura geral do algoritmo, e ainda antes da definição do foco da pesquisa no agrupamento de textos, seguiu-se uma primeira implementação de teste para avaliação das possibilidades do processamento paralelo com um módulo de busca exaustiva para a seleção da Rede Bayesiana, que já foi apresentada pelo autor por ocasião da Qualificação ao Curso de Mestrado e cujos resultados serão descritos de forma resumida no capítulo correspondente do presente texto.

Em seguida, foi desenvolvida uma implementação específica para o Agrupamento de Textos, no âmbito da Língua Portuguesa, a partir da preparação de um acervo de aprendizagem classificado por meio do uso de técnicas de Reconhecimento de Padrões.

Essas duas implementações são descritas a seguir.

\subsubsection{Módulo de Seleção da Rede Bayesiana - Busca Exaustiva}

Conforme mencionado, inicialmente foi desenvolvida uma implementação especifica de teste para o módulo de Seleção da Rede Bayesiana (RB) mais adequada, com vistas à avaliação da aplicação de processamento paralelo ao paradigma de Redes Bayesianas. Essa implementação usou o conceito simples de busca exaustiva, aplicável a redes de baixa complexidade (pequeno número de nós).

O algoritmo geral de busca exaustiva utilizado foi o apresentado na Figura 3. Basicamente, todas as possíveis estruturas de rede são testadas, a partir da conversão de cada inteiro entre 0 e $2^{\text {n2 }}-1$ em uma matriz de adjacências da eventual Rede Bayesiana a ser testada. No entanto, nem todo inteiro corresponde à matriz de adjacências de um Grafo Acíclico Dirigido ou Directed Acyclic Graph - DAG, logo, cada matriz precisa ser validada, a fim de se verificar se resulta em DAG válido, sendo descartada se é uma rede cíclica. Validada a rede, faz-se a apuração do seu score. Ao final, selecionam-se as redes de score máximo. 
Figura 3: Fluxograma do algoritmo de busca exaustiva da população de redes solução para os dados considerados

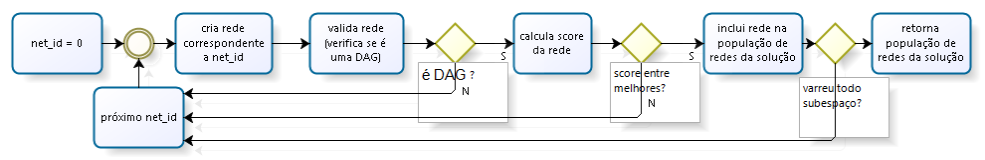

Fonte: elaborado pelo próprio autor

Portanto, na presente implementação, somente o algoritmo de busca exaustiva está operante, porém a estrutura está apta a receber qualquer outra implementação de seleção de redes, desde uma Naïve Bayes (Rede Bayesiana simples, onde todos os nós filhos provém de um único nó pai) até algoritmos mais complexos como aqueles orientados a abordagens genéticas.

\subsubsection{Módulo de Agrupamento de Textos}

O Módulo de Agrupamento de Textos foi desenvolvido com o objetivo de agrupar textos em Língua Portuguesa de quaisquer natureza de acordo com estrutura do texto, temas, estilos de redação ou qualquer outra característica que possa ser de interesse.

A ideia norteadora do agrupamento é que textos próximos poderiam refletir essa proximidade em algum grau numa correspondente proximidade entre suas distribuições de frequência da informação contida nas palavras utilizadas para sua escrita, seja essa informação a própria palavra, seu núcleo (radical) ou o campo semântico associado.

A partir dessa ideia central, o caminho seguido foi o de transformar os textos em distribuições de frequências de palavras e/ou de radicais e comparar essas distribuições. A comparação se dá tomando as distribuições em relação a todo o vocabulário considerado ou tomando-as dentro de grupos de vocábulos formados de acordo com a frequência (de grupos de vocábulos muito frequentes a grupos de vocábulos pouco frequentes ou raros entre os textos), agrupando de acordo com a proximidade do conjunto dessas distribuições.

Cabe aqui uma ressalva em relação à terminologia. Todos os termos que estiverem sendo usados dentro de uma significação específica para o presente trabalho serão registrados entre aspas. Nos casos em que possa haver maior risco de ambiguidades, os termos serão ainda antecedidos de "BNS_" (Bayesian Networks System - denominação provisória atribuída ao sistema desenvolvido na presente pesquisa). Proceder-se-á dessa forma para eventual diferenciação em caso de coincidência com o mesmo termo usado em na literatura.

Da abordagem de Linguagem Natural, utilizaram-se os conceitos de corpus e Vocabulário (NAVARRE; STEIMAN, 2002), adaptados aos objetivos do trabalho, e associados a conceitos e terminologia específicos para o escopo da presente pesquisa, conforme anotado 
ao longo do texto. O corpus é um conjunto de textos de determinada linguagem que se configure em uma amostra relevante e representativa da expressão daquela linguagem em um escopo determinado ou geral. O corpus efetivamente utilizado nessa pesquisa foi o conjunto formado pela agregação de todas as amostras. Adotaram-se também aqui os conceitos de "Vocabulário" e "Diretório". "Diretório" é definido aqui como o conjunto de todos os radicais presentes em todos os textos considerados, enquanto que o termo "Vocabulário" foi utilizado para designar um subconjunto do "Diretório" produzido pela restrição dos seus elementos a alguma condição. Nesse trabalho, foram formados diversos "Vocabulários", de acordo com alguns critérios de filtragem, dentre eles o grau de ocorrência dos radicais entre os diversos textos de amostra, conforme detalhado nas seções seguintes.

Para implementação do agrupamento de textos, foi necessário o desenvolvimento de diversos submódulos, a seguir descritos e exemplificados.

\section{Importação dos Textos}

O primeiro passo consistiu na importação dos textos como objetos a serem tratados pelo algoritmo.

O formato estabelecido como padrão para importação foi o formato texto padrão (extensão ".txt"), com duas possibilidades de formatação: um único arquivo contendo uma amostra em cada linha (a separação entre as amostras identificada pelo caracter "LF" - Line Feed) ou arquivos distintos para cada amostra nomeados de "0...01 - Txt.txt" a "9...99 - Txt.txt" conforme o número total de amostras. As duas alternativas visam agraciar de forma mais adequada universos de textos pequenos e universos de textos mais extensos.

O conteúdo dos arquivos é importado na forma de listas de palavras, das quais, por opção no Ambiente de Desenvolvimento, podem ser excluídos os caracteres que não integram a codificação "latin_1" usada para a Língua Portuguesa, além da conversão de todas as letras em minúsculas. Essas listas são inseridas um uma lista de textos.

Exemplo:

Seja um único arquivo "Exemplo.txt" constituído por três linhas, cada uma representando uma amostra (um texto):

A maçã é uma fruta vermelha x93n5.

A pera é uma fruta verde claro.

A laranja é uma fruta amarelo claro.

Após a importação, teríamos:

Textos[0] = [a, maçã, é, uma, fruta, vermelha]

Textos[1] = [a, pera, é, uma, fruta, verde, claro]

Textos[2] = [a, laranja, é, uma, fruta, amarelo, claro] 


\section{Criação do "Supertexto"}

O segundo passo da metodologia é a obtenção de um "Supertexto", que servirá de referência para determinar as distâncias na métrica das distribuições de frequências. O "Supertexto" utilizado foi formado a partir das listas de palavras correspondentes a cada amostra (texto), mas outra opção que foi disponibilizada no Ambiente de Desenvolvimento é a utilização de um corpus (extenso conjunto de textos de uma língua representativo do vernáculo, geral ou de áreas específicas); na implementação atual do Ambiente está disponível o corpus de Língua Portuguesa "Floresta".

O "Supertexto" é formado pela concatenação simples de todas as listas de palavras na ordem da importação.

Exemplo:

Supertexto $=[a$, maçã é, uma, fruta, vermelha, a, pera, é, uma, fruta, verde, claro, a, laranja, é, uma, fruta, amarelo, claro]

\section{Criação do "Diretório" de Palavras}

Um elemento essencial para a determinação das distribuições é o conjunto de todas as palavras existentes nos textos. Daí o passo seguinte ser a obtenção do "Diretório" de todas as essas palavras.

Esse "Diretório" é obtido a partir da eliminação das duplicidades do "Supertexto", fornecendo, assim, um conjunto de palavras únicas, que é organizado em ordem alfanumérica. Essa ordenação alfanumérica é apenas referencial e não tem relevância específica (poderia ser escolhida qualquer outra), pois o cálculo da Divergência K-L é internamente comutativo (vide capítulo sobre Teoria) e não é afetado pela ordenação escolhida. Sua vantagem é a pronta manipulação pelas rotinas e funções pré-existentes.

Para facilitar os tratamentos subsequentes, todos os textos, incluindo o "Supertexto", são indexados a partir do "Diretório" e seus índices.

Exemplo:

Diretório $=[a$, amarelo, claro, é, fruta, laranja, maçã, pera, uma, vermelha, verde]

\section{Criação de "BNS_Dialetos"}

A partir daí podem ser aplicadas diversas abordagens. Para caracterizar cada uma dessas abordagens de forma independente, utilizou-se o conceito de "BNS_Dialeto". Ressaltese que essa terminologia não guarda relação com o eventual uso desse termo fora do escopo da presente pesquisa, devendo ser considerado apenas conforme a definiçao que se segue.

Um "BNS_Dialeto" é um objeto complexo que tem como elementos principais um "Vocabulário" (que consiste em um conjunto de termos derivados direta ou indiretamente do "Diretório"), pela tradução entre esse "Vocabulário" e o "Diretório" e pelas versões dos textos de acordo com esse "Vocabulário".

A criação de um novo "BNS_Dialeto" inicia pela formação do seu "Vocabulário" a 
partir do "Diretório" ou a partir de um "Vocabulário" de outro "BNS_Dialeto" existente, mantendo o registro da tradução entre o novo "Vocabulário" e o "Diretório" na forma de uma tabela associativa.

No presente trabalho, foram utilizados três "BNS_Dialetos". O primeiro é simplesmente a replicação do "Diretório" e dos textos originais. O segundo, a limpeza do "BNS_Dialeto" anterior pela exclusão de caracteres de pontuação (vírgula, ponto e vírgula etc.). E o terceiro formado a partir da extração dos radicais das palavras constituintes do "Vocabulário" do "BNS_Dialeto" anterior.

Por se tratar de uma análise de similaridade entre textos, buscaram-se ferramentas simples na área de processamento de Linguagem Natural e recuperação de informação no sentido de estruturar a informação das amostras sob uma perspectiva minimamente semântica. A abordagem escolhida foi a de extração do radical (ou semantema) de cada palavra para ser o elemento celular a ser trabalhado. Essa opção faz mais sentido do que considerar as palavras originais, que além de poderem ter variações meramente de formatação (maiúsculas/minúsculas, por exemplo), também apresentaram variações de flexão e concordância que representam baixíssima relevância numa análise essencialmente voltada para o conteúdo estrutural ou temático. O instrumento usado nesse caso foi um algoritmo de stemming com implementação disponível e bastante usado, na forma de uma função do pacote NLTK 3.0 (NAVARRE; STEIMAN, 2002).

Uma sequência possível e natural seria a criação de um quarto "BNS_Dialeto" por meio de uma abordagem semântica, agrupando radicais conforme sua similaridade de significado (sinônimos, antônimos e campos semânticos em geral). Essa abordagem não foi aqui adotada pelo grau de complexidade que iria agregar ao trabalho em uma área (Linguagem Natural) que não é a área principal de interesse (Aprendizado de Máquina em geral).

Exemplo:

Dialetos[2].vocabulário $=$ [a, amarel, clar, e, frut, laranj, mac, per, um, vermelh,verd] Dialetos[2].tradução = [a, amarel, clar, e, frut, laranj, mac, per, um, vermelh, verd] Dialetos[2].textos[0] = [a, maç, é, um, frut, vermelh]

\section{Distribuições de Frequência dos Textos}

Formados os "BNS_Dialetos" por meio de seus elementos determinantes ("Vocabulário" e Textos), a fase seguinte é a da obtenção das Distribuições de Frequência de cada palavra do Vocabulário em cada um dos Textos e do "Supertexto".

Isso é feito simplesmente contando o número de ocorrências de cada vocábulo no Texto e dividindo pelo número total de vocábulos do Texto. O número decimal resultante corresponde ao valor da frequência para aquele vocábulo. A Distribuição é representada a partir da ordenação alfanumérica dos vocábulos para representar a dimensão das coordenadas horizontais do gráfico. 
Figura 4: Distribuição de frequência (vocábulo x frequência) dos vocábulos do Supertexto (Texto 0) - cada vocábulo é representado por seu índice na ordem alfanumérica.

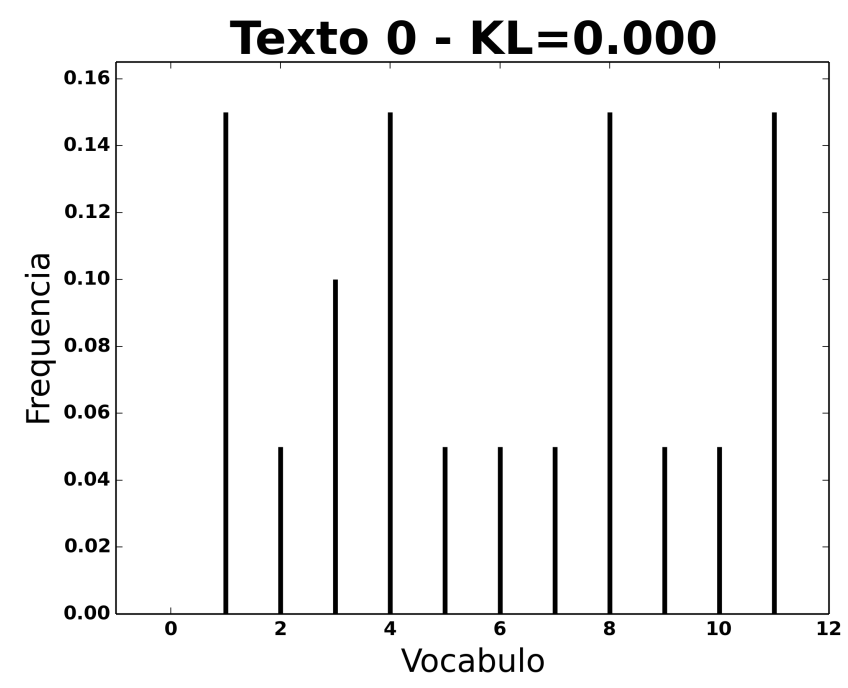

Fonte: elaborado pelo próprio autor

Figura 5: Distribuição de frequência dos vocábulos do Texto 3 (amostra 3), a título de exemplo - cada vocábulo é representado por seu índice na ordem alfanumérica. KL representa o valor da Divergência K-L entre esse Texto e o Supertexto. DKL $(3 ; 0)=$ 0,323 .

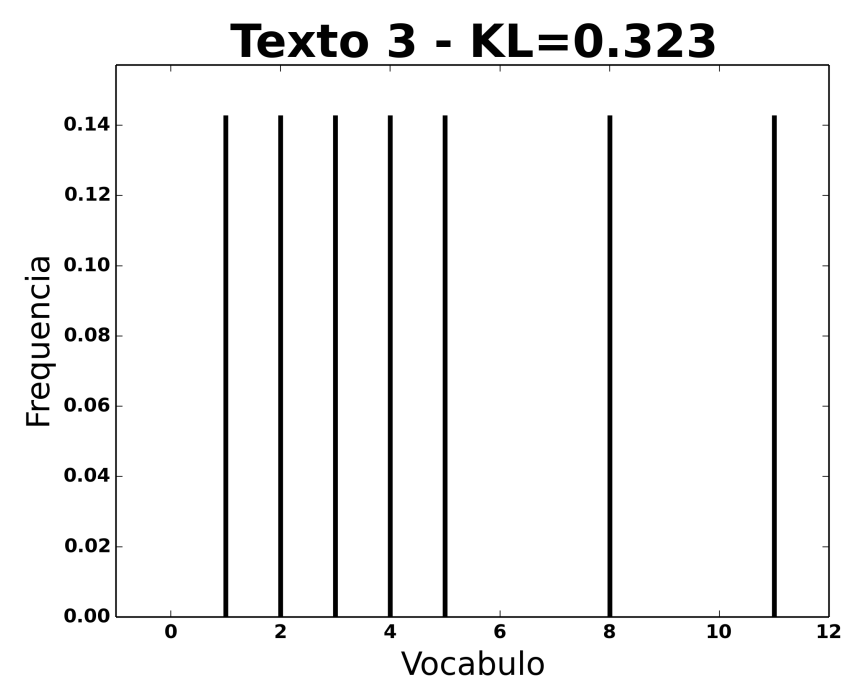

Fonte: elaborado pelo próprio autor

Uma ressalva importante a ser ratificada é que o critério para ordenamento das coordenadas horizontais não é relevante, pois as Distribuições serão utilizadas exclusivamente para o cálculo da Divergência K-L, que tem a propriedade de ser comutativa em relação a essas coordenadas (comutatividade interna). Isso é reflexo da própria comutatividade 
da operação aritmética de soma de fatores vinculados a uma única coordenada, que é o fundamento da definição dessa medida.

\section{Formação dos "Subvocabulários"}

À apuração das Distribuições de Frequência globais em relação ao "Vocabulário" completo do "BNS_Dialeto", segue-se a formação dos "Subvocabulários" (grupos de vocábulos) de acordo com a intensidade de ocorrência deles entre os diversos Textos.

Optou-se pelo adoção dos decis (faixas de $10 \%$ de largura), atribuindo um "Subvocabulário" a cada faixa entre 0\% e 100\%, com largura de 10\%, resultando em 10 "Subvocabulários" distintos de "Vocábulos" e um "Subvocabulário" correspondente ao Vocabulário completo, num total de 11 grupos. Ou seja, tem-se um "Subvocabulário" com todos os vocábulos (Grupo 0), um "Subvocabulário" com os vocábulos que só aparecem em até 10\% dos Textos ("Subvocabulário" 1), um com os que aparecem em $11 \%$ a $20 \%$ dos textos ("Subvocabulário" 2), e assim por diante, até o Grupo de 91\% a 100\% ("Subvocabulário" $10)$.

Quando o número de Textos é inferior a 10, não é possível formar todos os "Subvocabulários" e essa formação é adaptada aos percentis possíveis de forma proporcional.

Exemplo:

Com 3 Textos, as faixas são de $0 \%$ a $33 \%$ (vocábulos em somente 1 Texto), de $34 \%$ a $66 \%$ (2 Textos) e de $67 \%$ a $100 \%$ (3 Textos)

Dialetos[2].Subvocabularios[0] = [a, amarel, clar, e, frut, laranj, mac, per, um, vermelh, verd] (11)

Dialetos[2].Subvocabularios[1] = [amarel, laranj, maç, per, vermelh, verd] (6)

Dialetos[2].Subvocabularios[2] = [clar] (1)

Dialetos[2].Subvocabularios[3] $=[a$, e, frut, um] (4)

\section{Projeções das Distribuições de Frequência}

A cada "Subvocabulario" irá corresponder uma projeção da Distribuição de Frequência principal em relação ao "Subvocabulário" correspondente. Essa projeção é obtida pela restrição normalizada da Distribuição original às ordenadas correspondentes aos vocábulos presentes no Grupo. 
Figura 6: Distribuição de frequência dos vocábulos do Supertexto que pertencem ao Subvocabulário 2, a título de exemplo - cada vocábulo é representado por seu índice. Cada um dos seis vocábulos aparece uma vez em um dos dois dos textos, logo todas as frequências são iguais a $2 / 12=0.167$.

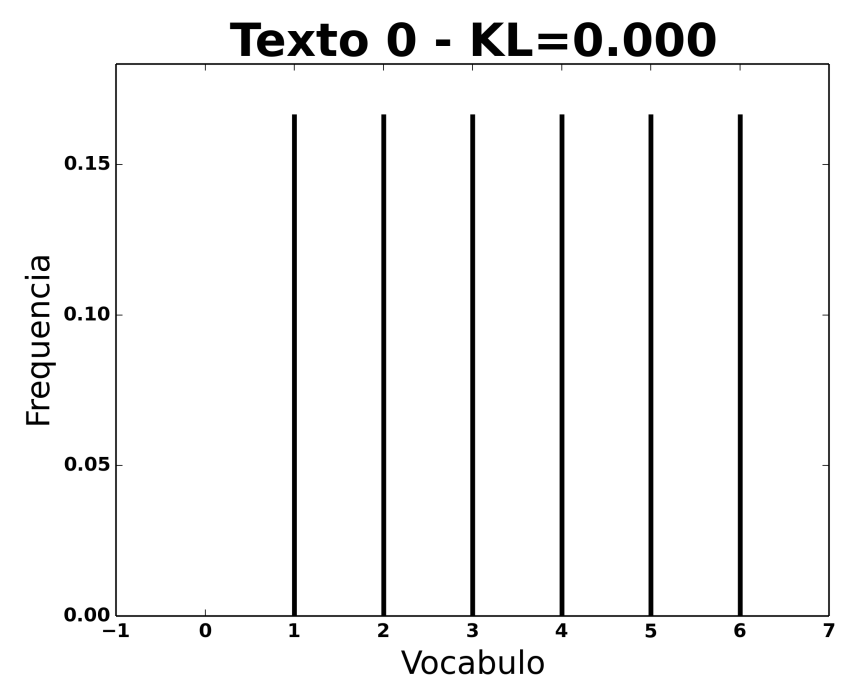

Fonte: elaborado pelo próprio autor

Figura 7: Distribuição de frequência dos vocábulos do Texto 3 (amostra 3) que pertencem ao Subvocabulário 2, a título de exemplo - cada vocábulo é representado por seu índice. $\operatorname{DKL}(3 ; 0)=1,099$.

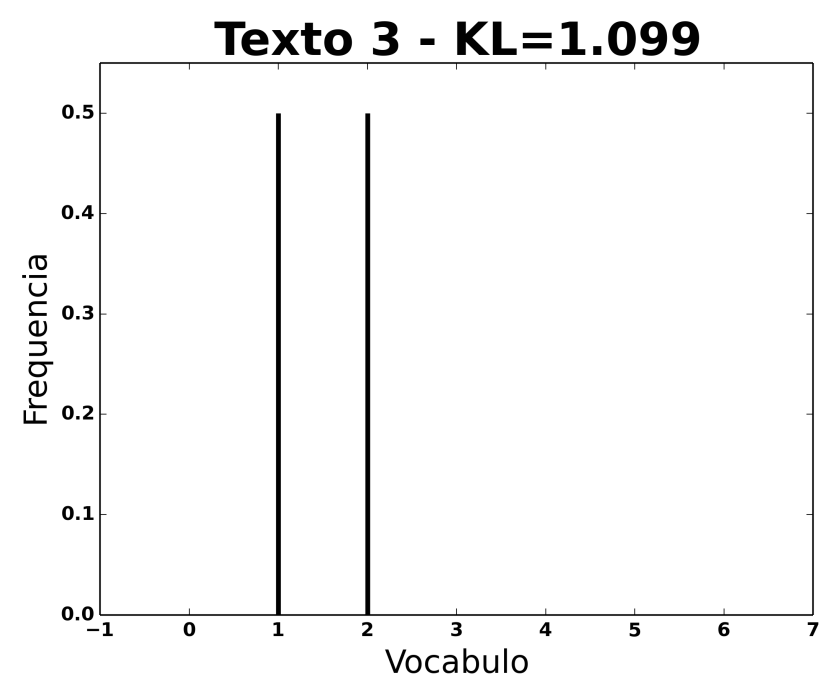

Fonte: elaborado pelo próprio autor

\section{Cálculo da Divergência K-L}

No "BNS_Dialeto" em foco, a cada amostra (Texto) e para cada "Subvocabulario" é associado um número que é obtido a partir do cálculo da Divergência K-L entre a 
Distribuição do Texto para aquele "Subvocabulario" e a Distribuição do "Supertexto" para aquele mesmo "Subvocabulario".

Por exemplo, a divergência K-L do Texto 3 em relação ao "Supertexto" para o "Subvocabulário" 2 pode ser calculada aqui com ajuda da observação das duas últimas figuras (Figura 6 e Figura 7). Todas as frequências do Supertexto são 0.167 e as duas do Texto 3 são 0,5 . O termo $\mathrm{p}(\mathrm{i}) \cdot \ln [\mathrm{p}(\mathrm{i}) / \mathrm{q}(\mathrm{i})]$ somente será não nulo para os vocábulos 1 e 2 , quando é igual a $0,5 * \ln [0,5 / 0,167]$. Logo, a divergência K-L será a soma de dois termos $0,5 *$ $\ln [0,5 / 0,167]$, que é igual a ln 3 ou 1,099, conforme mostrado na figura.

\section{Tabela de Características do Fenômeno}

Ao final do cômputo de todas as Divergências K-L, tem-se até 11 valores dessas Divergências para cada Texto, caso a complexidade e variedade dos textos permita que não haja nulidades.

Portanto, é natural a composição de uma Tabela de Características onde cada amostra de Texto é representada por seus 11 valores correspondentes a essas 11 dimensões.

Para o exemplo até aqui tratado, apenas 4 valores das divergências são gerados, pois formam-se apenas 4 "Subvocabulários" válidos, incluído o que considera todo o "Vocabulário". A Tabela então gerada é a que se segue:

Tabela 1: Valores das Divergências K-L entre cada amostra e o "Supertexto" para cada grupo de vocábulos. "KLx" representa as Divergências K-L para o "Subvocabulario x" e "S_x" é a amostra "x". O valor "inf" significa divergência infinita, que ocorre quando a amostra não possui nenhuma palavra do grupo. A última coluna representa o agrupamento ótimo obtido como resultado final do processamento.

\begin{tabular}{llllll}
\hline Amostra & KL0 & KL1 & KL2 & KL3 & Cluster \\
\hline S_0 & 0.47 & 1.1 & inf & 0 & 1 \\
S_1 & 0.32 & 1.1 & 0 & 0 & 0 \\
S_2 & 0.32 & 1.1 & 0 & 0 & 0
\end{tabular}

\section{Agrupamento das Amostras}

A partir da Tabela de Características, é possível efetuar o seu agrupamento em clusters por meio da utilização de qualquer das técnicas de Reconhecimento de Padrões bem estabelecidas na literatura.

Como o foco desse trabalho não demanda inserir complexidades desnecessárias e por se tratar de uma proposta evolutiva para sequências posteriores, optou-se por adotar uma técnica clássica e consolidada: o algoritmo K-Means com a seleção do número ótimo de clusters de agrupamento por meio da análise do equilíbrio entre as distâncias intracluster e intercluster.

No caso do exemplo, os gráficos dessas distâncias ficam da seguinte forma: 
Figura 8: Gráfico das distâncias intercluster e intracluster em função do número de clusters considerado (Distância x Número de Clusters). O cruzamento ocorre entre 1 e 2 clusters e, portanto, foi selecionado o maior desses números, caracterizando-se como solução o agrupamento em 2 clusters, conforme já apresentado na última coluna da Tabela 1 (cluster 0 e cluster 1$)$.

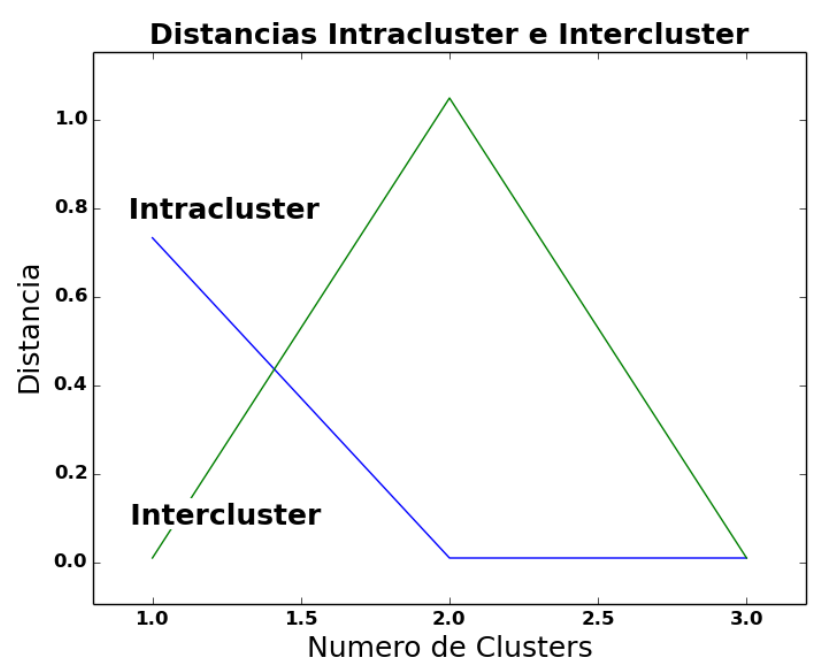

Fonte: elaborado pelo próprio autor

Figura 9: Gráfico do índice de Validação das distâncias intercluster e intracluster em função do número de clusters considerado (Razão de Validação x Número de Clusters). O mínimo ocorre para 2 clusters.

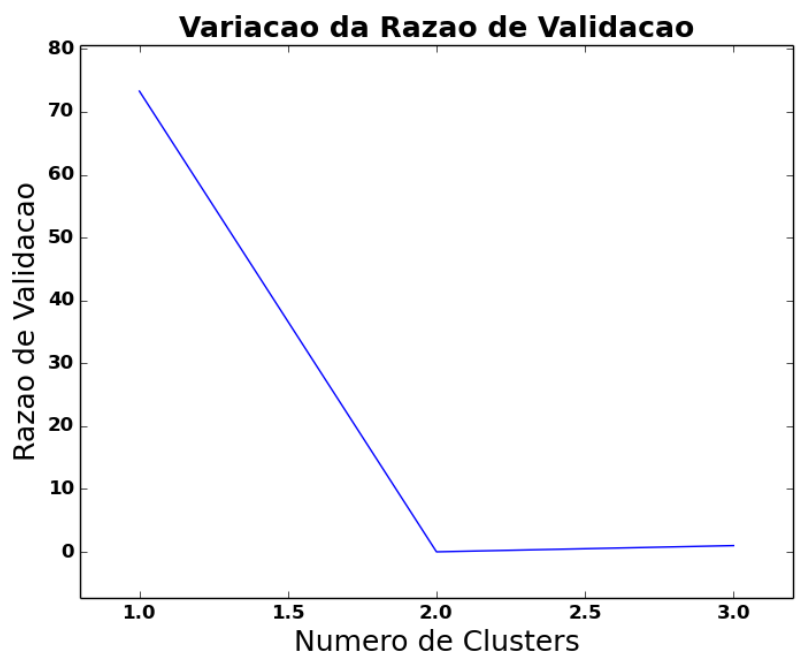

Fonte: elaborado pelo próprio autor

O resultado do agrupamento está graficamente representado na figura a seguir. 
Figura 10: Representação gráfica do agrupamento dos 3 textos em 2 clusters por meio de esferas coloridas, cada eixo representando uma das dimensões da representação em Componentes Principais (PCA). O número associado a cada esfera representa o número de amostras daquele cluster.

\section{Agrupamento das Amostras- Numeracao Otimizada $-\mathrm{n}=\mathbf{2}: \mathrm{AMI}=\mathbf{1 . 0}$}

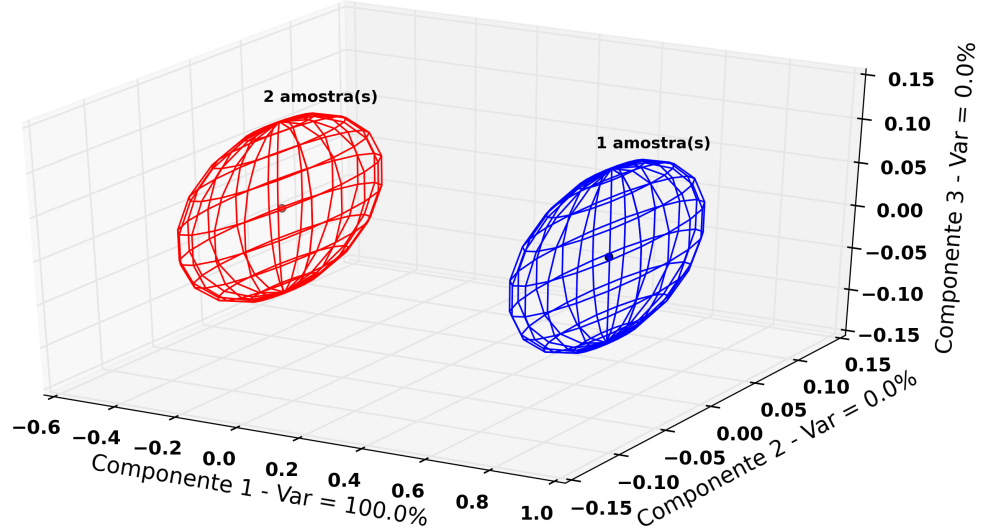

Fonte: elaborado pelo próprio autor

Nesse exemplo, o agrupamento ideal foi em 2 clusters, o que é perfeitamente compatível sob vários aspectos com as características das 3 amostras, pois as duas que continham a palavra "claro" ficaram no mesmo cluster e também são as que têm mesmo número de palavras.

Ao final, o agrupamento do algoritmo é comparado com o agrupamento real utilizandose o índice AMI, onde o objetivo é obter um resultado o mais próximo possível de 1 . No presente exemplo, o resultado obtido foi exatamente 1.0, pois o agrupamento obtido é exatamente o agrupamento real. Cumpre registrar que, para esse exemplo, o agrupamento feito pelo algoritmo em 3 clusters apresenta também o índice AMI de 1.0, o que pode ser facilmente explicado pelo fato de que a rotina de agrupamento retorna o mesmo agrupamento que aquele em 2 clusters, pois dois dos três clusters coincidem. 


\section{Resultados}

A seguir serão apresentados tanto os resultados principais associados ao núcleo do estudo (Agrupamento de Textos) como os resultados secundários gerados ao longo da pesquisa (Ambiente de Desenvolvimento e Processamento Paralelo).

\subsection{Ambiente de Desenvolvimento}

Na primeira fase do trabalho, que foi apresentada a título de Qualificação ao Mestrado em outubro de 2014, o foco foi na geração de um resultado básico e na verificação da consistência da estrutura do programa e da adequação dos ambientes de aquisição de dados e de apresentação dos resultados. Para tanto, o algoritmo implementado para aprendizado da Rede Bayesiana, conforme já mencionado, foi o da busca exaustiva, a fim de simplificar esse elemento e concentrar os esforços na elaboração da estrutura geral e na implementação da paralelização nesse nível. Reforce-se que a busca exaustiva é uma abordagem simples e que apresenta fortes limitações, a principal sendo em relação ao porte das redes a serem aprendidas, que não podem ultrapassar alguns poucos nós (foram utilizados até 5 nós na implementação), a fim de não saturar a capacidade de processamento disponível. Dentro desse escopo, os dados utilizados para os testes de implementação da estrutura e para geração dos primeiros resultados representam fenômenos simples e que permitiram validar inicialmente a estrutura e o algoritmo geral.

Para tanto, foi desenvolvido o Ambiente de Desenvolvimento com a estrutura básica de todos os seus módulos. Esse ambiente consistiu basicamente nas interfaces gráficas de cada módulo e em uma versão também básica de implementação de uma instância mínima cada um deles.

Dessa forma, o módulo de Aquisição de Dados foi implementado inicialmente de forma a simplesmente obter de um conjunto de amostras as próprias variáveis a serem diretamente consideradas nos módulos seguintes para modelagem do fenômeno. Essas variáveis são adquiridas por meio da leitura de um arquivo "txt" onde elas estão registradas de 
forma direta. Nessa implementação básica não há um processamento de amostras cruas do fenômeno observado, ao contrário de toda a implementação do agrupamento de textos.

Os módulos de Elicitação de Restrições, Apreensão de Superestrutura e Segmentação do Espaço de Busca não foram implementados com qualquer tratamento específico e estão presentes apenas as suas interfaces gráficas, pois a busca exaustiva ocorre apenas no módulo de Seleção das Redes.

A Seleção das Redes corresponde exatamente ao algoritmo de busca exaustiva a partir da tabela de amostras e características obtida na Aquisição de Dados. São varridas todas as redes possíveis, com as correspondentes tabelas de probabilidades condicionais de cada nó, e são selecionadas as redes de score máximo.

O Registro do Resultado utiliza as ferramentas do pacote pebl para registrar graficamente as redes selecionadas e para expressar o score dessas redes.

Seguem figuras que descrevem essa primeira versão do Ambiente de Desenvolvimento.

Figura 11: Visão panorâmica da tela inicial do Ambiente de Desenvolvimento.

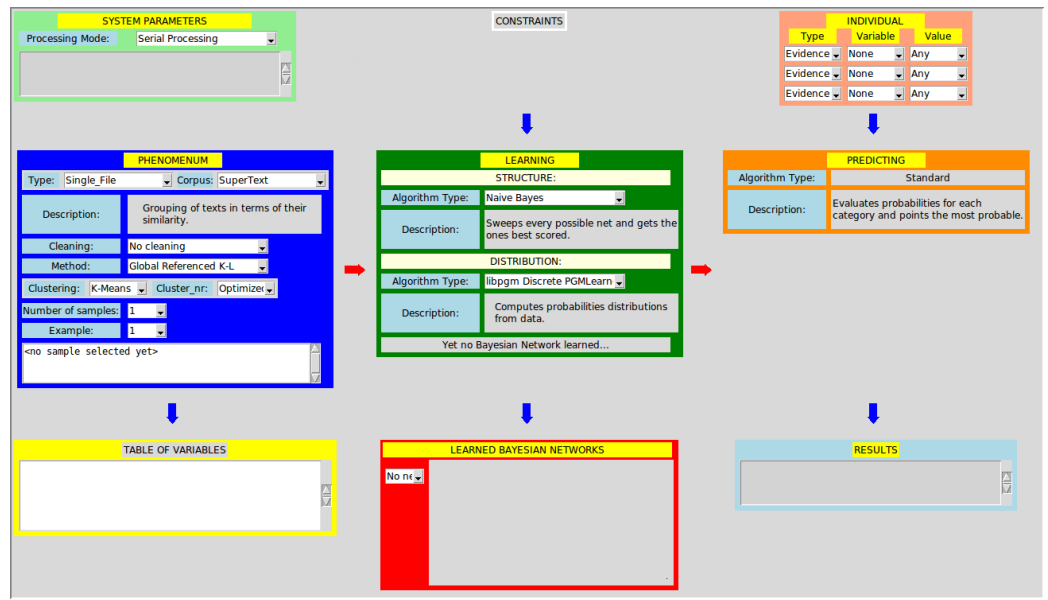

Fonte: elaborado pelo próprio autor 
Figura 12: Quadro de configuração de parâmetros gerais e de acompanhamento da execução do Ambiente de Desenvolvimento. Aqui se determina se será utilizado processamento paralelo nos módulos em que essa opção está implementada e são mostradas as mensagens de andamento da execução.

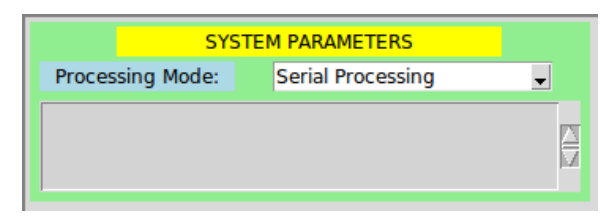

Fonte: elaborado pelo próprio autor

Figura 13: Módulo de Aquisição de Dados, do Ambiente de Desenvolvimento, no qual os arquivos que contém as amostras do fenômeno a serem analisadas são lidos e processados. A tela mostrada apresenta a versão que implementa o fenômeno de Agrupamento de Textos.

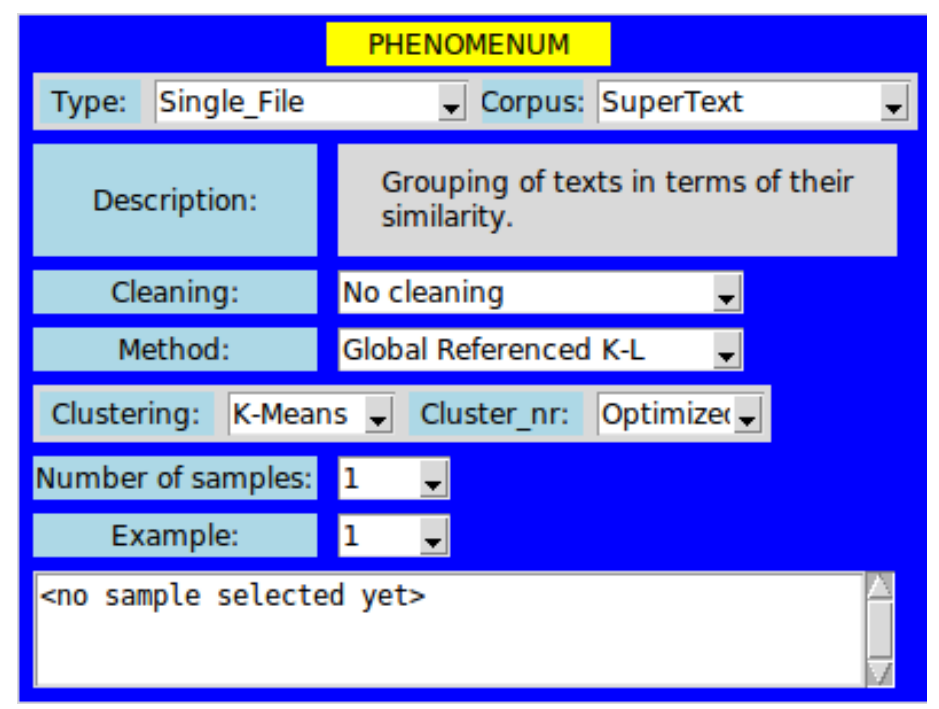

Fonte: elaborado pelo próprio autor

Figura 14: Quadro que mostra o resultado final da aquisição de dados na forma de uma tabela onde as linhas indicam cada amostra e as colunas os valores de cada variável característica (feature).

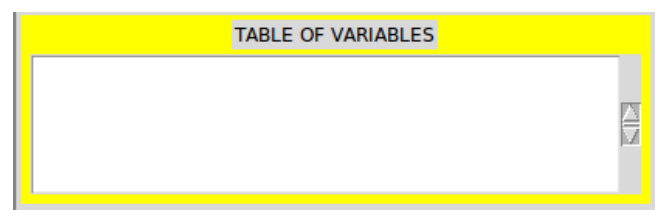

Fonte: elaborado pelo próprio autor 
Figura 15: Módulo gráfico de Aprendizagem do Modelo, que corresponde aos módulos de processamento de Elicitação de Restrições, Apreensão de Superestrutura, Segmentação do Espaço de Busca e Seleção das Redes. Nessa versão inicial, a interface gráfica prevê os algoritmos de busca exaustiva e de Naïve Bayesian Network, associados a um algoritmo libpgm discreto para aprendizagem dos parâmetros da rede.

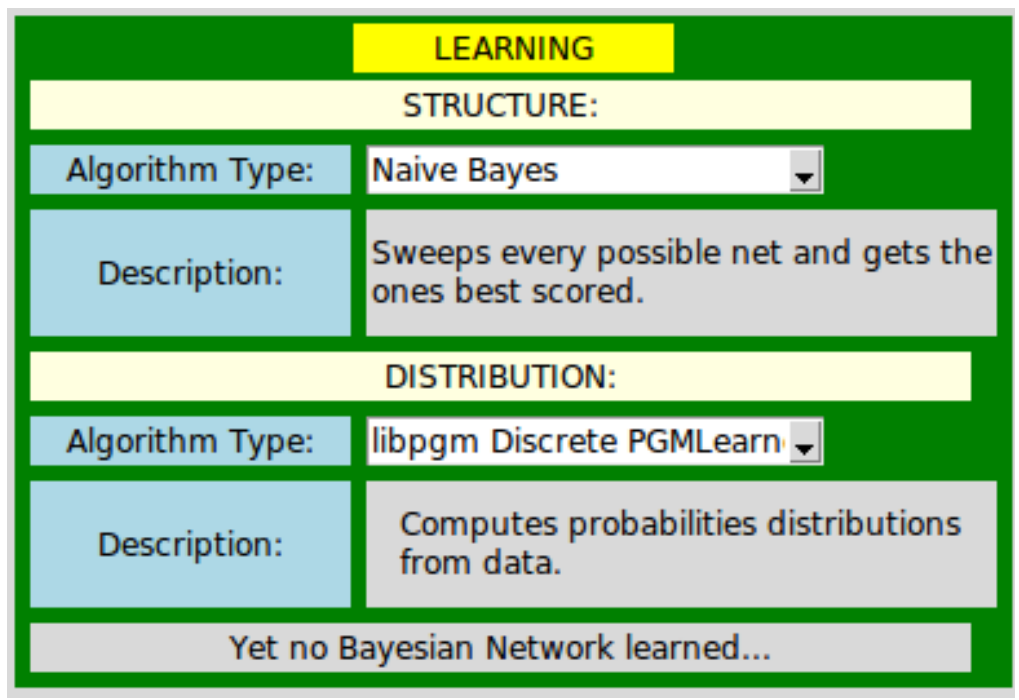

Fonte: elaborado pelo próprio autor

Figura 16: Quadro de apresentação das Redes Bayesianas selecionadas por meio do modelo de representação utilizado pelo pacote "pebl".

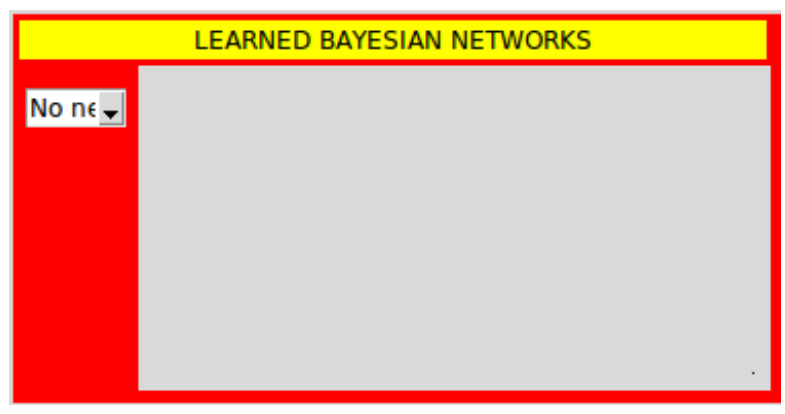

Fonte: elaborado pelo próprio autor

A operação do Ambiente de Desenvolvimento é bastante intuitiva a partir das próprias opções disponíveis na interface gráfica.

Do ponto de vista dos resultados, o Ambiente de Desenvolvimento produzido caracterizase como uma ferramenta de integração, sistematização e simplificação do trabalho de pesquisa na área de Reconhecimento de Padrões e Aprendizado de Máquina baseado em Redes Bayesianas, pois apresenta de forma visual como cada parte da aplicação dos conceitos se relaciona com as demais a fim de produzir um resultado final, partindo dos dados do fenômeno sob observação, passando pelo aprendizado e modelagem desse fenômeno pela 
máquina e culminando na predição das características de novas amostras. Portanto, é um resultado de caráter instrumental. Além disso, pode ser aplicado no ambiente de pesquisa sob o foco da Gestão do Conhecimento, pois permite registrar e difundir de forma simples parte do conhecimento obtido em pesquisas futuras.

\subsection{Processamento Paralelo e Busca Exaustiva}

Dos resultados da parte da pesquisa relacionada a Processamento Paralelo e Busca Exaustiva será aqui reproduzido somente um resumo conclusivo dos resultados consistente com sua relevância para o foco do presente trabalho.

O experimento utilizou inicialmente dados gerados artificialmente e, em seguida, foi estendido para um conjunto de dados mais próximo da realidade, correspondente ao banco de dados utilizado como exemplo pelo pacote pebl, relativos ao Cell Cycle data de (SPELLMAN et al., 1998), que contém 76 amostras de medições do gene do 6177 S. cerevisiae ORFs, com uma limitação do número de variáveis do exemplo a 4 e 5 para fins de adequação aos limites da busca exaustiva.

A mesma abordagem foi adotada para todos os conjuntos de dados de teste, tendo sido registrados os resultados dos processamentos paralelo e serial nos dois ambientes de processamento disponíveis, local no computador portátil e remota no cluster de computadores, proporcionando uma combinação de quatro alternativas de processamento: serial-local, paralelo-local, serial-cluster e paralelo-cluster. Os resultados obtidos estão resumidos na tabela a seguir:

Tabela 2: Comparação dos resultados obtidos com o processamento dos diversos conjuntos de dados de teste e respectivos valores de aceleração (speed up).

\begin{tabular}{llllllll}
\hline Tipos de Dados & $\begin{array}{l}\text { Número de Va- } \\
\text { riáveis }\end{array}$ & $\begin{array}{l}\text { Serial } \\
(\min )\end{array}$ & $\begin{array}{l}\text { Paralelo } \\
(\min )\end{array}$ & $\begin{array}{l}\text { Speed } \\
U p\end{array}$ & $\begin{array}{l}\text { Serial } \\
(\min )\end{array}$ & $\begin{array}{l}\text { Paralelo } \\
(\mathrm{min})\end{array}$ & $\begin{array}{l}\text { Speed } \\
U p\end{array}$ \\
\hline Acoplado & 2 & 0 & 0,014 & 0 & 0 & 0,052 & 0 \\
Múltiplo-100 & 2 & 0 & 0,013 & 0 & 0 & 0,066 & 0 \\
Múltiplo-1000 & 2 & 0 & 0,013 & 0 & 0 & 0,191 & 0 \\
Acoplado & 3 & 0,03 & 0,015 & 2 & 0,001 & 0,106 & 0,009 \\
Múltiplo-100 & 3 & 0,002 & 0,013 & 0,154 & 0,001 & 0,066 & 0,015 \\
Múltiplo-1000 & 3 & 0,002 & 0,015 & 0,133 & 0,001 & 0,206 & 0,004 \\
Acoplado & 4 & 0,771 & 0,251 & 3,0717 & 0,277 & 0,095 & 2,916 \\
Múltiplo-100 & 4 & 0,312 & 0,196 & 1,592 & 0,153 & 0,063 & 2,429 \\
Múltiplo-1000 & 4 & 0,393 & 0,203 & 1,936 & 0,155 & 0,192 & 0,807 \\
Múltiplo-100 & 5 & 384,109 & 204,716 & 1,876 & 221,385 & 4,072 & 54,368 \\
Múltiplo-1000 & 5 & 583,816 & 198,058 & 2,948 & 319,967 & - \\
Pebl-V1a4 & 4 & 0,378 & 0,192 & 1,969 & 0,117 & 0,061 & - \\
Pebl-V5a8 & 4 & 0,376 & 0,193 & 1,948 & 0,119 & 0,083 & 1,434 \\
Pebl-V9a12 & 4 & 0,378 & 0,192 & 1,969 & 0,118 & 0,07 \\
Pebl-V1a5 & 5 & 917,379 & 118,69 & 7,729 & 77,358 & 3,882 & 1,686 \\
Pebl-V6a10 & 5 & 262,23 & 149,186 & 1,758 & 102,524 & 3,987 & 25,715 \\
\hline
\end{tabular}

A partir dos resultados obtidos, observa-se que o processamento paralelo resultou em speed-up de até 54 vezes em relação ao processamento serial no mesmo ambiente. Considerando que são utilizados 56 núcleos de processamento, isso indica uma aproximação bastante forte do limite de aceleração. Isso foi possível porque a parcela do algoritmo que 
permaneceu serial representa um processamento de baixo custo, referente basicamente à rotina de segmentação do espaço, que é muito simples no caso do uso da busca exaustiva como mecanismo de seleção das melhores redes.

Outra observação é que o speed-up cai na medida em que a carga de processamento é menor e o tempo do processamento no modo serial é menor. Isso é esperado porque nessa situação o custo do processamento paralelo, que consiste em um valor aproximadamente constante para o algoritmo testado, passa a se mostrar relevante em relação à carga total de processamento. Esse custo consiste no tempo gasto na inicialização do ambiente paralelo (criação da visão com identificação de todos os núcleos e distribuição das informações) e nas comunicações entre os núcleos ao longo do processamento. No algoritmo de teste de busca exaustiva, esses fenômenos são bastante simples e esse custo se torna rapidamente irrelevante na medida em que a carga de processamento total aumenta. É esse mesmo efeito que derruba o speed-up dos testes de baixa carga de processamento, para os quais o tempo de processamento paralelo é maior do que o tempo de processamento serial.

Outra abordagem interessante acerca do processamento do algoritmo é a análise da distribuição do tempo de processamento pelas diversas rotinas. Essa análise pode ser feita por meio do uso do pacote "profile" da linguagem Python, que gera relatórios com o número de acessos e o tempo de processamento de cada rotina do algoritmo executado. Um extrato do relatório gerado para o caso Múltiplo-100 é apresentado na Figura 17 e o resumo dessas informações encontra-se organizado na Tabela 3 a seguir.

Figura 17: Extrato do perfil de processamento das rotinas para o conjunto de dados Múltiplo-100

Fonte: elaborado pelo próprio autor 
Tabela 3: Perfil de processamento do algoritmo processado em modo serial para o exemplo dos múltiplos com 4 variáveis (complementado com informações do processamento paralelo para as rotinas específicas do modo paralelo)

\begin{tabular}{|c|c|c|c|c|c|c|}
\hline Rotina & Subrotinas & & Chamadas & Tempo (s) & Tempo Acum (s) & $\%$ Tempo \\
\hline InitParallel & & & {$[1]^{* *}$} & {$[0,006]^{* *}$} & & 0 \\
\hline StartRecords & & & 1 & 1,605 & 1,605 & 0,062 \\
\hline SetEdgesWeight & & & 1 & 0 & 0 & 0 \\
\hline ReduceSpace & & & 1 & 0 & 0 & 0 \\
\hline SegSpace & & & 1 & 0 & 0 & 0 \\
\hline ElectParallel & & & {$[1]^{* *}$} & {$[0,000]^{* *}$} & & 0 \\
\hline \multirow[t]{6}{*}{ ElectNet } & & & 1 & 0,313 & 24,322 & 0,934 \\
\hline & EvolutePop & & 65536 & 0,632 & 24,008 & 0,922 \\
\hline & & CreateNet & 65536 & $1,673^{*}$ & 7,478 & 0,287 \\
\hline & & ValidadeInd & 65537 & $1,797^{*}$ & 14,149 & 0,543 \\
\hline & & ScorePop & 544 & $0,006^{*}$ & 0,356 & 0,014 \\
\hline & & SelectPop & 65537 & $0,939^{*}$ & 1,393 & 0,053 \\
\hline ShowRecords & & & 1 & 0 & 0 & 0 \\
\hline TOTAL & & & & & 26,053 & 1 \\
\hline
\end{tabular}

* Não inclui o tempo das subrotinas pebl

** Obtido do profile do processamento paralelo dos mesmos dados

Os resultados obtidos nessa etapa da pesquisa associada ao uso de Processamento Paralelo na aprendizagem de Redes Bayesianas confirmaram a expectativa de que é possível obter ganhos consideráveis na velocidade de processamento a partir da paralelização dos algoritmos de aprendizado.

Os testes realizados indicam que a aceleração apresenta uma tendência de se aproximar da razão entre o número de núcleos de processamento na medida em que o número de variáveis aumenta, o que significou ganhos da ordem de grandeza de até 54 vezes para o ambiente de processamento com 56 núcleos disponíveis para todo o processamento (parte serial, parte paralela e housekeeping).

Há que se considerar que esse nível de aceleração depende em alto grau dos algoritmos implementados. Os resultados obtidos o foram com o uso da busca exaustiva e suas características específicas, dentre elas a natural segmentação do espaço em subespaços e a distribuição do processamento desses subespaços resultantes. No entanto, há outros algoritmos em que essa segmentação não é natural, como no caso dos algoritmos genéticos, nos quais a população vai evoluindo de maneira heurística, o que não permite garantir que ela vá permanecer dentro de um subespaço previamente definido, dificultando o paralelismo nesse aspecto do algoritmo geral.

Em contrapartida, podem ainda ser exploradas outras linhas de abordagem do processamento paralelo, como é o caso do paralelismo no cálculo da pontuação das redes (cálculo paralelo da pontuação de diversas redes) ou do paralelismo interno ao cálculo da própria pontuação (cálculos paralelos para a pontuação de uma mesma rede). 


\subsection{Agrupamento de Textos}

A fase seguinte à elaboração do Ambiente de Desenvolvimento e da Busca Exaustiva, e que representa o foco principal da presente pesquisa, foi a de implementação da aplicação referente a Agrupamento de Textos.

Essa fase corresponde a uma implementação do módulo de Aquisição de Dados, do Ambiente de Desenvolvimento, que corresponde à sua aplicação ao fenômeno "Produção de Textos". Nessa abordagem, caso todos os módulos fossem implementados (o que ultrapassa o escopo da presente pesquisa), o Ambiente de Desenvolvimento completo seria aplicado com a finalidade de classificação de textos a partir de dados iniciais desse fenômeno que seriam os próprios textos. O processo completo seria, então, a extração de um grupo de características relevantes capazes de caracterizar cada amostra a partir do seu texto correspondente, o aprendizado do modelo Bayesiano (Rede Bayesiana) a partir de um grupo de amostras pré-classificadas e a predição da classificação de novas amostras a partir de suas características.

Considerando que para o fenômeno representado pelos textos é comum que esses textos não estejam pré-classificados, o foco do trabalho foi exatamente a pré-classificação das amostras, sob a forma de um seu agrupamento. Para tanto, foram utilizadas técnicas de Reconhecimento de Padrões, conforme descrito na seção que descreve a metodologia.

O trabalho foi desenvolvido em duas etapas. A primeira etapa foi a realização de testes iniciais de consistência com grupos de textos artificialmente produzidos e que possuem um agrupamento bem determinado previamente conhecido. Em seguida, foram processadas amostras oriundas de fenômenos reais.

A seguir serão apresentados resumos dos resultados obtidos para cada tipo de amostras estudado.

\section{Experimento 1 - Amostra de Teste de 3 Frases com Estrutura Simples}

O primeiro teste foi o já descrito na seção de Metodologia, com apenas 3 amostras contidas em um único arquivo "txt", cada linha representado uma amostra, de frases simples com a estrutura básica "A < fruta $>$ é uma fruta $<$ cor $>$ [claro]".

Dado que os resultados já foram apresentados em detalhes, basta fazer as considerações acerca dos resultados. O processamento dessas amostras detectou a similaridade entre as amostras 2 e 3 (ambas apresentavam a palavra "claro" a mais) e as agrupou corretamente.

O índice AMI encontrado foi de 1.000.

O processamento ocorreu em 2,29 segundos. 


\section{Experimento 2 - Amostra de Teste de 30 Frases com Estrutura Simples}

O segundo teste foi realizado com amostras contidas em um único arquivo "txt", cada linha representado uma amostra, num total de 30 linhas com exatamente a mesma estrutura: "A $<$ fruta $>$ é <qualidade $>$ ", conforme exemplificado a seguir.

"A maçã é vermelha.

A pera é verde.

A laranja é amarela.

A maçã é dura.

A pera é tenra.

A laranja é mole.

(...)

A maçã é única.

A pera é comum.

A laranja é trivial."

O agrupamento resultante foi o mostrado a seguir na Tabela 4.

Tabela 4: Experimento 2 - Valores das variáveis (Divergências K-L) para cada amostra em relação a cada grupo de radicais e clusterização proposta. Cada coluna "KLn" representa o valor da Divergência em relação ao grupo "n", onde n=0 é o vocabulário completo e n de 1 a 10 são os grupos associados a cada decil. A coluna "Cluster" mostra o índice do cluster obtido pelo algoritmo.

\begin{tabular}{|c|c|c|c|c|c|c|c|c|c|c|c|c|}
\hline Amostra & KL0 & KL1 & KL2 & KL3 & KL4 & KL5 & KL6 & KL7 & KL8 & KL9 & KL10 & Cluster \\
\hline S_0 & 1,12 & 3,40 & inf & inf & 1,10 & inf & inf & inf & inf & inf & 0,00 & 0 \\
\hline $\mathrm{S} \_2$ & 1,12 & 3,40 & $\inf$ & inf & 1,10 & $\inf$ & $\inf$ & $\inf$ & inf & $\inf$ & 0,00 & 0 \\
\hline S_ 4 & 1,12 & 3,40 & $\inf$ & inf & 1,10 & inf & $\inf$ & $\inf$ & inf & $\inf$ & 0,00 & 0 \\
\hline $\mathrm{S} \_5$ & 1,12 & 3,40 & $\inf$ & $\inf$ & 1,10 & inf & $\inf$ & $\inf$ & $\inf$ & $\inf$ & 0,00 & 0 \\
\hline S_ 6 & 1,12 & 3,40 & $\inf$ & $\inf$ & 1,10 & inf & $\inf$ & $\inf$ & $\inf$ & $\inf$ & 0,00 & 0 \\
\hline S_ 8 & 1,12 & 3,40 & $\inf$ & $\inf$ & 1,10 & $\inf$ & $\inf$ & $\inf$ & $\inf$ & $\inf$ & 0,00 & 0 \\
\hline S_9 & 1,12 & 3,40 & $\inf$ & inf & 1,10 & $\inf$ & $\inf$ & $\inf$ & $\inf$ & $\inf$ & 0,00 & 0 \\
\hline $\mathrm{S} \_10$ & 1,12 & 3,40 & $\inf$ & $\inf$ & 1,10 & $\inf$ & $\inf$ & $\inf$ & $\inf$ & $\inf$ & 0,00 & 0 \\
\hline S__11 & 1,12 & 3,40 & $\inf$ & $\inf$ & 1,10 & $\inf$ & $\inf$ & $\inf$ & $\inf$ & $\inf$ & 0,00 & 0 \\
\hline $\mathrm{S} \_12$ & 1,12 & 3,40 & $\inf$ & inf & 1,10 & inf & $\inf$ & $\inf$ & inf & inf & 0,00 & 0 \\
\hline $\mathrm{S} \_13$ & 1,12 & 3,40 & $\inf$ & inf & 1,10 & $\inf$ & $\inf$ & $\inf$ & $\inf$ & $\inf$ & 0,00 & 0 \\
\hline $\mathrm{S} \_18$ & 1,12 & 3,40 & $\inf$ & $\inf$ & 1,10 & $\inf$ & $\inf$ & $\inf$ & inf & $\inf$ & 0,00 & 0 \\
\hline S_- 19 & 1,12 & 3,40 & $\inf$ & inf & 1,10 & $\inf$ & $\inf$ & $\inf$ & inf & $\inf$ & 0,00 & 0 \\
\hline $\mathrm{S} \_20$ & 1,12 & 3,40 & $\inf$ & inf & 1,10 & $\inf$ & $\inf$ & $\inf$ & inf & $\inf$ & 0,00 & 0 \\
\hline $\mathrm{S} \_21$ & 1,12 & 3,40 & $\inf$ & $\inf$ & 1,10 & $\inf$ & $\inf$ & $\inf$ & $\inf$ & $\inf$ & 0,00 & 0 \\
\hline $\mathrm{S} \_22$ & 1,12 & 3,40 & $\inf$ & $\inf$ & 1,10 & $\inf$ & $\inf$ & $\inf$ & $\inf$ & $\inf$ & 0,00 & 0 \\
\hline $\mathrm{S} \_23$ & 1,12 & 3,40 & $\inf$ & inf & 1,10 & $\inf$ & $\inf$ & $\inf$ & inf & $\inf$ & 0,00 & 0 \\
\hline $\mathrm{S} \_24$ & 1,12 & 3,40 & $\inf$ & inf & 1,10 & $\inf$ & $\inf$ & inf & inf & inf & 0,00 & 0 \\
\hline $\mathrm{S} \_25$ & 1,12 & 3,40 & $\inf$ & $\inf$ & 1,10 & $\inf$ & $\inf$ & $\inf$ & $\inf$ & $\inf$ & 0,00 & 0 \\
\hline $\mathrm{S} \_26$ & 1,12 & 3,40 & $\inf$ & $\inf$ & 1,10 & $\inf$ & $\inf$ & $\inf$ & $\inf$ & $\inf$ & 0,00 & 0 \\
\hline $\mathrm{S} \_27$ & 1,12 & 3,40 & $\inf$ & $\inf$ & 1,10 & $\inf$ & $\inf$ & $\inf$ & $\inf$ & $\inf$ & 0,00 & 0 \\
\hline $\mathrm{S} \_28$ & 1,12 & 3,40 & $\inf$ & inf & 1,10 & $\inf$ & $\inf$ & $\inf$ & $\inf$ & $\inf$ & 0,00 & 0 \\
\hline
\end{tabular}


Figura 18: Experimento 2 - Gráfico do agrupamento definido pelo algoritmo, onde os eixos representam as 3 dimensões dos Componentes Principais (PCA). A esfera representa o cluster, cada ponto representa uma amostra e o número anotado na lateral é o número de pontos do cluster correspondente à esfera. Nesse experimento, todas as amostras coincidem em um único ponto.

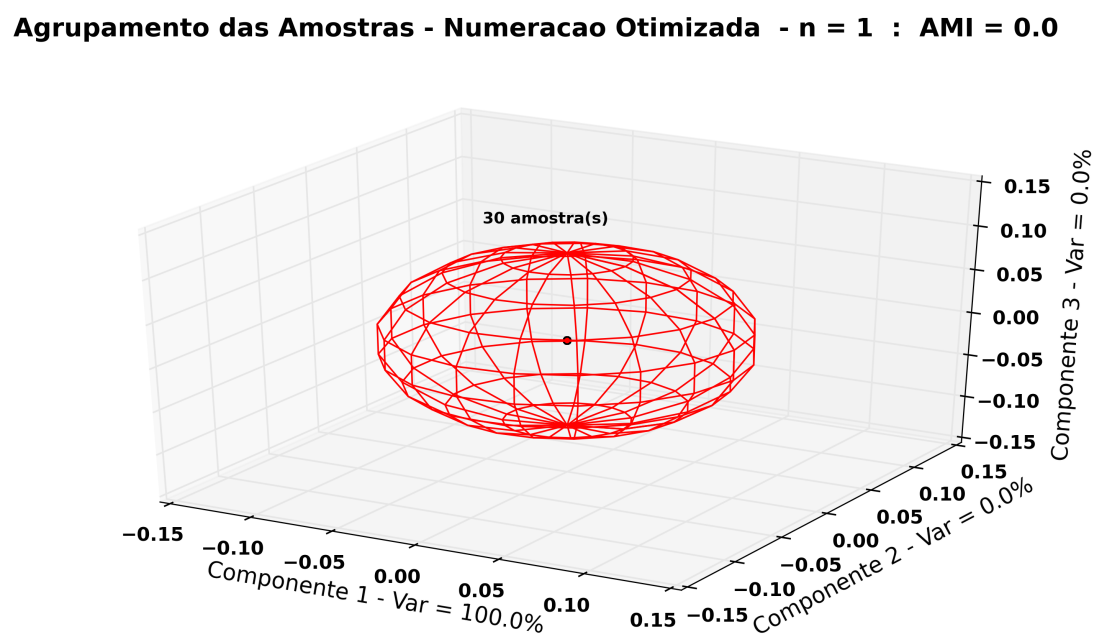

Fonte: elaborado pelo próprio autor

O resultado do processamento foi indicar que o melhor agrupamento seria em um único cluster, ao contrário da intuição inicial de que haveria um agrupamento temático nos grupos "maçã", "pera" e "laranja". Portanto, a estrutura das frases sobrepujou os seus temas.

Isso ocorre porque as distribuições das amostras de cada tema são idênticas a menos da palavra típica do tema ("maçã", "pera" e "laranja"). Como a Divergência K-L não é sensível à posição da frequência relativa no eixo horizontal (coordenada "x") em razão da comutatividade interna associada ao somatório, o fato dos valores serem iguais é suficiente para igualar as divergências dessas amostras.

O índice AMI na aproximação de 3 casas decimais foi de 0.000 (na verdade, 4,6 x 10-16), pois o agrupamento encontrado em apenas 1 cluster se mostra muito distante do agrupamento "real" predito, em 3 classes temáticas, porém isso é justificável por essa classificação ser totalmente baseada em um aspecto para o qual a técnica usada não é sensível, conforme descrito no parágrafo anterior.

O processamento ocorreu em 7,84 segundos.

\section{Experimento 3 - Amostras de Registros de Falhas Elétricas}

A título de experimento, o agrupamento de textos foi aplicado a um fenômeno real, a ocorrência de falhas em sistema elétrico, a partir de dados de registro dessas falhas na subestação elétrica de Congonhinhas obtidos da Copel Distribuição S/A. 
Essa aplicação do agrupamento e seus resultados foram apresentados no XII SBAI Simpósio Brasileiro de Automação Inteligente 2015, realizado em Natal - RN, de 25 a 28 de outubro de 2015.

Os registros consistem de textos simples, de uma linha, correspondentes a anotações dos técnicos de campo dos resultados do atendimento às falhas comunicadas. São ao todo 106 amostras, dispostas em um único arquivo texto, no formato a seguir:

SE Alimentador Descrição

Congonhinhas PADRE ANCHIETA 13,8kV Poste 150 10,5M abalroado após CF 4739 Congonhinhas PADRE ANCHIETA 13,8kV Nada encontrado (Atuou Neutro e SEF) As 14 h26 religado total.

(...)

Os registros foram agrupados com base em opinião de especialista, resultando em 20 classes de acordo com a causa principal da falha.

O vocabulário formado a partir dessas amostras contou com 329 vocábulos.

O resultado do agrupamento é descrito nas figuras e tabelas a seguir, extraídas do artigo apresentado no XII SBAI.

Figura 19: Experimento 3 - Exemplos de distribuições de frequências dos radicais - Supertexto versus todos os radicais das amostras

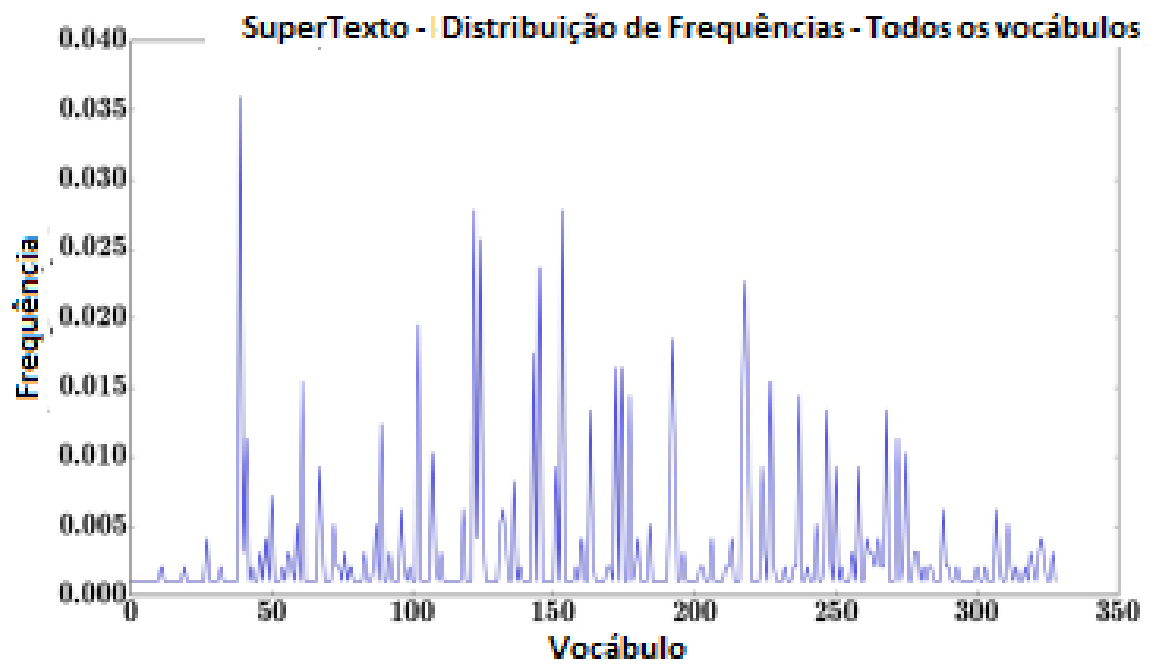

Fonte: elaborado pelo próprio autor 
Figura 20: Experimento 3 - Exemplos de distribuições de frequências dos radicais - Amostra 10 versus todos os radicais das amostras

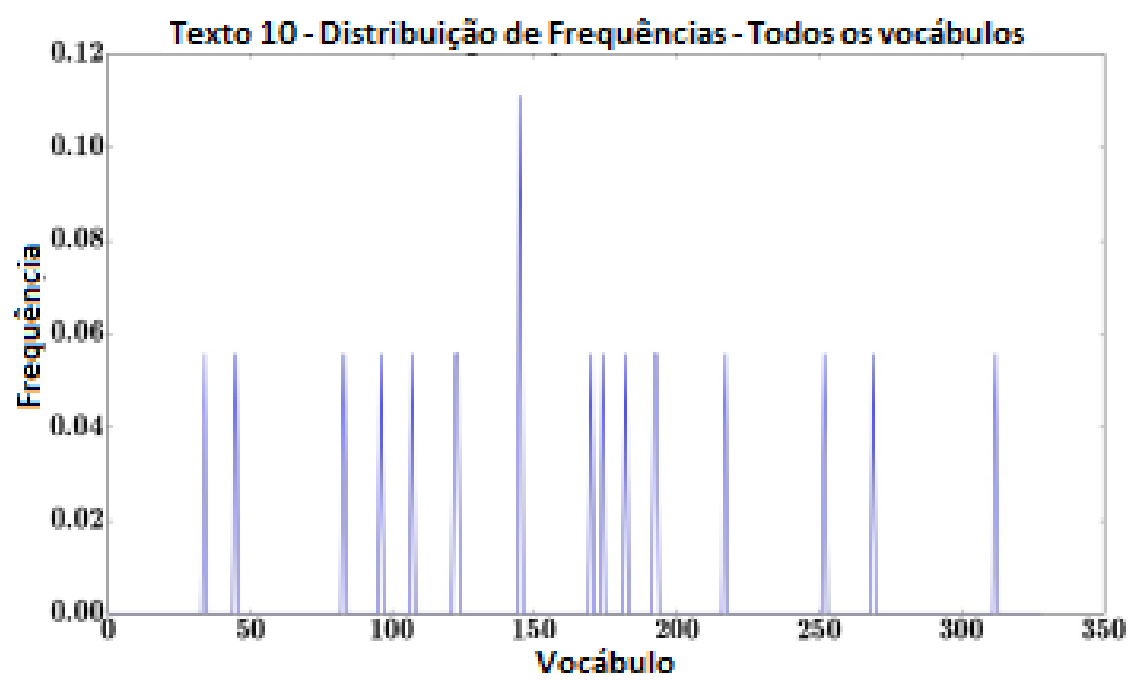

Fonte: elaborado pelo próprio autor

Figura 21: Experimento 3 - Exemplos de distribuições de frequências dos radicais - Supertexto versus radicais presentes em até $10 \%$ das amostra

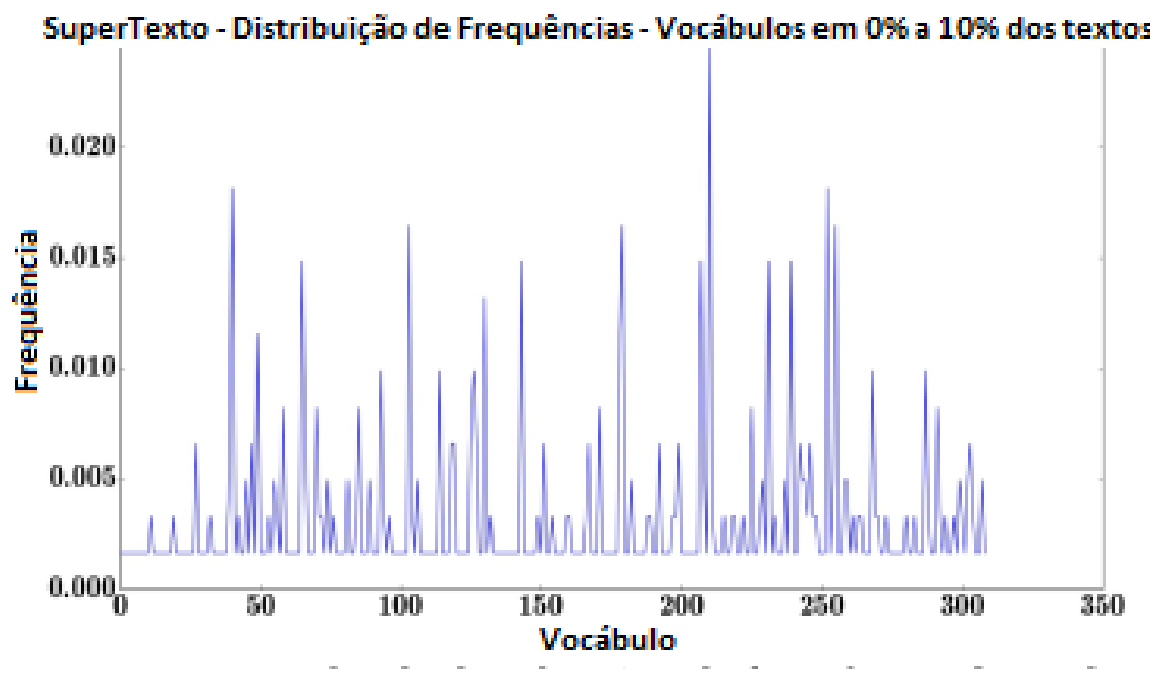

Fonte: elaborado pelo próprio autor 
Tabela 5: Experimento 3 - Variáveis K-L para as 10 primeiras amostras. "KLn" é a Divergência K-L da amostra em relação ao Supertexto, onde "n" de 1 a 3 indica o percentil não vazio e 0 o diretório com todos os radicais.

\begin{tabular}{lllll}
\hline Amostra & KL0 & KL1 & KL2 & KL3 \\
\hline S__1 & 3,99 & 4,18 & 2,69 & 0,02 \\
S_2 & 3,15 & 4,62 & 2,41 & 1,21 \\
S_3 & 2,46 & 4,13 & 1,94 & 1,28 \\
S_4 & 3,21 & 0,18 & 2,46 & 1,93 \\
S_5 & 2,06 & 2,93 & 1,13 & 0,98 \\
S_6 & 3,25 & 4,26 & 2,58 & 1,46 \\
S_7 & 2,38 & 3,30 & 1,42 & 0,72 \\
S_8 & 3,27 & 2,85 & 1,48 & 0,94 \\
S_9 & 3,20 & 4,58 & 3,14 & 0,02 \\
S_10 & 3,60 & 4,64 & 3,14 & 1,20
\end{tabular}

Figura 22: Experimento 3 - Distâncias intraclusters (em verde) e interclusters (em azul) em função do número de clusters. O equilíbrio entre essas distâncias ocorre próximo a $\mathrm{n}=5$.

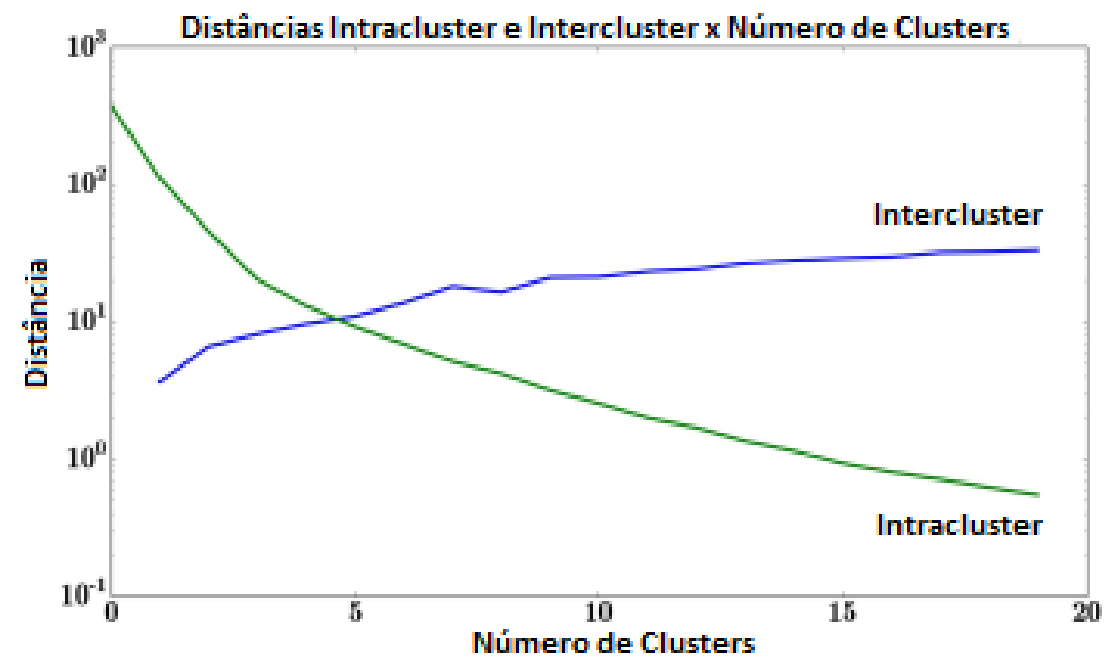

Fonte: elaborado pelo próprio autor 
Tabela 6: Experimento 3 - Acurácia do agrupamento proposto para $n=5$ em relação às classes indicadas pelo especialista.

\begin{tabular}{llll}
\hline Classe & Agrupadas & $\begin{array}{l}\text { \# Amos- } \\
\text { tras }\end{array}$ & Acurácia (\%) \\
\hline Animal & 2 & 2 & $100 \%$ \\
Balão & 1 & 1 & $100 \%$ \\
Condutor & 1 & 1 & $100 \%$ \\
Cruzeta & 1 & 1 & $100 \%$ \\
Retorno & 2 & 3 & $100 \%$ \\
Vazamento & 1 & 1 & $100 \%$ \\
Chave & 10 & 13 & $77 \%$ \\
Árvore & 8 & 12 & $67 \%$ \\
Para-raio & 2 & 3 & $67 \%$ \\
Desconhecido & 3 & 5 & $60 \%$ \\
Descarga & 3 & 5 & $60 \%$ \\
Não identificado & 4 & 7 & $57 \%$ \\
Vento & 4 & 7 & $57 \%$ \\
Diverso & 2 & 4 & $50 \%$ \\
Isolador & 4 & 8 & $50 \%$ \\
Poste & 3 & 6 & $50 \%$ \\
Bloqueio & 2 & 4 & $50 \%$ \\
Trafo & 1 & 2 & $50 \%$ \\
Nada & 8 & 18 & $44 \%$ \\
Cabo & 1 & 3 & $33 \%$ \\
\hline AGREGADO & 64 & 106 & $60 \%$ \\
& & &
\end{tabular}

Figura 23: Experimento 3 - Representação gráfica da clusterização nos três Componentes Principais (eixos da figura). Cada cluster é representado por uma esfera. O agrupamento se mostra bem definido.

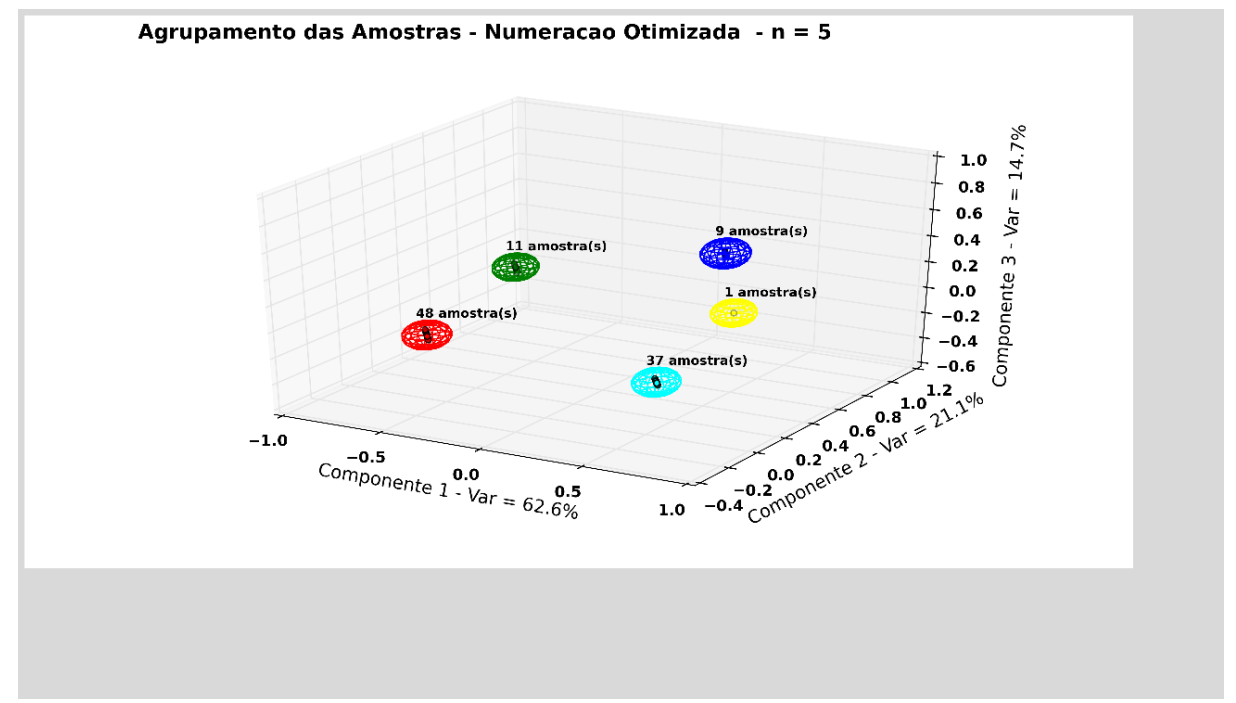

Fonte: elaborado pelo próprio autor 
O resultado de $60 \%$ de compatibilidade entre a classificação realizada pelo sistema e aquela previamente atribuída pelo especialista se mostra razoável, principalmente consideradas todas as limitações impostas à análise efetuada, na forma da extrema simplicidade dos textos utilizados e da opção pela generalidade.

Posteriormente à apresentação do artigo no XII SBAI, a análise foi estendida para incluir as técnicas de Razão de Validação e do índice AMI.

O mínimo da Razão de Validação ocorreu para $n=12$.

O índice AMI para $n=20$ resultou em 0,036, muito próximo do máximo de 0,038 que ocorreu para $n=13$. O índice AMI para $n=5$ na aproximação de 3 casas decimais foi de zero.

O processamento ocorreu em 42,42 segundos.

\section{Experimento 4 - Amostra de 20 Textos Aleatórios sobre Temas Arbitrários}

Outro teste realizado, mas já com textos reais, foi um teste com foco temático, no qual se escolheram alguns temas e se coletou na Internet textos aleatórios fornecidos por uma pesquisa aberta sobre cada tema.

Os temas ( 5 ao todo) e o número de textos coletados de cada um foram: Aerodinâmica (3 textos), Tributos (1 texto), Felicidade ( 5 textos), Girafa (4 textos), Inconstitucionalidade (7 textos), e a numeração das amostras seguiu essa mesma ordem.

O vocabulário formado a partir dessas amostras contou com 2.459 vocábulos.

O processamento ocorreu em 181,58 segundos (3 m 1,58 s).

O resultado do agrupamento foi o seguinte:

Figura 24: Experimento 4 - Distâncias Intraclusters e Interclusters em função do número de clusters. O equilíbrio entre essas distâncias ocorre próximo a $\mathrm{n}=5$.

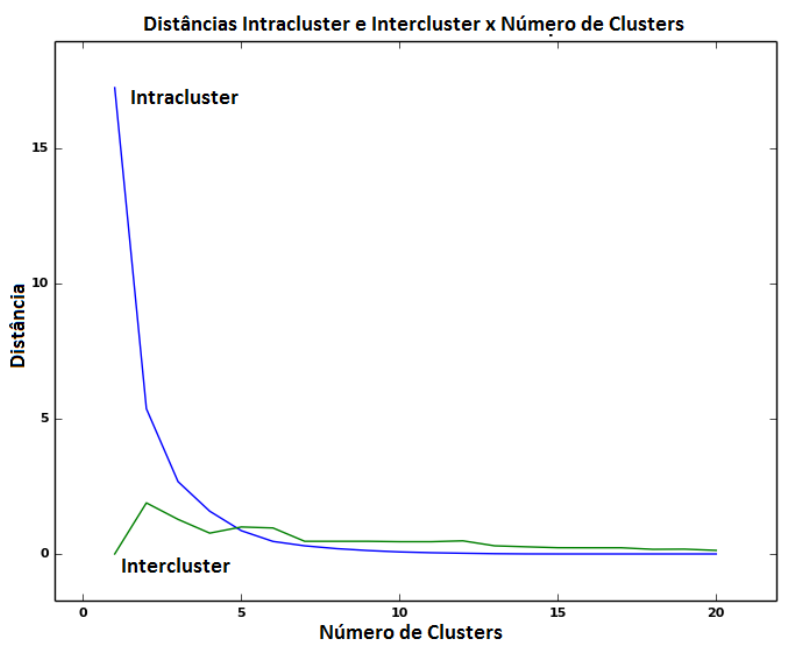

Fonte: elaborado pelo próprio autor 
Figura 25: Experimento 4 - Gráfico da Razão de Validação entre as Distâncias Intracluster e Intercluster. O mínimo compensado pelo custo da complexidade (fator $(n+1) / n$ ) ocorre $\mathrm{em} n=14$.

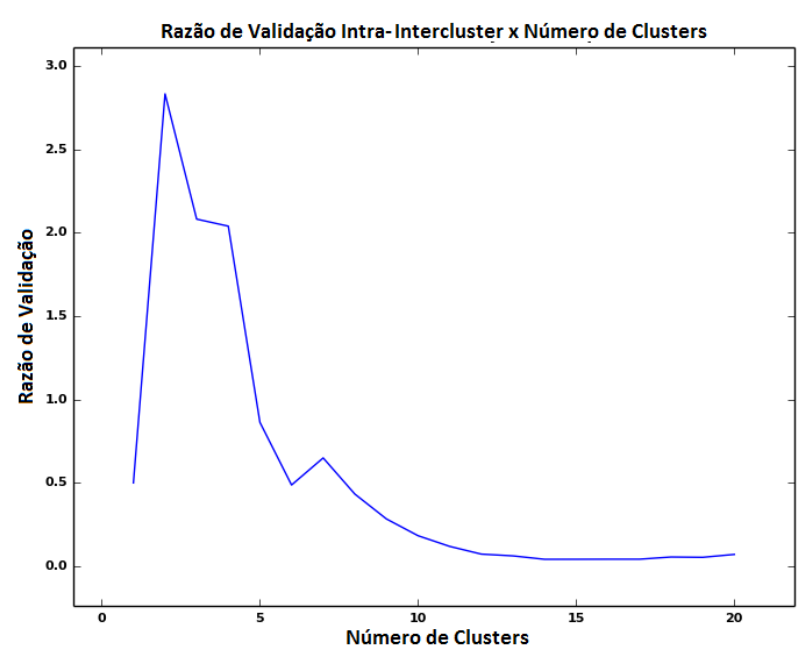

Fonte: elaborado pelo próprio autor

Tabela 7: Experimento 4 - Valores das variáveis (Divergências K-L) para cada amostra em relação a cada grupo de radicais e clusterização proposta para $n=5$ clusters. Cada coluna "KLn" representa o valor da divergência em relação ao grupo "n", onde n=0 é o vocabulário completo e n de 1 a 10 são os grupos associados a cada percentil. A coluna "Cluster" mostra o índice do cluster obtido pelo algoritmo.

\begin{tabular}{|c|c|c|c|c|c|c|c|c|c|c|c|c|}
\hline Amostra & KL0 & KL1 & KL2 & KL3 & $\overline{\mathrm{KL} 4}$ & KL5 & KL6 & KL7 & KL8 & KL9 & KL10 & Cluster \\
\hline S_0 & 1,62 & 3,23 & 2,08 & 2,55 & 1,00 & 0,61 & 0,72 & 0,22 & 0,00 & 0,18 & 0,03 & 1 \\
\hline S_1 1 & 1,51 & 3,35 & 1,98 & 2,06 & 1,25 & 0,64 & 0,17 & 0,00 & 0,00 & 0,01 & 0,03 & 1 \\
\hline $\mathrm{S} \_2$ & 1,61 & 3,53 & 1,95 & 2,35 & 1,42 & 0,96 & 0,38 & 0,10 & 0,00 & 0,10 & 0,07 & 1 \\
\hline $\mathrm{S} \_3$ & 1,15 & 0,82 & 1,32 & 1,46 & $\inf$ & inf & 2,21 & $\inf$ & inf & 1,22 & 0,30 & 2 \\
\hline $\mathrm{S} \_4$ & 1,50 & 2,99 & 2,01 & 1,70 & 1,41 & 0,41 & 0,38 & 0,05 & 0,00 & 0,09 & 0,07 & 1 \\
\hline S_ 5 & 1,25 & 2,47 & 1,73 & 1,52 & 0,97 & 0,40 & 0,20 & 0,41 & 0,00 & 0,01 & 0,09 & 1 \\
\hline S_6 & 2,15 & 4,17 & 3,30 & 1,91 & 2,25 & 1,60 & 0,39 & $\inf$ & 0,00 & 0,07 & 0,14 & 0 \\
\hline S_ 7 & 2,13 & 4,49 & 3,11 & 2,12 & 2,07 & 1,16 & 1,24 & 0,41 & 0,00 & 0,27 & 0,09 & 1 \\
\hline S_8 & 2,26 & 4,17 & 3,03 & 2,31 & 1,74 & 0,83 & 0,36 & 0,02 & 0,00 & 0,88 & 0,11 & 1 \\
\hline S__ & 1,74 & 3,51 & 2,33 & 2,86 & 1,55 & 0,69 & 0,40 & 0,05 & 0,00 & 0,05 & 0,14 & 1 \\
\hline S_10 & 2,03 & 4,63 & 2,66 & 2,96 & 1,71 & 0,79 & 0,51 & 0,00 & 0,00 & 0,04 & 0,15 & 1 \\
\hline S_11 & 2,39 & 4,75 & 2,86 & 3,89 & 3,46 & 1,07 & 1,31 & 1,08 & 0,00 & 1,24 & 0,17 & 4 \\
\hline $\mathrm{S} \_12$ & 2,35 & 4,96 & 3,19 & 3,57 & 3,05 & 1,01 & 1,91 & 1,08 & inf & 0,48 & 0,18 & 4 \\
\hline S_13 & 1,52 & 4,04 & 1,95 & 1,06 & 0,44 & 1,28 & 1,91 & inf & 0,00 & 0,71 & 0,04 & 0 \\
\hline $\mathrm{S} \_14$ & 1,37 & 3,43 & 1,79 & 0,88 & 0,40 & 1,04 & 0,49 & 0,02 & 0,00 & 0,13 & 0,05 & 1 \\
\hline $\mathrm{S} \_15$ & 2,84 & 5,25 & 5,14 & 2,19 & 1,89 & inf & 2,21 & $\inf$ & $\inf$ & 0,01 & 0,13 & 3 \\
\hline S__16 & 1,70 & 4,00 & 2,47 & 1,31 & 1,36 & 0,40 & 1,44 & 0,02 & inf & 0,05 & 0,03 & 4 \\
\hline S__17 & 1,42 & 3,72 & 2,02 & 1,13 & 0,33 & 1,06 & 0,63 & 0,41 & 0,00 & 0,05 & 0,04 & 1 \\
\hline S__18 & 0,57 & 1,38 & 0,83 & 0,45 & 0,11 & 0,11 & 0,04 & 0,00 & 0,00 & 0,02 & 0,01 & 1 \\
\hline S_19 & 1,39 & 3,81 & 2,19 & 0,99 & 0,44 & 1,72 & 0,64 & 1,08 & 0,00 & 0,21 & 0,11 & 1 \\
\hline
\end{tabular}


Tabela 8: Experimento 4 - Valores das variáveis (Divergências K-L) para cada amostra em relação a cada grupo de radicais e clusterização proposta para $n=14$ clusters. Cada coluna "KLn" representa o valor da divergência em relação ao grupo "n", onde n=0 é o vocabulário completo e $\mathrm{n}$ de 1 a 10 são os grupos associados a cada percentil. A coluna "Cluster" mostra o índice do cluster obtido pelo algoritmo.

\begin{tabular}{|c|c|c|c|c|c|c|c|c|c|c|c|c|}
\hline Amostra & KL0 & KL1 & KL2 & KL3 & KL4 & KL5 & KL6 & KL7 & KL8 & KL9 & KL10 & Cluster \\
\hline S_0 & 1.94 & 3.68 & 2.14 & 2.34 & 1.02 & 0.54 & 0.96 & 0.20 & 0.00 & 0.18 & 0.03 & 4 \\
\hline S_1 & 1.84 & 3.80 & 2.10 & 1.95 & 1.20 & 0.65 & 0.18 & 0.08 & 0.00 & 0.01 & 0.03 & 12 \\
\hline $\mathrm{S} \_2$ & 1.89 & 3.89 & 2.00 & 2.30 & 1.37 & 0.95 & 0.32 & 0.33 & 0.11 & 0.10 & 0.07 & 12 \\
\hline $\mathrm{S} \_4$ & 1.83 & 3.43 & 2.01 & 1.62 & 1.43 & 0.43 & 0.62 & 0.06 & 0.39 & 0.09 & 0.07 & 8 \\
\hline $\mathrm{S} \_5$ & 1.51 & 2.95 & 1.74 & 1.46 & 0.96 & 0.54 & 0.17 & 0.21 & 0.12 & 0.01 & 0.09 & 0 \\
\hline S_ 6 & 2.47 & 4.65 & 3.24 & 1.91 & 2.27 & 1.73 & 0.33 & 0.81 & 1.14 & 0.07 & 0.14 & 13 \\
\hline S_ 8 & 2.47 & 4.77 & 3.01 & 2.09 & 1.76 & 0.96 & 0.31 & 0.06 & 0.02 & 0.88 & 0.11 & 6 \\
\hline S_9 & 2.07 & 3.99 & 2.34 & 2.79 & 1.57 & 0.70 & 0.64 & 0.18 & 0.35 & 0.05 & 0.14 & 7 \\
\hline S_10 & 2.38 & 5.00 & 2.55 & 2.78 & 1.73 & 0.66 & 0.75 & 0.00 & 0.03 & 0.04 & 0.15 & 7 \\
\hline S__11 & 2.84 & 5.20 & 2.73 & 3.69 & 3.48 & 1.20 & 1.55 & 1.67 & 1.14 & 1.24 & 0.17 & 2 \\
\hline $\mathrm{S} \_12$ & 2.73 & 5.38 & 2.89 & 3.42 & 3.07 & 1.01 & 2.15 & 1.67 & 0.38 & 0.48 & 0.18 & 9 \\
\hline S_13 & 1.85 & 4.53 & 2.02 & 1.04 & 0.45 & 1.24 & 1.31 & $\inf$ & 1.14 & 0.71 & 0.04 & 5 \\
\hline S__ 18 & 0.82 & 1.80 & 0.83 & 0.46 & 0.12 & 0.13 & 0.06 & 0.10 & 0.01 & 0.02 & 0.01 & 10 \\
\hline S_19 & 1.79 & 4.07 & 2.19 & 1.05 & 0.46 & 1.48 & 0.50 & 1.67 & 0.25 & 0.21 & 0.11 & 8 \\
\hline
\end{tabular}

Figura 26: Experimento 4 - Gráfico do agrupamento definido pelo algoritmo para $\mathrm{n}=14$, onde os eixos são as 3 dimensões dos Componentes Principais (PCA). As esferas representam os clusters, cada ponto representa uma amostra e o número anotado na lateral é o número de pontos do cluster correspondente à esfera.

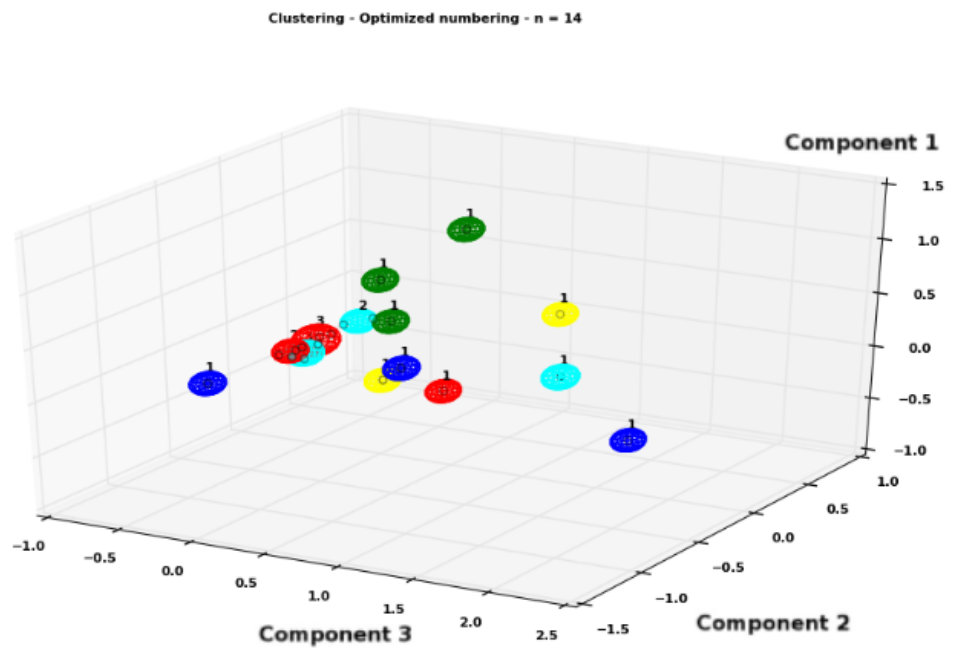

Fonte: elaborado pelo próprio autor

O índice AMI na aproximação de 3 casas decimais para $n=5$ e $n=14$ foi de 0,076 e 0,157. Primeiro, o número de clusters indicado pelo cruzamento das curvas de distância aponta exatamente para 5, que é de fato o número de categorias de textos original. Já o critério do fator de validação aponta para 14 clusters como o mínimo relevante. 
Tabela 9: Experimento 4 - Acurácia do agrupamento em relação às classes indicadas pelo especialista para os agrupamentos de $n=5$ e $n=14$. A acurácia é medida pelo percentual de pontos corretamente agrupados para cada classe.

\begin{tabular}{|c|c|c|c|c|c|}
\hline CLASSE & AMOSTRAS & $\begin{array}{l}\text { CLUSTERS } N=5 \\
{[0,1,2,3 \text { e } 4]}\end{array}$ & $\%$ & $\begin{array}{l}\text { CLUSTERS } \quad \mathrm{N}=14 \\
{[0,1,2, \ldots, 12 \text { e } 13]}\end{array}$ & $\%$ \\
\hline Aerodinâmica & $1,2,3$ & 0 (3 amostras) & $100 \%$ & 10 (3 amostras) & $100 \%$ \\
\hline Tributos & 4 & 2 & $100 \%$ & 2 & $100 \%$ \\
\hline Felicidade & $5,6,7,8,9$ & 1 (4 ams.), 0 & $80 \%$ & 0 (2 ams.), 4, 8, 13 & $40 \%$ \\
\hline Girafa & $\begin{array}{l}10,11,12, \\
13\end{array}$ & $\begin{array}{l}4 \text { (2 ams.), } 1 \text { (2 } \\
\text { ams.) }\end{array}$ & $50 \%$ & 7 (2 ams.) $, 3,9$ & $50 \%$ \\
\hline Constitucionalidade & $\begin{array}{lll}14, & 15, & 16 \\
17, & 18, & 19 \\
20 & & \end{array}$ & 1 (4 ams.), 0, 3, 4 & $57 \%$ & $\begin{array}{l}12 \text { (3 ams.), 1, 5, 6, } \\
11\end{array}$ & $43 \%$ \\
\hline
\end{tabular}

Da comparação dos resultados apresentada na Tabela 9, observa-se que o agrupamento em 5 clusters não coincide com as classes originais, mas coincide exatamente para a Classe 2 (Tributos) e mantém agregados em um único grupo os elementos da Classe 1 (Aerodinâmica). As classes 3 e 4 são dividas em dois grupos, com 80\% e 50\% dos elementos em um único grupo e a Classe 5 é dispersada em 4 grupos, mas com predominância de um grupo principal, com 57\% dos elementos nesse grupo. Em resumo, para todas as classes é possível identificar um grupo com pelo menos $50 \%$ dos elementos da classe.

Já o agrupamento com 14 clusters proporciona grupos distintos para cada classe, apenas com subdivisões eventuais dentro de cada classe. Assim, a Classe 1 corresponde ao grupo 10, a Classe 2 ao grupo 2, a Classe 3 aos grupos 0, 4, 8 e 13, a Classe 4 aos grupos 3, 7 e 9, e a Classe 5 aos grupos 1, 5, 6, 11 e 12. Em resumo, o agrupamento não violou o agrupamento natural, apenas identificou possíveis subclasses.

\section{Experimento 5 - Amostra de 99 Textos Jurídicos}

Para esse experimento foram extraídos 99 textos jurídicos referentes a decisões de um órgão julgador administrativo, o Conselho Administrativo de Recursos Fiscais - CARF. Esse experimento foi selecionado por estar ligado à área de trabalho atual do autor desta pesquisa que, como especialista, vislumbra uma interessante gama de aplicações para uma ferramenta associada ao objeto pesquisado e pela disponibilidade e pela publicidade do material, que pode ser coletado diretamente na Internet por qualquer pessoa. Apenas a título de exemplo, o agrupamento de textos jurídicos pode agilizar os julgamentos de processos por meio do encaminhamento de lotes de processos similares a uma mesma turma de julgamento ou a um mesmo julgador. Os processos foram selecionados de forma aleatória dentre todos os disponíveis no acervo.

Inicialmente, os textos foram submetidos a um especialista que os classificou de acordo com 14 temas, referentes ao tributo tratado ou à categoria da questão tributária discutida: COMP (compensação), CPMF (tributo Contribuição Provisória sobre a Movimentação Financeira), II (tributo Imposto de Importação), IOF (tributo Imposto sobre Operações 
Financeiras), IPI (tributo Imposto sobre Produtos Industrializados), IRPF (tributo Imposto de Renda da Pessoa Física), IRPJ (tributo Imposto de Renda da Pessoa Jurídica), ITR (tributo Imposto Territorial Rural), PAF (Processo Administrativo Fiscal), PIS (tributo Contribuição para PIS/COFINS), PREV (tributo Contribuições Previdenciárias), REST (pedido de Restituição), SIMPLES (regime tributário simplificado Simples Nacional), TRIB (questões tributárias gerais). Cabe ressaltar que essa classificação em relação ao tema tem diversas limitações, pois os temas não são necessariamente disjuntos e normalmente se superpõem. Por exemplo, um processo de Compensação pode ter questões de PAF e tratar de créditos de PIS. Assim, essa classificação por especialista fundamenta-se no aspecto principal de cada processo, mas não significa que haja uma exclusividade de características daquela classe, apenas predominância. A classificação das 99 amostras é apresentada na Tabela 10.

O vocabulário formado a partir dessas amostras contou com 3.587 vocábulos.

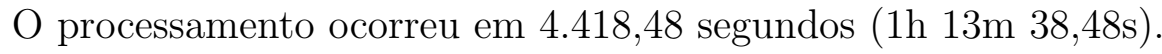

O resultado da classificação pelo especialista foi o descrito na Tabela 10 a seguir. Na sequência são apresentadas telas que resultaram do processamento dos textos.

Tabela 10: Experimento 5 - Classificação prévia das amostras em função do tema principal.

\begin{tabular}{lll} 
Classe & \# Amostras & Amostras \\
\hline COMP & 13 & $2,5,6,22,35,57,71,80,81,89,90,95,99$ \\
CPMF & 1 & 49 \\
II & 1 & 60 \\
IOF & 1 & 40 \\
IPI & 4 & $11,12,19,96$ \\
IRPF & 10 & $1,8,14,54,58,68,74,82,85,91$ \\
IRPJ & 8 & $23,38,56,67,69,87,92,98$ \\
ITR & 1 & 97 \\
PAF & 28 & $4,7,18,20,21,24,25,26,27,28,29,30,37,39,41,44,45$, \\
& & $48,51,52,61,64,66,72,75,76,77,78$ \\
PIS & 7 & $9,33,47,50,62,63,70$ \\
PREV & 16 & $10,13,16,31,32,42,43,46,55,65,73,83,84,86,88,94$ \\
REST & 5 & $15,17,36,79,93$ \\
SIMPLES & 2 & 34,53 \\
TRIB & 2 & 3,59
\end{tabular}


Figura 27: Experimento 5 - Janela do Monitor de Texto após processamento do Experimento 5.

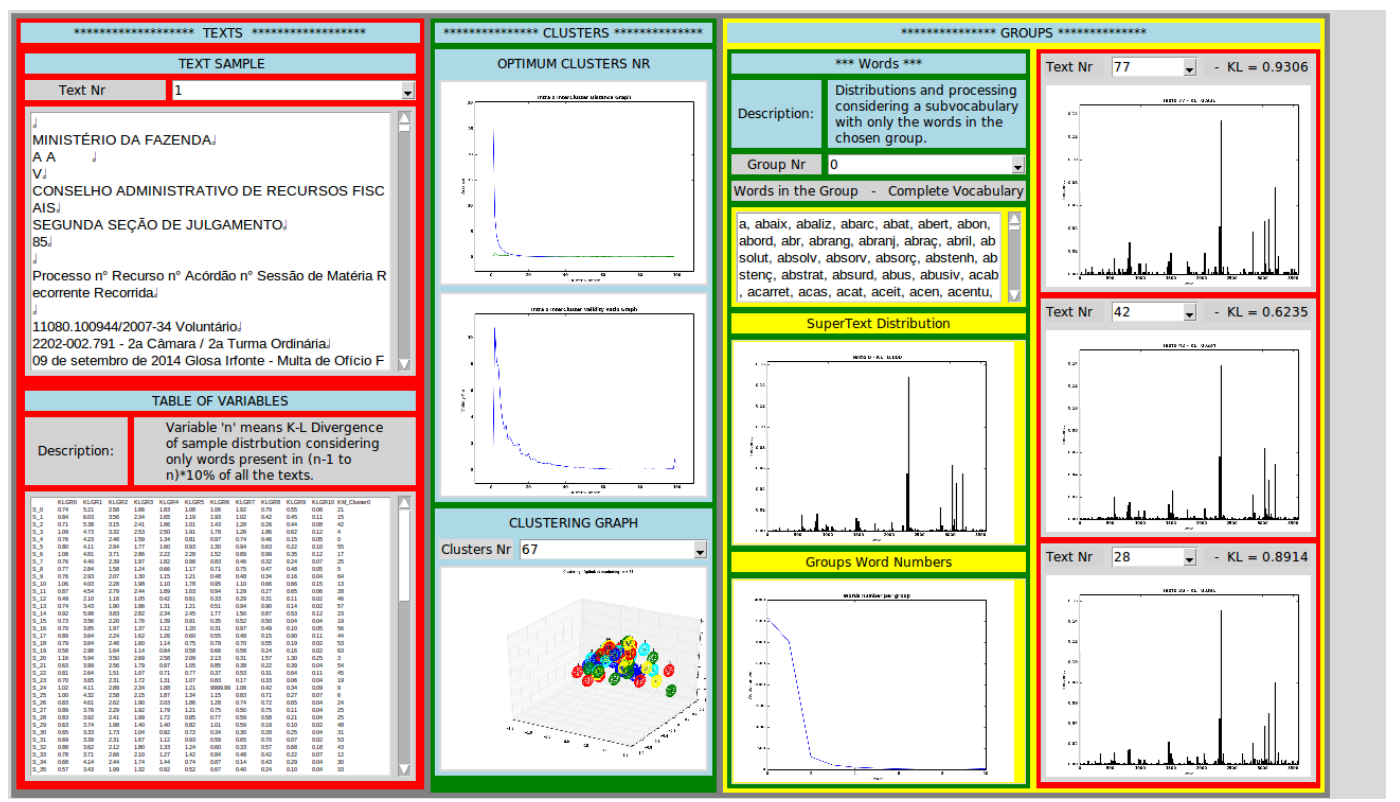

Fonte: elaborado pelo próprio autor

Figura 28: Experimento 5 - Exemplos de amostras do Experimento 5 obtidas do Ambiente de Desenvolvimento.

\begin{tabular}{|c|c|c|}
\hline TEXT SAMPLE & TEXT SAMPLE & TEXT SAMPLE \\
\hline Text Nr & Text Nr & Text Nr \\
\hline 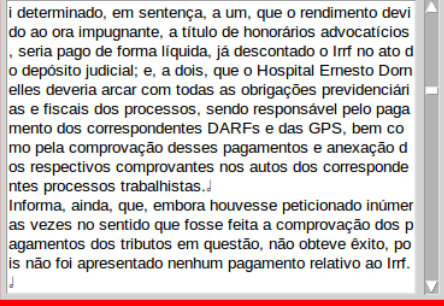 & $\begin{array}{l}\text { COMPENSAÇĀO. DO DESPACHO } \\
\text { Em face da homologaçāo tácita da compensaçāo, reputa- } \\
\text { se insubsistente o despacho decisorio proferido após o pr } \\
\text { azo de cinco anos, contado da data da entrega da declara } \\
\text { çāo compensaçâ.d } \\
\text { Recurso Voluntário Provido.d } \\
\text { Vistos, relatados e discutidos os presentes autos.d } \\
\text { ACORDAM os membros da 2a Turma Especial da Tercei } \\
\text { ra Seçāo de Julgamento, por unanimidade, dar proviment } \\
\text { o ao recurso, nos termos do voto do Relator.d } \\
\text { (assinado digitalmente)! }\end{array}$ & 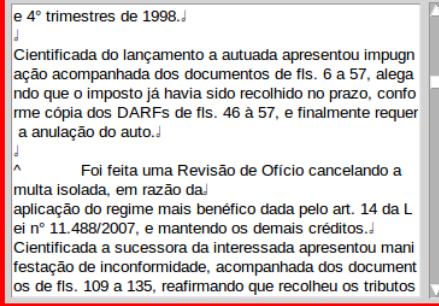 \\
\hline TEXT SAMPLE & TEXT SAMPLE & TEXT SAMPLE \\
\hline Text Nr & Text Nr & Text Nr \\
\hline 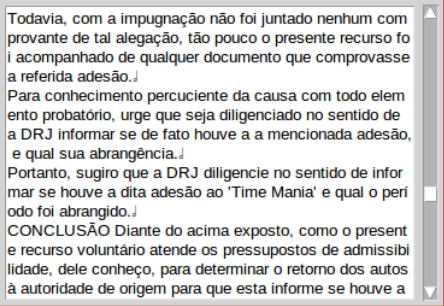 & 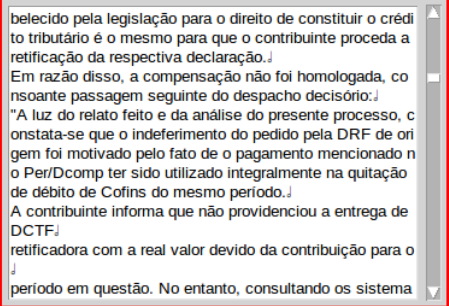 & 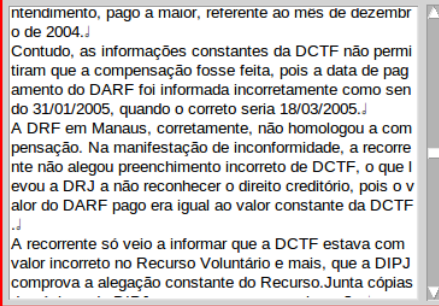 \\
\hline
\end{tabular}

Fonte: elaborado pelo próprio autor

Os "Subvocabulários" obtidos no tratamento dos textos jurídicos foi o que se segue: "Subvocabulario" 0 - Vocabulário completo (3.587 vocábulos): a, abaix, abaliz, abarc, abat, abert, abon, abord, abr, abrang, ..., víci, víde, víncul, xi, zel, zer, zon, à, 
àquel, às, ági, águ, áre, âmbit, ângel, ângul, ão, é, époc, ênfas, êxit, indic, integr, intim, iril, óbv, óbvi, ócul, órg, ótic, ônu, últ, únic, útil

"Subvocabulario" 1 - Vocábulos presentes em até 10\% das amostras (3.017 vocábulos): abaliz, abarc, abat, abert, abon, abord, abr, abrang, ?, víci, víde, víncul, zer, à, àquel, às, ági, áre, âmbit, ângel, ão, é, ênfas, êxit, indic, integr, intim, íril, óbv, óbvi, ócul, órg, ônu, últ, únic, útil

"Subvocabulario" 2 - Vocábulos presentes em 10\% a 20\% das amostras (302 vocábulos): afinal, aflor, afront, agênc, ..., vinhed, vir, vis, vié, vodc, volunt, voluntári, vê, zon, águ

"Subvocabulario" 3 - Vocábulos presentes em $20 \%$ a $30 \%$ das amostras (108 vocábulos): afast, ambient, anul, arquidioces, ..., transpost, traum, veicul, vist, volum, vár, xi, zel, ângul, ótic

"Subvocabulario" 4 - Vocábulos presentes em $30 \%$ a $40 \%$ das amostras (57 vocábulos): acess, anunci, baix, ..., quantific, quinzen, quit, repar, ser, sessent, sistem, suc, unic, unânim, vinh

"Subvocabulario" 5 - Vocábulos presentes em 40\% a 50\% das amostras (34 vocábulos): abaix, agost, alinh, açúc, ..., seqüestr, sigl, sol, vint

"Subvocabulario" 6 - Vocábulos presentes em 50\% a 60\% das amostras (19 vocábulos): antevej, coloc, comprov, consult, ..., querel, ra, repercut, rubr, suport, trag, transit, vislumbr

"Subvocabulario" 7 - Vocábulos presentes em $60 \%$ a $70 \%$ das amostras (9 vocábulos): compensatóri, confus, corre, liter, nul, peremptóri, sucessiv, verdad, époc

"Subvocabulario" 8 - Vocábulos presentes em $70 \%$ a $80 \%$ das amostras (9 vocábulos): automatic, constru, desequilibr, dinh, discut, no, oit, pól, reda

"Subvocabulario" 9 - Vocábulos presentes em $80 \%$ a $90 \%$ das amostras (10 vocábulos): alimentíci, criv, descrit, equívoc, extravi, inexat, mud, nu, oci, rua

"Subvocabulario" 10 - Vocábulos presentes em 90\% a 100\% das amostras (22 vocábulos): a, anual, coment, comerci, correspond, ..., receit, rememor, rio, salári, seiscent, subestim

Seguem os gráficos, tabelas e figuras resultantes do processamento segundo esses "Subvocabulários". 
Figura 29: Experimento 5 - Gráfico do número de radicais em cada "Subvocabulário".

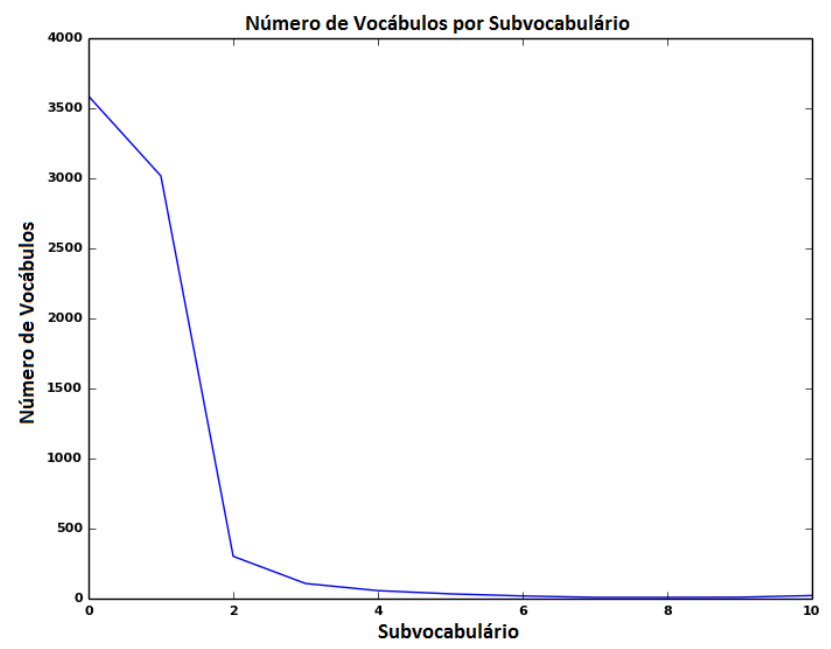

Fonte: elaborado pelo próprio autor

Figura 30: Experimento 5 - Exemplos de distribuições de frequências dos radicais - Supertexto versus todos os radicais das amostras.

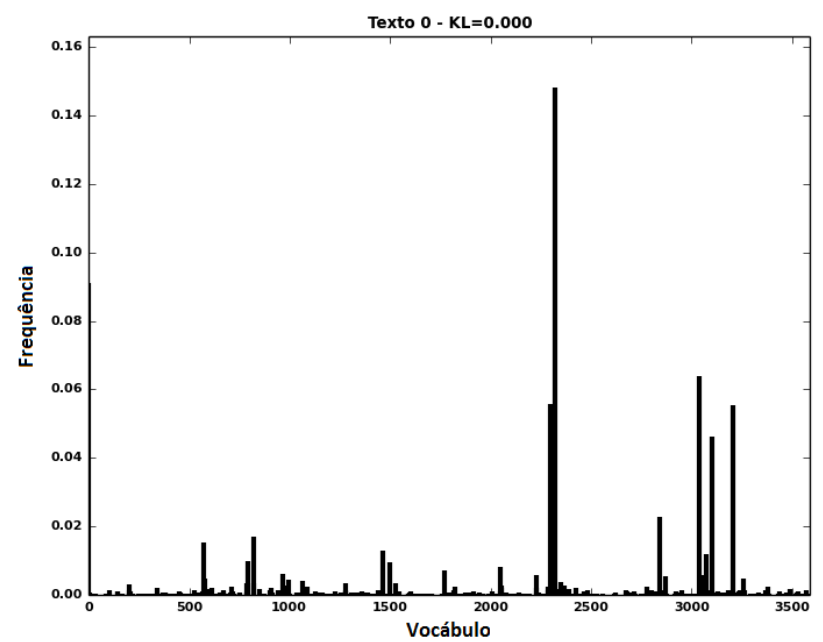

Fonte: elaborado pelo próprio autor 
Figura 31: Experimento 5 - Exemplos de distribuições de frequências dos radicais - Amostra 1 versus todos os radicais das amostras.

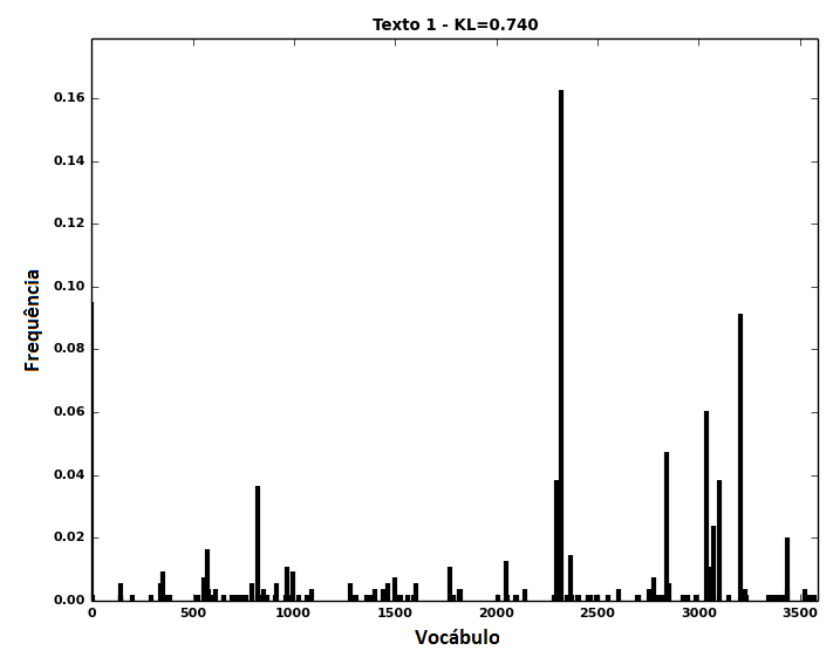

Fonte: elaborado pelo próprio autor

Figura 32: Experimento 5 - Exemplos de distribuições de frequências dos radicais - Supertexto versus todos os radicais do "Subvocabulário" 1

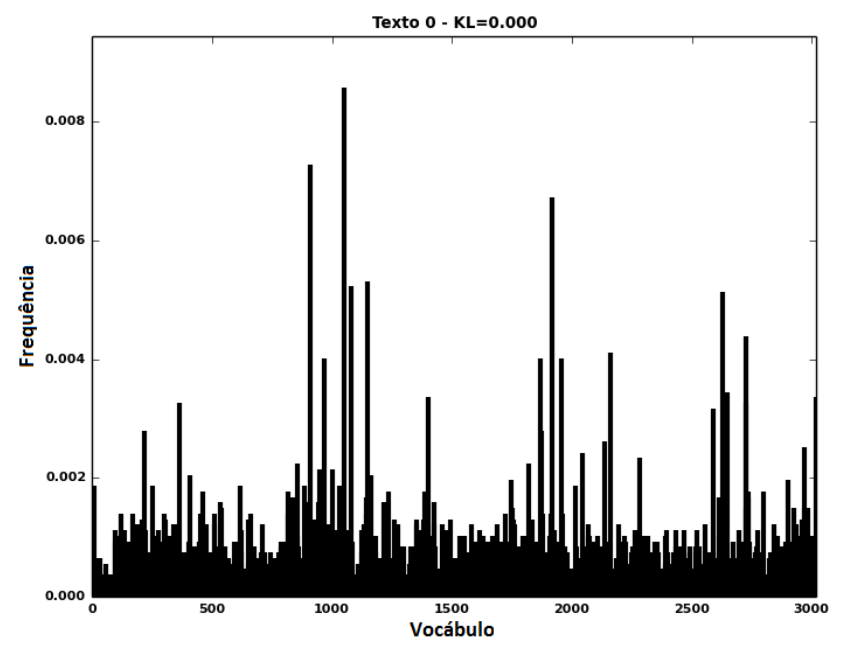

Fonte: elaborado pelo próprio autor 
Figura 33: Experimento 5 - Exemplos de distribuições de frequências dos radicais - Amostra 1 versus todos os radicais do "Subvocabulário" 1

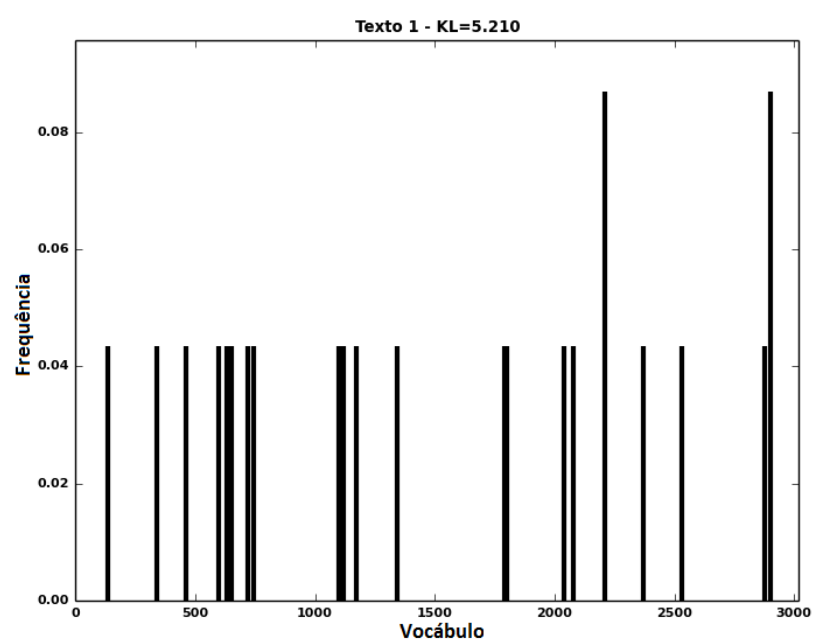

Fonte: elaborado pelo próprio autor 
Tabela 11: Experimento 5 - Valores das variáveis (Divergências K-L) para cada amostra em relação a cada "Subvocabulário" e clusterização proposta para n=14 clusters. Cada coluna "KLn" representa o valor da divergência em relação ao grupo "n", onde n=0 é o vocabulário completo e $\mathrm{n}$ de 1 a 10 são os grupos associados a cada percentil. A coluna "Cluster" mostra o índice do cluster obtido pelo algoritmo.

\begin{tabular}{|c|c|c|c|c|c|c|c|c|c|c|c|c|}
\hline Amostra & KL0 & KL1 & KL2 & KL3 & KL4 & KL5 & KL6 & KL7 & KL8 & KL9 & KL10 & Cluster \\
\hline S_0 & 0,74 & 5,21 & 2,58 & 1,86 & 1,83 & 1,08 & 1,06 & 1,92 & 0,79 & 0,55 & 0,06 & 11 \\
\hline S_1 & 0,84 & 6,03 & 3,56 & 2,34 & 1,65 & 1,19 & 1,93 & 1,02 & 0,42 & 0,45 & 0,11 & 5 \\
\hline $\mathrm{S} \_2$ & 0,71 & 5,38 & 3,15 & 2,41 & 1,86 & 1,01 & 1,43 & 1,28 & 0,26 & 0,44 & 0,08 & 5 \\
\hline $\mathrm{S} \_4$ & 0,76 & 4,23 & 2,46 & 1,59 & 1,34 & 0,81 & 0,97 & 0,74 & 0,46 & 0,15 & 0,05 & 10 \\
\hline $\mathrm{S} \_5$ & 0,80 & 4,11 & 2,94 & 1,77 & 1,60 & 0,93 & 1,30 & 0,94 & 0,63 & 0,22 & 0,10 & 0 \\
\hline S_ 6 & 1,08 & 4,81 & 3,71 & 2,86 & 2,22 & 2,28 & 1,52 & 0,89 & 0,99 & 0,35 & 0,12 & 12 \\
\hline S_ 8 & 0,77 & 2,84 & 1,58 & 1,24 & 0,66 & 1,17 & 0,71 & 0,75 & 0,47 & 0,48 & 0,05 & 13 \\
\hline S_9 & 0,76 & 2,93 & 2,07 & 1,30 & 1,15 & 1,21 & 0,48 & 0,48 & 0,34 & 0,16 & 0,04 & 13 \\
\hline S_10 & 1,06 & 4,03 & 2,28 & 1,98 & 1,10 & 1,78 & 0,95 & 1,10 & 0,66 & 0,66 & 0,15 & 4 \\
\hline S__11 & 0,87 & 4,54 & 2,79 & 2,44 & 1,89 & 1,03 & 0,94 & 1,29 & 0,27 & 0,65 & 0,06 & 5 \\
\hline $\mathrm{S} \_12$ & 0,49 & 2,10 & 1,16 & 1,05 & 0,42 & 0,61 & 0,33 & 0,29 & 0,31 & 0,11 & 0,02 & 7 \\
\hline S_13 & 0,74 & 3,43 & 1,90 & 1,96 & 1,31 & 1,21 & 0,51 & 0,94 & 0,90 & 0,14 & 0,02 & 10 \\
\hline S__ 18 & 0,79 & 3,64 & 2,46 & 1,60 & 1,14 & 0,75 & 0,79 & 0,70 & 0,55 & 0,19 & 0,02 & 10 \\
\hline S__ 19 & 0,58 & 2,96 & 1,64 & 1,14 & 0,64 & 0,58 & 0,66 & 0,58 & 0,24 & 0,16 & 0,02 & 3 \\
\hline S_20 & 1,16 & 5,94 & 3,50 & 2,69 & 2,58 & 2,09 & 2,13 & 0,31 & 1,57 & 1,30 & 0,25 & 9 \\
\hline $\mathrm{S} \_21$ & 0,63 & 3,99 & 2,56 & 1,79 & 0,97 & 1,05 & 0,85 & 0,38 & 0,22 & 0,39 & 0,04 & 10 \\
\hline $\mathrm{S} \_22$ & 0,81 & 2,64 & 1,51 & 1,07 & 0,71 & 0,77 & 0,37 & 0,53 & 0,31 & 0,64 & 0,11 & 6 \\
\hline $\mathrm{S} \_23$ & 0,70 & 3,65 & 2,31 & 1,72 & 1,31 & 1,07 & 0,83 & 0,17 & 0,33 & 0,06 & 0,04 & 10 \\
\hline $\mathrm{S} \_24$ & 1,02 & 4,11 & 2,89 & 2,34 & 1,88 & 1,21 & inf & 1,06 & 0,42 & 0,34 & 0,09 & 8 \\
\hline $\mathrm{S} \_25$ & 1,00 & 4,32 & 2,58 & 2,15 & 1,87 & 1,34 & 1,15 & 0,83 & 0,71 & 0,27 & 0,07 & 0 \\
\hline $\mathrm{S} \_26$ & 0,83 & 4,61 & 2,62 & 1,90 & 2,03 & 1,86 & 1,28 & 0,74 & 0,72 & 0,65 & 0,04 & 5 \\
\hline $\mathrm{S} \_27$ & 0,89 & 3,76 & 2,29 & 1,92 & 1,79 & 1,21 & 0,75 & 0,50 & 0,75 & 0,11 & 0,04 & 0 \\
\hline $\mathrm{S} \_28$ & 0,83 & 3,92 & 2,41 & 1,99 & 1,72 & 0,85 & 0,77 & 0,59 & 0,58 & 0,21 & 0,04 & 0 \\
\hline $\mathrm{S} \_36$ & 1,07 & 4,83 & 3,85 & 3,76 & 2,57 & 2,37 & 3,60 & 2,29 & 1,62 & 0,58 & 0,12 & 1 \\
\hline $\mathrm{S} \_37$ & 0,71 & 3,46 & 2,47 & 1,46 & 1,23 & 1,27 & 0,77 & 0,75 & 0,46 & 0,25 & 0,02 & 10 \\
\hline $\mathrm{S} \_38$ & 0,79 & 4,65 & 2,55 & 2,36 & 1,58 & 2,05 & 1,12 & 1,84 & 0,93 & 0,44 & 0,05 & 11 \\
\hline $\mathrm{S} \_39$ & 0,66 & 3,45 & 2,08 & 1,46 & 1,07 & 1,07 & 0,77 & 0,57 & 0,69 & 0,23 & 0,05 & 10 \\
\hline $\mathrm{S} \_40$ & 0,90 & 4,43 & 2,36 & 2,93 & 1,52 & 1,58 & 1,20 & 0,57 & 0,44 & 0,08 & 0,05 & 0 \\
\hline $\mathrm{S} \_41$ & 0,62 & 3,54 & 1,79 & 1,36 & 0,83 & 1,16 & 0,25 & 0,43 & 0,14 & 0,14 & 0,01 & 3 \\
\hline $\mathrm{S} \_42$ & 0,61 & 3,41 & 1,70 & 0,98 & 0,74 & 0,66 & 0,32 & 0,53 & 0,48 & 0,42 & 0,10 & 6 \\
\hline $\mathrm{S} \_43$ & 0,75 & 4,69 & 3,27 & 2,07 & 1,42 & 1,97 & 0,90 & 0,65 & 0,67 & 0,35 & 0,05 & 5 \\
\hline $\mathrm{S} \_44$ & 0,70 & 4,02 & 2,20 & 1,50 & 1,46 & 1,08 & 0,77 & 0,48 & 0,19 & 0,19 & 0,04 & 10 \\
\hline $\mathrm{S} \_45$ & 0,92 & 3,51 & 2,53 & 1,66 & 1,11 & 1,87 & 1,00 & 0,43 & 0,91 & 0,16 & 0,05 & 10 \\
\hline $\mathrm{S} \_46$ & 0,70 & 3,13 & 1,88 & 1,48 & 1,04 & 0,63 & 0,70 & 0,27 & 0,35 & 0,13 & 0,07 & 3 \\
\hline $\mathrm{S} \_47$ & 0,87 & 4,34 & 3,14 & 1,51 & 1,78 & 0,97 & 1,49 & 1,77 & 0,44 & 0,48 & 0,03 & 11 \\
\hline $\mathrm{S} \_48$ & 0,67 & 3,70 & 1,77 & 1,43 & 1,03 & 1,02 & 0,61 & 0,51 & 0,16 & 0,45 & 0,12 & 6 \\
\hline $\mathrm{S} \_49$ & 0,65 & 4,04 & 2,46 & 1,61 & 1,53 & 1,07 & 1,24 & 0,08 & 0,60 & 0,19 & 0,06 & 10 \\
\hline $\mathrm{S} \_50$ & 0,95 & 4,16 & 2,82 & 2,66 & 2,00 & 1,27 & 0,92 & 0,58 & 0,66 & 0,24 & 0,07 & 0 \\
\hline
\end{tabular}


Tabela 12: Experimento 5 (continuação) - Valores das variáveis (Divergências K-L) para cada amostra em relação a cada grupo de radicais e clusterização proposta para n=14 clusters. Cada coluna "KLn" representa o valor da divergência em relação ao grupo "n", onde $\mathrm{n}=0$ é o vocabulário completo e $\mathrm{n}$ de 1 a 10 são os grupos associados a cada percentil. A coluna "Cluster" mostra o índice do cluster obtido pelo algoritmo.

\begin{tabular}{|c|c|c|c|c|c|c|c|c|c|c|c|c|}
\hline Amostra & KL0 & KL1 & KL2 & KL3 & KL4 & KL5 & KL6 & KL7 & KL8 & KL9 & KL10 & Cluster \\
\hline S_51 & 1,01 & 4,73 & 2,89 & 2,60 & 2,93 & 1,28 & 1,73 & 0,32 & 0,44 & 0,61 & 0,10 & 5 \\
\hline $\mathrm{S} \_53$ & 0,87 & 4,16 & 2,69 & 2,16 & 1,81 & 1,64 & 1,05 & 1,08 & 0,35 & 0,66 & 0,10 & 5 \\
\hline $\mathrm{S} \_55$ & 0,51 & 1,79 & 1,01 & 0,77 & 0,75 & 0,63 & 0,70 & 0,29 & 0,35 & 0,08 & 0,03 & 7 \\
\hline $\mathrm{S} \_56$ & 0,75 & 4,18 & 2,74 & 2,30 & 1,42 & 1,08 & 1,12 & 0,58 & 0,52 & 0,23 & 0,06 & 0 \\
\hline $\mathrm{S} \_57$ & 0,89 & 3,74 & 2,54 & 1,58 & 1,94 & 1,41 & 1,27 & 1,07 & 1,00 & 0,61 & 0,06 & 5 \\
\hline $\mathrm{S} \_59$ & 0,76 & 3,86 & 2,19 & 1,81 & 1,33 & 1,39 & 0,56 & 0,62 & 0,16 & 0,12 & 0,04 & 10 \\
\hline S_60 & 1,23 & 5,82 & 3,73 & 2,41 & 2,35 & 3,23 & 2,04 & 1,96 & 1,25 & 0,93 & 0,17 & 2 \\
\hline S_6 61 & 0,65 & 2,78 & 1,58 & 1,14 & 1,06 & 0,80 & 1,21 & 0,32 & 0,78 & 0,22 & 0,03 & 13 \\
\hline S_62 & 0,70 & 3,54 & 2,13 & 1,21 & 1,53 & 0,80 & 0,65 & 0,35 & 0,13 & 0,16 & 0,05 & 3 \\
\hline $\mathrm{S} \_63$ & 0,62 & 3,37 & 1,90 & 1,44 & 0,79 & 0,59 & 0,89 & 0,36 & 0,31 & 0,10 & 0,04 & 3 \\
\hline S_64 & 0,58 & 3,41 & 1,74 & 1,03 & 0,80 & 0,72 & 0,47 & 0,17 & 0,28 & 0,16 & 0,03 & 3 \\
\hline $\mathrm{S} \_69$ & 0,92 & 3,84 & 2,49 & 1,76 & 1,72 & 0,89 & 1,18 & 1,15 & 0,49 & 0,29 & 0,04 & 0 \\
\hline $\mathrm{S} \_70$ & 0,59 & 3,62 & 2,17 & 1,21 & 1,11 & 0,53 & 0,60 & 0,33 & 0,42 & 0,28 & 0,02 & 3 \\
\hline$S_{-} \quad 71$ & 0,52 & 2,61 & 1,23 & 0,84 & 0,57 & 0,59 & 0,19 & 0,25 & 0,09 & 0,16 & 0,02 & 7 \\
\hline $\mathrm{S} \_72$ & 0,48 & 3,25 & 1,58 & 1,01 & 0,98 & 0,50 & 0,27 & 0,20 & 0,23 & 0,07 & 0,02 & 3 \\
\hline $\mathrm{S} \_73$ & 0,85 & 3,44 & 2,28 & 2,19 & 1,75 & 1,23 & 0,77 & 0,67 & 0,42 & 0,23 & 0,04 & 0 \\
\hline $\mathrm{S}-74$ & 0,76 & 2,88 & 1,71 & 1,07 & 0,98 & 0,95 & 0,49 & 0,29 & 0,17 & 0,39 & 0,14 & 6 \\
\hline $\mathrm{S}_{-} 75$ & 0,64 & 3,74 & 1,98 & 1,40 & 1,40 & 0,82 & 1,01 & 0,59 & 0,19 & 0,10 & 0,02 & 3 \\
\hline $\mathrm{S} \_76$ & 0,93 & 4,45 & 2,75 & 1,97 & 2,18 & 1,32 & 1,13 & 0,73 & 1,02 & 0,21 & 0,06 & 0 \\
\hline $\mathrm{S} \_77$ & 0,75 & 3,72 & 2,29 & 1,64 & 1,20 & 1,37 & 0,86 & 0,32 & 0,71 & 0,20 & 0,02 & 10 \\
\hline $\mathrm{S} \_78$ & 0,67 & 3,47 & 2,11 & 1,40 & 1,30 & 0,91 & 0,86 & 0,38 & 0,43 & 0,07 & 0,03 & 3 \\
\hline$S \_79$ & 0,52 & 3,22 & 1,72 & 1,38 & 1,13 & 0,42 & 0,24 & 0,46 & 0,19 & 0,09 & 0,02 & 3 \\
\hline $\mathrm{S} \_87$ & 0,79 & 3,81 & 2,97 & 1,80 & 1,40 & 0,95 & 1,06 & 1,13 & 0,50 & 0,54 & 0,06 & 11 \\
\hline $\mathrm{S} \_88$ & 0,70 & 3,71 & 2,28 & 1,48 & 1,11 & 0,59 & 0,94 & 0,34 & 0,31 & 0,22 & 0,05 & 3 \\
\hline $\mathrm{S} \_89$ & 0,56 & 3,79 & 2,14 & 1,47 & 1,12 & 0,60 & 0,71 & 0,18 & 0,61 & 0,32 & 0,05 & 3 \\
\hline S__ 90 & 1,08 & 5,01 & 3,18 & 2,28 & 2,26 & 2,13 & 1,44 & 1,26 & 1,83 & 0,97 & 0,15 & 2 \\
\hline S__ 91 & 0,64 & 3,82 & 1,96 & 1,59 & 1,22 & 1,56 & 0,89 & 0,36 & 0,39 & 0,26 & 0,03 & 10 \\
\hline $\mathrm{S} \_92$ & 0,79 & 3,43 & 2,12 & 1,41 & 1,08 & 1,07 & 0,63 & 0,39 & 0,42 & 0,61 & 0,12 & 6 \\
\hline S_-93 & 0,71 & 3,91 & 2,38 & 1,93 & 1,22 & 1,41 & 1,09 & 0,93 & 0,37 & 0,16 & 0,03 & 10 \\
\hline S_94 & 0,68 & 3,45 & 1,97 & 1,73 & 1,34 & 0,55 & 0,69 & 0,26 & 0,19 & 0,11 & 0,01 & 3 \\
\hline $\mathrm{S} \_95$ & 0,30 & 1,45 & 0,65 & 0,42 & 0,27 & 0,32 & 0,09 & 0,35 & 0,15 & 0,11 & 0,01 & 7 \\
\hline $\mathrm{S} \_96$ & 0,92 & 4,91 & 3,64 & 2,18 & 2,53 & 1,57 & 1,96 & 1,61 & 2,06 & 0,62 & 0,05 & 1 \\
\hline S__97 & 0,75 & 2,93 & 1,70 & 1,20 & 0,82 & 0,78 & 0,53 & 0,31 & 0,35 & 0,35 & 0,04 & 13 \\
\hline S_98 & 0,56 & 3,41 & 1,85 & 1,47 & 1,11 & 0,64 & 0,51 & 0,82 & 0,35 & 0,05 & 0,02 & 3 \\
\hline
\end{tabular}


Figura 34: Experimento 5 - Gráfico das Distâncias Intracluster e Intercluster. O ponto de inversão ocorre entre $n=18$ e $n=19$.

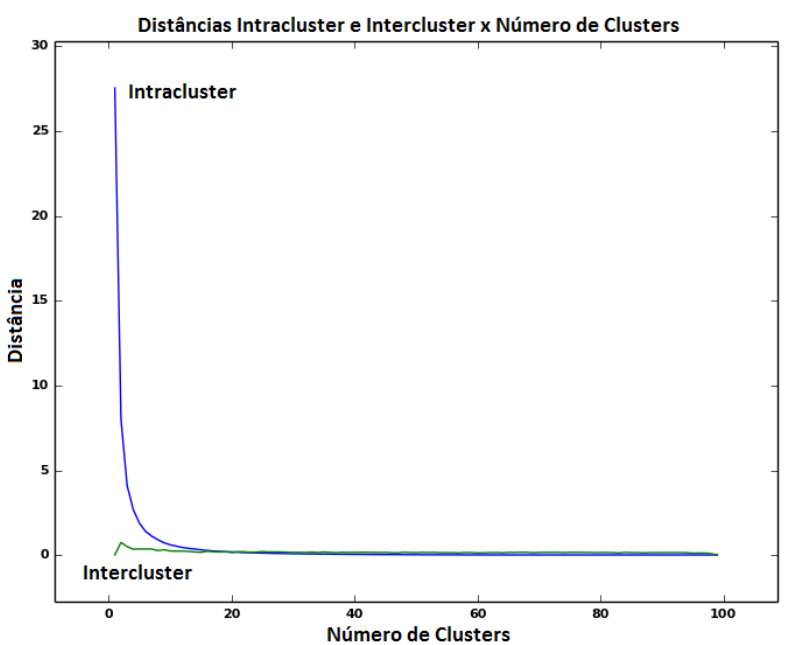

Fonte: elaborado pelo próprio autor

Figura 35: Experimento 5 - Gráfico da Razão de Validação entre as Distâncias Intracluster e Intercluster. O mínimo compensado pelo custo da complexidade (fator $(n+1) / n$ ) ocorre em $\mathrm{n}=67$, porém nota-se um mínimo local relativamente acentuado em $\mathrm{n}=25$.

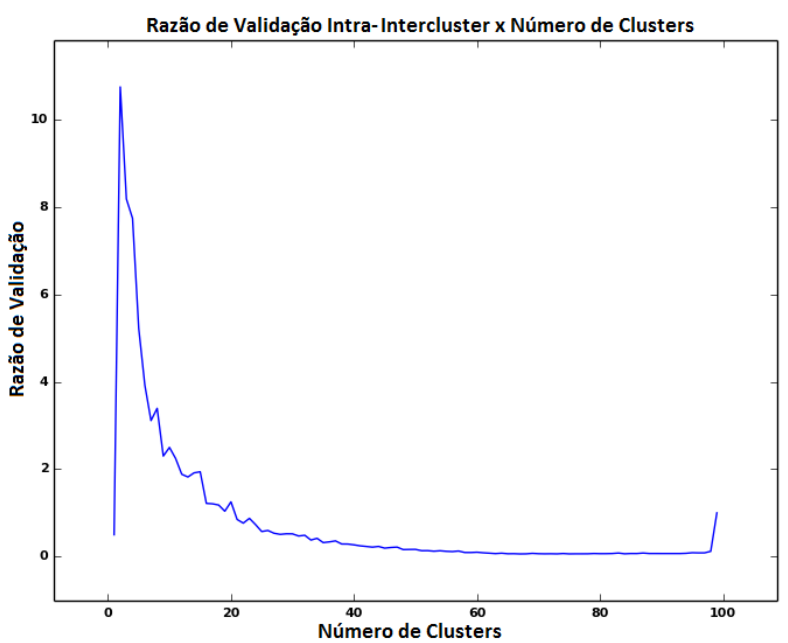

Fonte: elaborado pelo próprio autor 
Figura 36: Experimento 5 - Gráfico da Razão de Validação entre as Distâncias Intra e InterCluster a partir de $\mathrm{n}=5$ ampliado. O mínimo local em $\mathrm{n}=25$ fica mais evidente e a curva entra em relativo decaimento suave a partir daí.

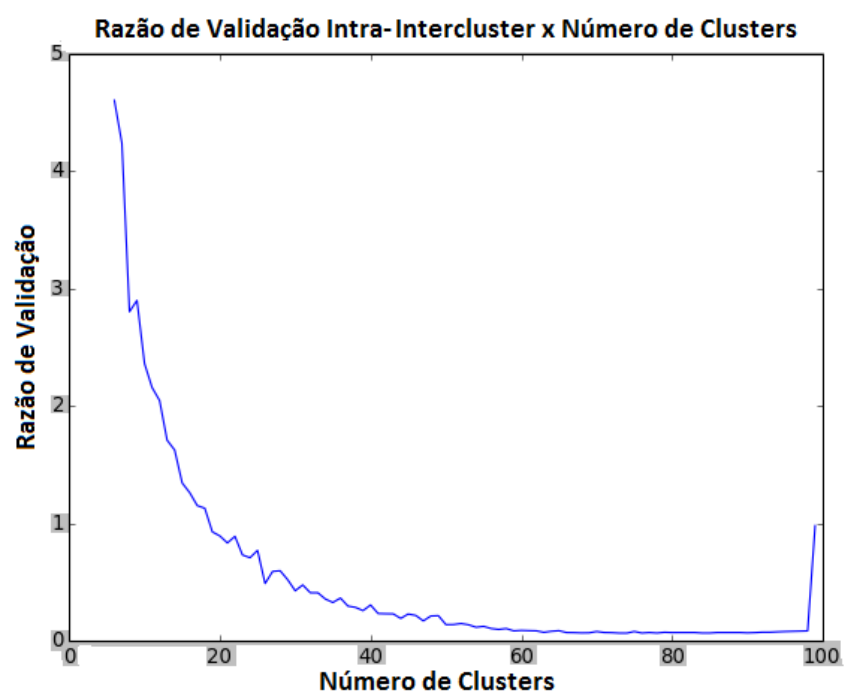

Fonte: elaborado pelo próprio autor

Figura 37: Experimento 5 - Gráfico das Distâncias Intracluster e Intercluster a partir de $\mathrm{n}=5$ ampliado. Evidencia-se o ponto de inversão entre $\mathrm{n}=18$ e n=19.

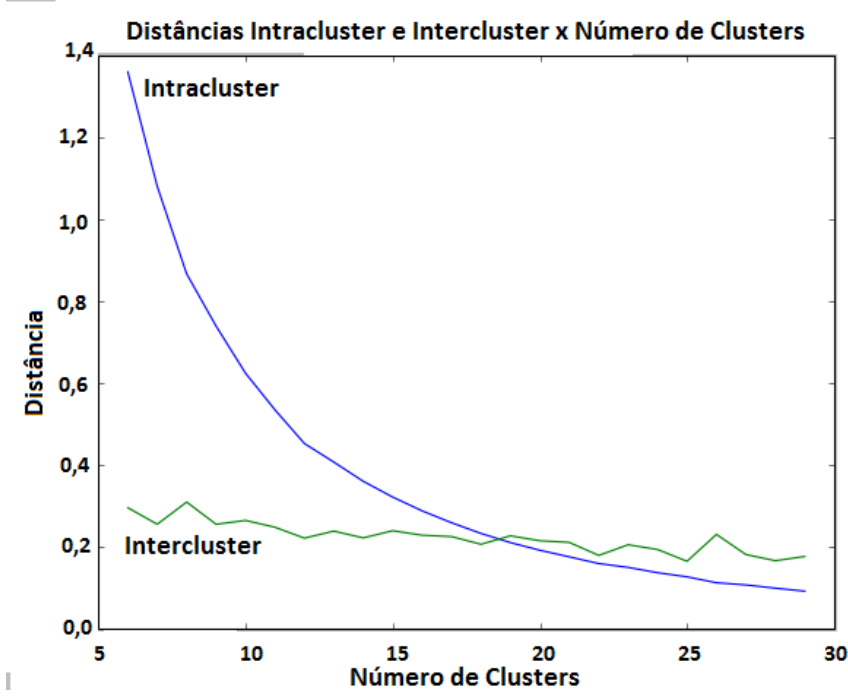

Fonte: elaborado pelo próprio autor 
Figura 38: Experimento 5 - Gráfico do agrupamento definido pelo algoritmo para $\mathrm{n}=14$, onde os eixos são as 3 dimensões dos Componentes Principais (PCA). As esferas representam os clusters, cada ponto representa uma amostra e o número anotado na lateral é o número de pontos do cluster correspondente à esfera.

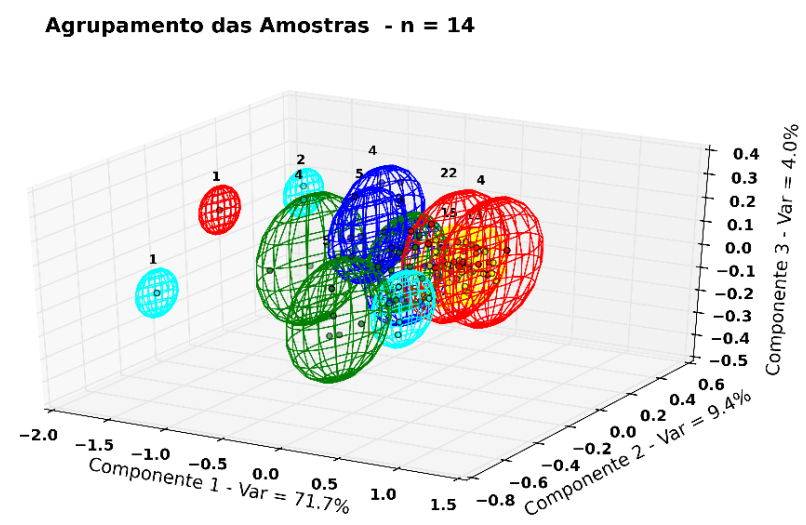

Fonte: elaborado pelo próprio autor

Tabela 13: Experimento 5 - Acurácia do agrupamento em relação às classes indicadas pelo especialista para os agrupamentos de $n=14, n=19$ e $n=25$. A acurácia é medida pelo percentual de pontos corretamente agrupados para cada classe.

\begin{tabular}{|c|c|c|c|c|c|c|c|}
\hline Classe & $\begin{array}{l}\# \\
\text { Ams. }\end{array}$ & Clusters $\mathrm{N}=14$ & $\%$ & Clusters $\mathrm{N}=19$ & $\%$ & Clusters $\mathrm{N}=25$ & $\%$ \\
\hline COMP & 13 & $3(7), 10(3), 0(2), 5(1)$ & $54 \%$ & $\begin{array}{l}8(4), 18(3), 0(2), 9 \\
11,13,17\end{array}$ & $31 \%$ & $\begin{array}{l}7(4), 2(3), 20(2), 8 \\
17,19,22\end{array}$ & $31 \%$ \\
\hline CPMF & 1 & 6 & $100 \%$ & 17 & $100 \%$ & 4 & $100 \%$ \\
\hline II & 1 & 10 & $100 \%$ & 9 & $100 \%$ & 17 & $100 \%$ \\
\hline $\mathrm{IOF}$ & 1 & 10 & $100 \%$ & 9 & $100 \%$ & 17 & $100 \%$ \\
\hline IPI & 4 & $4,5,10,7$ & $25 \%$ & $17(2), 9,13$ & $50 \%$ & $4,8,17,22$ & $25 \%$ \\
\hline IRPF & 10 & $\begin{array}{l}0(3), 5(2), 11,10,13, \\
1,2\end{array}$ & $30 \%$ & $\begin{array}{l}17(3), 0(2), 1,3,9 \\
11,12\end{array}$ & $30 \%$ & $\begin{array}{l}8(2), 20(2), 1,4,9 \\
17,19,23\end{array}$ & $20 \%$ \\
\hline IRPJ & 8 & $13(3), 10(2), 6,10,7$ & $38 \%$ & $17(3), 9(3), 1,8$ & $38 \%$ & $4(3), 17(3), 7,9$ & $38 \%$ \\
\hline ITR & 1 & 1 & $100 \%$ & 12 & $100 \%$ & 23 & $100 \%$ \\
\hline PAF & 28 & $\begin{array}{l}0(5), \quad 3(5), \quad 5(3), \\
10(3), \quad 11(3), \quad 2(2), \\
6(2), 1,9,8,7,12\end{array}$ & $18 \%$ & $\begin{array}{l}17(5), \quad 1(3), \quad 8(4), \\
11(3), \quad 13(4), \quad 0(2), \\
3(2), 6,9(2), 12,18\end{array}$ & $18 \%$ & $\begin{array}{l}22(4), \quad 1(2), \quad 2, \quad 3, \\
4(3), 7(3), 8(2), 9(3), \\
17(2), 19(3), 20(2), \\
21,23\end{array}$ & $14 \%$ \\
\hline PIS & 7 & $13(2), 3(2), 0,4,10$ & $29 \%$ & $18(4), 0,9,11$ & $58 \%$ & $2(4), 17,19,20$ & $58 \%$ \\
\hline PREV & 16 & $\begin{array}{l}10(5), 3(4), \quad 13(2), \\
7(2), 6,4,11\end{array}$ & $31 \%$ & $\begin{array}{l}8(5), 9(3), \quad 1(3), \quad 0 \\
17(3), 13\end{array}$ & $31 \%$ & $\begin{array}{l}7(5), \quad 4(3), \\
17(3), 20,22\end{array}$ & $31 \%$ \\
\hline REST & 5 & $3(2), 12,10,6$ & $40 \%$ & $9(2), 8,11,17$ & $40 \%$ & $17(2), 7,9,19$ & $40 \%$ \\
\hline SIMPLES & 2 & 10,13 & $50 \%$ & 1,9 & $50 \%$ & 9,17 & $50 \%$ \\
\hline TRIB & 2 & 5,6 & $50 \%$ & 3,11 & $50 \%$ & 1,19 & $50 \%$ \\
\hline
\end{tabular}

O índice AMI na aproximação de 3 casas decimais para $n=14, n=19$ e $n=25$ foi de 0,043, 0,020 e 0,068.

Ao contrário do exemplo anterior, o número de clusters indicado pelo cruzamento das curvas de distância aponta para $n=19$, que é maior do que número de categorias de 
textos original $(\mathrm{n}=14)$. Já o critério do fator de validação aponta para 67 clusters como o mínimo relevante, um número excessivo para 99 amostras, pois propõe um número médio de menos de 2 amostras em cada cluster; entretanto, é possível observar que há um mínimo local em $n=25$, a partir do qual o decaimento da curva estabiliza.

Quanto ao agrupamento dos textos, o resultado obtido não foi favorável. As classes com maior número de amostras resultaram em dispersão por diversos clusters e as amostras isoladas não permaneceram isoladas no agrupamentos feitos pelo algoritmo.

Ao contrário do exemplo anterior, o agrupamento em número de clusters maior do que o das classes não provocou uma simples segmentação das mesmas marcando a separação entre elas, mas apenas aumentou a difusão já presente nos agrupamentos em menor número de clusters.

Conclui-se que a metodologia proposta aplicada isoladamente não produziu resultados determinantes para esse tipo mais complexo de textos de uma mesma área. 


\section{Discussão e Conclusão}

O primeiro resultado do trabalho é o próprio Ambiente de Desenvolvimento, que ficará à disposição do Laboratório de Processamento de Sinais e dos estudantes e pesquisadores que se interessarem pela sua utilização e sua evolução. Esse ambiente já permite obter a Rede Bayesiana mais adequada para fenômenos representados diretamente em tabelas de até 5 variáveis. Também é possível processar o Agrupamento de Textos para qualquer amostra de textos devidamente formatada na forma de linhas de um único arquivo "txt" denominado "SingleFile.txt" ou na forma de um arquivo "txt" para cada amostra com denominação no formato "\#.txt", onde \# é o número da amostra com o número de dígitos adequado.

A modularidade aplicada no desenvolvimento do Ambiente, incluindo a codificação orientada a objeto, é característica fundamental, pois permite sua evolução apenas pela inserção de novos módulos na estrutura já existente. A estrutura da codificação em pacotes também permite a seleção apenas dos pacotes necessários, sem ocupação desnecessária de espaço de memória.

Além das vantagens evidentes de permitir futuras reutilizações do processamento, evolução do ambiente com incorporação de novos algoritmos para processamento de outros fenômenos, para aprendizagem da rede ou para estimação de características de novas amostras, a utilização de um Ambiente de Desenvolvimento aberto tem mais duas vantagens: gestão do conhecimento, pois o conhecimento adquirido em cada etapa da pesquisa está registrado e disponível para uso imediato no código produzido, e facilidade na reprodutibilidade dos resultados, uma grande preocupação dos pesquisadores atuais.

Quanto aos experimentos de processamento paralelo, os resultados obtidos confirmam até aqui a expectativa de que é possível obter ganhos consideráveis na velocidade de processamento a partir da paralelização dos algoritmos de aprendizado de Redes Bayesianas.

Os testes realizados indicam que a aceleração apresenta uma tendência de se aproximar da razão entre o número de núcleos de processamento, na medida em que o número de variáveis aumenta, o que significou ganhos da ordem de grandeza de até 54 vezes para o ambiente de processamento com 56 núcleos disponíveis para todo o processamento (parte 
serial, parte paralela e housekeeping).

Há que se considerar que esse nível de aceleração depende em alto grau dos algoritmos implementados. Os resultados até agora obtidos o foram com o uso da busca exaustiva e suas características específicas, dentre elas a natural segmentação do espaço em subespaços e a distribuição do processamento desses subespaços resultantes. No entanto, há outros algoritmos em que essa segmentação não é natural, como no caso dos algoritmos genéticos, nos quais a população vai evoluindo de maneira heurística, o que não permite garantir que ela vá sempre permanecer dentro de um subespaço previamente definido, o que pode dificultar o paralelismo nesse aspecto do algoritmo.

Em contrapartida, não foram ainda desenvolvidas outras linhas de abordagem do processamento paralelo, como é o caso do paralelismo no cálculo da pontuação das redes (cálculo paralelo da pontuação de diversas redes) ou do paralelismo interno ao cálculo da própria pontuação (cálculos paralelos para a pontuação de uma mesma rede), e que podem representar ganhos ainda não explorados.

Em relação à versão originalmente apresentada por ocasião da Qualificação, foi efetuada a conversão do algoritmo em uma implementação mais encapsulada, com a utilização de classes e de orientação a objetos, cuja tentativa inicial nesse sentido no período préqualificação havia sido interrompida em privilégio da produção tempestiva dos resultados para aquela apresentação.

Há que se ressaltar que se optou por evoluir por caminho diferente de parte da proposta de continuidade do trabalho apresentada na Qualificação, que seriam, dentre outros, a implementação do algoritmo de aprendizado de rede proposto por (RAFAEL; TALAVERA; CARLOS, 2012) e a utilização do processamento paralelo utilizando GPUs, pois, no desenrolar das pesquisas, percebeu-se o risco de não haver ganho significativo em termos de pesquisa ao se enveredar por áreas de conhecimento menos afetas à equipe do Laboratório e historicamente associadas a outros núcleos de pesquisa. Isso, somado à oportunidade de aplicar um trabalho a experimentos de interesse imediato da equipe, fez com que a linha de pesquisa fosse reorientada para o Agrupamento de Textos.

Quanto ao Agrupamento de Textos em específico, os resultados obtidos permitem diversas discussões e conclusões.

O primeiro ponto é que a Divergência K-L permite detectar similaridades e diferenças relacionadas à estrutura dos textos, assim considerada a proporção relativa entre um conjunto de vocábulos, mas sem considerar quais são esses vocábulos ou sua posição relativa no texto, não extraindo, portanto, nenhuma informação direta relacionada ao seu conteúdo. O experimento 2 permite identificar com clareza esse aspecto, pois todos os textos foram agrupados no mesmo cluster, apesar de tratarem de três frutas diferentes. Isso decorre da absoluta comutatividade do cálculo dessa medida em relação à frequência de cada vocábulo. Portanto, para que essa abordagem produza resultados, é necessário que o universo amostrado tenha como característica que a classificação natural dos textos 
seja tal que reflita de alguma forma em uma diferença nas estruturas dos textos de cada classe. Isso, é claro, depende do universo estudado. No presente trabalho, isso se mostrou presente no Experimento 4, porém não foi observado de forma relevante no Experimento 5, o que pode ter decorrido do fato de se tratarem de textos de uma mesma área (textos jurídicos).

Há que se discorrer, também, sobre algumas das condições de contorno assumidas no presente estudo.

A primeira delas trata da referência adotada para comparação dos textos, que foi o denominado "Supertexto". A justificativa de se utilizar o agregado de todos os textos reside no intuito da pesquisa ser diferenciar os textos entre si, portanto sob uma abordagem relativa. Caso se desejasse identificar cada texto dentro do contexto de uma língua, a referência mais adequada poderia ser um "corpus" que representa essa língua da forma mais abrangente possível. Esse critério segue a lógica de que quanto mais próxima do universo de amostras for a referência, mais destacada será a distinção entres eles, pois uma referência muito distante das características particulares dessas amostras irá resultar em uma natural atenuação das suas diferenças relativas.

Outro ponto importante é o elemento nuclear considerado para análise dos textos. Adotou-se o radical das palavras por se considerar que palavras com o mesmo radical têm alta probabilidade de refletirem textos de conteúdos extremamente próximos. Tomar meramente palavras levaria a considerar como distintas as versões singular e plural do mesmo substantivo, por exemplo, o que não seria adequado ao objetivo de similaridade de conteúdo aqui buscado. No entanto, uma evolução da metodologia proposta poderá considerar outras possibilidades, a depender de um maior balisamento e estudo do campo da Linguagem Natural.

O estudo foi desenvolvido com base em estruturas da Língua Portuguesa, porém é versátil o suficiente para que se possa adaptar a qualquer outra língua. O que é específico basicamente é o vocabulário de referência do filtro que verifica se cada palavra é uma palavra válida da língua e a função de associação de radicais (stemmer) utilizado para extrair o radical a partir de uma palavra válida. Portanto, a adaptação para outra língua consiste simplesmente em substituir esses dois elementos do algoritmo pelo seus correspondentes da língua desejada.

A estratégia de transformar cada amostra em uma distribuição de frequências de radicais depende da ordenação desses radicais por algum critério a fim de gerar um eixo horizontal ordenado sobre o qual se possa registrar a frequência de cada um deles. Ocorre que não existe uma ordenação natural ou intrínseca aos radicais de uma língua. A ordenação alfanumérica é uma ordenação meramente referencial e foi aqui adotada nesses termos, mas qualquer outra ordenação poderia ser adotada sem prejuízo do resultado, pois a comutatividade interna da formulação da Divergência K-L permite isso. Portanto, não há perda de generalidade pela adoção da ordenação alfanumérica ou qualquer outra 
que fosse adotada.

O critério de determinar a distância em relação a uma referência foi utilizado porque as distâncias dois-a-dois não agregariam maior significado e trariam maior complexidade ao tratamento.

O vocabulário foi particionado em 10 grupos de radicais de acordo com sua maior ou menor frequência entre os textos. Esse número de 10 grupos foi adotado de forma a ser grande o suficiente para caracterizar um razoável espectro da intensidade de presença desses radicais e também prevendo a possibilidade de um reagrupamento em um número menor de grupos em evoluções da pesquisa. E a formação das variáveis de caracterização de cada amostra também pode ser modificada para testar novas possibilidades. Assim, as variáveis "KL" podem ser reformuladas a partir de grupos cujos pontos de corte sejam identificados de forma adequada à distribuição da variância.

Quanto à identificação do número de clusters mais adequado, observa-se que o ponto de corte entre as distâncias intracluster e intercluster se mostrou eficiente para identificar o número de clusters para os experimentos 1,2 e 4, mas chegou a um número mais distante do real nos experimentos 3 e 5 . Já o critério da razão de validação com a relação de custo "n/(n+1)", apesar de ter apresentado um número de classes maior do que o real para o agrupamento do experimento 4, esse agrupamento com $n=14$ conseguiu destacar os elementos das 5 classes, distribuídos em um número maior de classes do que o original. Para os experimentos 3 e 5, o número de clusters indicado pelo critério da Razão de Validação aproximou-se do indicado pelos máximos do índice AMI, mas não correspondeu ao número real de classes $(n=12$ e $n=67$, ambos para 20 classes). No caso do experimento 5, há um destacado mínimo local em $n=25$, o que pode indicar uma necessidade de adequação da relação de custo de complexidade utilizada.

Como se concluiu que a Divergência K-L não representa informação suficiente acerca dos textos para realizar o agrupamento em uma situação geral, não se pode concluir pela eficiência ou não dos critérios de obtenção do número de classes em agrupamento de textos apenas a partir dos resultados do uso isolado dessa divergência.

Portanto, o uso da Divergência K-L se mostra relevante como um elemento para detecção de similaridades nas estruturas dos textos, e que pode ser usado no agrupamento de textos em composição com outros que detectem outras características, como conteúdo. A detecção de conteúdo pode ser prospectada, por exemplo, a partir da introdução de variáveis baseadas em medidas que considerem o tamanho do texto, a posição de ocorrência das palavras e dos radicais, associadas à consideração dos radicais de destaque de cada texto (os mais e os menos frequentes, por exemplo).

A vantagem da metodologia aqui proposta é a simplificação resultante do afastamento de um tratamento complexo baseado em Linguagem Natural, sem a necessidade do aprofundamento nessas técnicas e sem vinculação a estruturas específicas de uma ou outra língua. 
No contexto dos objetivos da presente pesquisa, os resultados não evidenciaram qualquer desequilíbrio relevante entre generalidade, efetividade e custo. O algoritmo atendeu ao requisito da generalidade, pois não privilegiou nenhuma especificidade dos contextos das amostras utilizadas, e pode ser aplicado a outros contextos; foi relativamente efetivo, pois produziu um agrupamento com grau de eficiência aceitável nos experimentos controlados e, naqueles em que os resultados não foram conclusivos, as conclusões indicam que pode ser um elemento a se tornar útil se complementado por outros elementos; e o tempo de processamento observado se mostrou compatível com os volumes processados.

Há, de imediato, diversas linhas de pesquisa que podem ser propostas em continuidade aos estudos desenvolvidos no presente trabalho, como a utilização de formas derivadas da Divergência K-L (por exemplo, sua versão simétrica), a utilização de uma referência externa (um corpus padrão da língua nativa dos textos utilizados) e o estudo do melhor número de grupos a ser usado de acordo com o conjunto de textos a ser analisado, dentre outros.

Concluindo, há que se ressaltar que o presente estudo buscou agregar, em essência, os seguintes valores ao campo de pesquisa de Reconhecimento de Padrões e Aprendizado de Máquina: uma ferramenta, com o Ambiente de Desenvolvimento para aprendizagem de máquina com Redes Bayesianas; uma referência básica, com a experimentação de mecanismos de Processamento Paralelo na aprendizagem de Redes Bayesianas; e uma alternativa a ser avaliada, com a proposição de uma metodologia para o uso da Divergência K-L no agrupamento de textos, uma medida que se mostrou útil, desde que não utilizada de forma isolada, mas em conjunto com variáveis representativas de conteúdo. 


\section{Referências}

ABDAT, F.; LECLERCQ, S.; CUNY, X.; TISSOT, C. Extracting recurrent scenarios from narrative texts using a Bayesian network: Application to serious occupational accidents with movement disturbance. Accident Analysis and Prevention, 2014. v. 70, p. 155-166, 2014. ISSN 00014575.

ABRAHAMS, D.; GROSSE-KUNSTLEVE, R. W. Building hybrid systems with boost. python. CC Plus Plus Users Journal, 2003. CMP Media LLC, v. 21, n. 7, p. 29-36, 2003.

ALIFERIS, C. F.; TSAMARDINOS, I.; STATNIKOV, A. R.; BROWN, L. E. Causal Explorer: A Causal Probabilistic Network Learning Toolkit for Biomedical Discovery. Metmbs, 2003. v. 3, p. 371-376, 2003.

BASOLE, R. C.; SEUSS, C. D.; ROUSE, W. B. IT innovation adoption by enterprises: Knowledge discovery through text analytics. Decision Support Systems, 2013. Elsevier B.V., v. 54, n. 2, p. 1044-1054, 2013. ISSN 01679236. Disponível em: $<$ http://dx.doi.org/10.1016/j.dss.2012.10.029>.

BIRD, S. Nltk: the natural language toolkit. In: ASSOCIATION FOR COMPUTATIONAL LINGUISTICS. Proceedings of the COLING/ACL on Interactive presentation sessions. [S.1.], 2006. p. 69-72.

BOSE, R. Advanced analytics: opportunities and challenges. Industrial Management \& Data Systems, 2009. v. 109, n. 2, p. 155-172, 2009. ISSN 0263-5577. Disponível em: <http://www.emeraldinsight.com/doi/abs/10.1108/02635570910930073>.

BRUNING, E. Streamed clustering of lightning mapping data in python using sklearn. In: Proceedings 12th Python in Science Conference (SciPy). [S.l.: s.n.], 2013. v. 2 .

CARVAlHO, A. A Cooperative Coevolutionary Genetic Algorithm for Learning Bayesian Network Structures. In: Gecco-2011: Proceedings of the 13th Annual Genetic and Evolutionary Computation Conference. New York, NY, USA: ACM, 2011. (GECCO '11), p. 1131-1138. ISBN 9781450305570.

CASTILLO, E.; HADI, A. S. Fitting the Generalized Pareto Distribution to Data.

Journal of the American Statistical Association, 1997. v. 92, n. 440, p. 1609-1620, 
1997. ISSN 0162-1459. Disponível em: <http://www.tandfonline.com/doi/abs/10.1080/01621459.1997.10473683\backslashnpapers2://publication/doi/10.1080/01621459.1997$.10473683>$.

COHEN, K. B.; HUNTER, L. Getting started in text mining. PLoS Computational Biology, 2008. v. 4, n. 1, p. 0001-0003, 2008. ISSN 1553734X.

COOPER, G. F. The computational complexity of probabilistic inference using bayesian belief networks. 1990. 393-405 p.

COOPER, G. F.; HERSKOVITS, E. H. A Bayesian method for the induction of probabilistic networks from data. Machine Learning, 1992. v. 9, n. 4, p. 309-347, oct 1992. ISSN 0885-6125. Disponível em: <http://www.springerlink.com/content/t2k011n123r16831>.

COVER, T. M.; THOMAS, J. A.; KIEFFER, J. Elements of information theory. [S.l.]: John Wiley \& Sons, 1994. ISBN 0-471-06259-6.

DEMPSTER, A. P.; LAIRD, N.; D.B. Rubin. Maximum Likelihood from Incomplete Data via the EM Algorithm. Journal of the Royal Statistical Society. Series B, 1976. v. 39, n. 1, p. 290-295, 1976. ISSN 00359246. Disponível em: <http://www.jstor.org/stable/10.2307/2984875>.

DHILLON, I. S.; MALLELA, S.; KUMAR, R. A divisive information theoretic feature clustering algorithm for text classification. The Journal of Machine Learning Research, 2003. JMLR. org, v. 3, p. 1265-1287, 2003.

GANDOMI, A.; HAIDER, M. Beyond the hype: Big data concepts, methods, and analytics. International Journal of Information Management, 2014. Elsevier Ltd, v. 35, n. 2, p. 137-144, 2014. ISSN 02684012. Disponível em: <http://dx.doi.org/10$.1016 /$ j.ijinfomgt.2014.10.007>.

GARCIA, E.; ZSCHIEGNER, N.; HAUSOTTE, T. Parallel high-performance computing of Bayes estimation for signal processing and metrology the open source parallel Bayesian toolbox. In: 2013 International Conference on Computing, Management and Telecommunications, ComManTel 2013. [S.l.: s.n.], 2013. p. 212-218. ISBN 9781467320870 .

GHOSH, S. A.; STREHL, A. Clusters Ensembles-A Knowledge Reuse Framework for Combining Multiple Partition. Journal of Mathine Learning Research, 2002. v. 3, p. $583-617,2002$.

GOMES, F. T.; ALEXANDRE, T.; PARDO, S. Classificação e agrupamento de textos para processamento multidocumento. 2009. p. 2-5, 2009.

GRAMA, A.; GUPTA, A.; KARYPIS, G.; KUMAR, V. Introduction to Parallel Computing; 2nd Edition. Search, 2003. p. 856, 2003.

GRAYSON, J. E. Python and Tkinter programming. [S.l.]: Manning Greenwich, 2000.

GRIMES, S. A Brief History of Text Messaging. BeyeNetwork, October, 2012. v. 30, p. 5-6, 2012. 
GUElPeli, M. V. C. Cassiopeia: Um Modelo De Agrupamento De Textos Baseado Em Sumarizacao. Tese (Doutorado) - Universidade Federal Fluminense, 2012.

GUELPELI, M. V. C.; HORTA, A.; GARCIA, A. C. B. CASSIOPEIA: A model based on summarization and clusterization used for knowledge discovery in textual bases. In: IEEE. 2009 International Conference on Natural Language Processing and Knowledge Engineering, NLP-KE 2009. [S.l.], 2009. p. 1-8. ISBN 9781424445387.

HINCKS, T. K.; KOMOROWSKI, J.-C.; SPARKS, S. R.; ASPINALL, W. P. Retrospective analysis of uncertain eruption precursors at La Soufriere volcano, Guadeloupe, 1975-77: volcanic hazard assessment using a Bayesian Belief Network approach. Journal of Applied Volcanology, 2014. v. 3, n. 1, p. 3, 2014. ISSN 2191-5040. Disponível em: <http://www.appliedvolc.com/content/3/1/3>.

HUANG, A. Similarity measures for text document clustering. Proceedings of the Sixth New Zealand, 2008. n. April, p. 49-56, 2008.

HUBERT, L.; ARABIE, P. Comparing partitions. Journal of Classification, 1985. v. 2, n. 1, p. 193-218, 1985. ISSN 01764268. Disponível em: <http://dx.doi.org/10.1007/BF01908075>.

HUNTER, J. D. Matplotlib: A 2d graphics environment. Computing In Science \& Engineering, 2007. IEEE COMPUTER SOC, v. 9, n. 3, p. 90-95, 2007.

HUSMEIER, D.; DYBOWSKI, R.; ROBERTS, S. Probabilistic Modelling in Bioinformatics and Medical Informatics. [S.l.: s.n.], 2004. xix, 504 p. ISSN 09641998. ISBN 1852337788.

IPYTHON, T.; TEAM, D. IPython Documentation. Development, 2011. v. 3, p. 293-299, 2011. Disponível em: <http://ipython.scipy.org/moin/>.

IYER, S. P.; SHAFRAN, I.; GRAYSON, D.; GATES, K.; NIGG, J. T.; FAIR, D. A. Inferring functional connectivity in MRI using Bayesian network structure learning with a modified PC algorithm. Neuroimage, 2013. Elsevier, v. 75C, p. 165-175, 2013. ISSN 1095-9572; 1053-8119.

JAIN, A. K. Data clustering: 50 years beyond K-means. Pattern Recognition Letters, 2010. Elsevier B.V., v. 31, n. 8, p. 651-666, 2010. ISSN 01678655. Disponível em: <http://dx.doi.org/10.1016/j.patrec.2009.09.011>.

JIA, H. Y.; LIU, D. Y.; CHEN, J.; GUAN, J. H. Learning Markov equivalence classes of Bayesian network with immune genetic algorithm. In: IEEE. Iciea 2008: 3rd Ieee Conference on Industrial Electronics and Applications, Proceedings, Vols 1-3. [S.l.], 2008. p. 197-202.

JONES, E.; OLIPHANT, T.; PETERSON, P. et al. SciPy: Open source scientific tools for Python. 2001. [Online; accessed 2016-03-12]. Disponível em: $<$ http://www.scipy.org/>.

JOSEPH, J. F.; GUILLAUME, J. H. A. Using a parallelized MCMC algorithm in R to identify appropriate likelihood functions for SWAT. Environmental Modelling and Software, 2013. Elsevier, v. 46, p. 292-298, 2013. ISSN 13648152. 
KAHN, C. E.; ROBERTS, L. M.; SHAFFER, K. A.; HADDAWY, P. Construction of a Bayesian network for mammographic diagnosis of breast cancer. Computers in Biology and Medicine, 1997. v. 27, n. 1, p. 19-29, 1997. ISSN 00104825.

KARMALI, F.; MERFELD, D. M. A distributed, dynamic, parallel computational model: the role of noise in velocity storage. Journal of Neurophysiology, 2012. Am Physiological Soc, v. 108, n. 2, p. 390-405, 2012. ISSN 0022-3077.

KHATTER, H.; AGGARWAL, V. Efficient parallel processing by improved cpu-gpu interaction. In: IEEE. Issues and Challenges in Intelligent Computing Techniques (ICICT), 2014 International Conference on. [S.l.], 2014. p. 159-161.

KOLEV, K.; BROX, T.; CREMERS, D. Fast joint estimation of silhouettes and dense 3D geometry from multiple images. IEEE Transactions on Pattern Analysis and Machine Intelligence, 2012. IEEE, v. 34, n. 3, p. 493-505, 2012. ISSN 01628828.

KROEZE, J. a. N. H.; MATTHEE, M. C.; BOTHMA, T. J. D. Differentiating Data- and Text-Mining Terminology. Proceedings of the 2003 annual research conference of the South African institute of computer scientists and information technologists on Enablement through technology, 2003. v. 6, n. December, p. 93 -101, 2003. Disponível em: <http://dl.acm.org/citation.cfm?id=954014.954024>.

KULLBACK, S.; LEIBLER, R. A. On Information and Sufficiency. The Annals of Mathematical Statistics, 1951. v. 22, n. 1, p. 79-86, 1951. ISSN 0003-4851.

LARRAÑAGA, P.; MORAL, S. Probabilistic graphical models in artificial intelligence. Applied Soft Computing, 2011. v. 11, n. 2, p. 1511-1528, mar 2011. ISSN 15684946. Disponível em: <http://linkinghub.elsevier.com/retrieve/pii/S1568494608000094>.

LI, C.; LIAKATA, M.; REBHOLZ-SCHUHMANN, D. Biological network extraction from scientific literature: State of the art and challenges. Briefings in Bioinformatics, 2013. v. 15, n. 5, p. 856-877, 2013. ISSN 14774054. Disponível em: <http://bib.oxfordjournals.org/content/early/2013/02/22/bib.bbt006.abstract>.

Lía Chávez, B.; YAMAMOTO, J. M. Análisis de contenido y lingüística computacional: $\mathrm{Su}$ rapidez, confiabilidad y perspectives. Anales de Psicologia, 2014. v. 30, n. 3, p. 1146-1150, 2014. ISSN 16952294.

LU, D.; YE, M.; HILL, M. C.; POETER, E. P.; CURTIS, G. P. A computer program for uncertainty analysis integrating regression and Bayesian methods. Environmental Modelling and Software, 2014. Elsevier, v. 60, p. 45-56, 2014. ISSN 13648152.

MARRON, J. S.; ALONSO, A. M. Overview of object oriented data analysis. Biometrical Journal, 2014. v. 56, n. 5, p. 732-753, 2014. ISSN 15214036. Disponível em: <http://www.ncbi.nlm.nih.gov/pubmed/24421177>.

MCLACHLAN, G. J.; KRISHNAN, T. The EM Algorithm and Extensions: Second Edition. The EM Algorithm and Extensions: Second Edition, 2007. v. 274, p. 1-369, 2007. ISSN 00401706. Disponível em: <http://doi.wiley.com/10.1002/9780470191613>.

MORAIS, S. R. de; AUSSEM, A. A novel Markov boundary based feature subset selection algorithm. Neurocomputing, 2010. v. 73, n. 4-6, p. 578-584, 2010. ISSN 09252312 . 
MORIMOTO, Y.; KONDO, Y.; KATAOKA, H.; HONDA, Y.; KOZU, R.; SAKAMOTO, J.; NAKANO, J.; ORIGUCHI, T.; YOSHIMURA, T.; OKITA, M. Heat treatment inhibits skeletal muscle atrophy of glucocorticoid-induced myopathy in rats.

Physiological Research, 2015. v. 64, n. 6, p. 897-905, 2015. ISSN 08628408. Disponível em: <http://dl.acm.org/citation.cfm?id=2078195\backslashnhttp://arxiv.org/abs$/ 1201.0490>$.

NAVARRE, S.; STEIMAN, H. Root-End Fracture During Retropreparation: A Comparison Between Zirconium Nitride-Coated and Stainless Steel Microsurgical Ultrasonic Instruments. In: Journal of Endodontics. [s.n.], 2002. v. 28, n. 4, cap. Preface, p. 330-332. ISBN 9780596516499. Disponível em: <http://linkinghub.elsevier.com/retrieve/pii/S0099239905606371>.

NEAPOLITAN, R. E. Learning Bayesian Networks. [s.n.], 2010. 505-19 p. ISSN 1748-5673. ISBN 0130125342. Disponível em: <http://www.ncbi.nlm.nih.gov/pubmed/21659034>.

OUSTERHOUT, J. K. Tcl and the tk toolkit. Computer Science Division, Department of Electrical Engineering and Computer Science, University of California, Berkeley, 1993. 1993.

PARK, H. S.; CHO, S. B. Evolutionary attribute ordering in Bayesian networks for predicting the metabolic syndrome. Expert Systems with Applications, 2012. v. 39, n. 4, p. 4240-4249, 2012. ISSN 09574174.

PARK, S.; AGGARWAL, J. K. A hierarchical Bayesian network for event recognition of human actions and interactions. Multimedia Systems, 2004. v. 10, n. 2, p. 164-179, 2004. ISSN 09424962.

PARK, S.; LEE, W.; MOON, I. C. Efficient extraction of domain specific sentiment lexicon with active learning. Pattern Recognition Letters, 2015. Elsevier Ltd., v. 56, p. 38-44, 2015. ISSN 01678655. Disponível em: <http://linkinghub.elsevier.com/retrieve/pii/S0167865515000227>.

PEARL, J. Probabalistic Reasoning in Intelligent Systems. [S.l.: s.n.], 1988. 552 p. ISBN 0-444-88650-8.

PÉREZ, F.; GRANGER, B. E. IPython: A system for interactive scientific computing. Computing in Science and Engineering, 2007. IEEE Computer Society, v. 9, n. 3, p. 21-29, 2007. ISSN 15219615. Disponível em: <http://ipython.org>.

PHAN, K.; XIE, A.; La Meir, M.; BLACK, D.; YAN, T. D. Surgical ablation for treatment of atrial fibrillation in cardiac surgery: a cumulative meta-analysis of randomised controlled trials. Heart, 2014. BMJ Publishing Group Ltd and British Cardiovascular Society, v. 100, n. 9, p. 722-730, 2014. ISSN 1355-6037. Disponível em: $<$ http://heart.bmj.com/content/100/9/722.long $>$.

POLlinO, C. A.; WOODBERRY, O.; NICHOLSON, A.; KORB, K.; HART, B. T. Parameterisation and evaluation of a Bayesian network for use in an ecological risk assessment. Environmental Modelling and Software, 2007. v. 22, n. 8, p. 1140-1152, 2007. ISSN 13648152. Disponível em: <http://www.sciencedirect.com/science/article/pii/S1364815206000788>. 
PREVITALI, F.; ARRIETA, A. F.; ERMANNI, P. Double-walled corrugated structure for bending-stiff anisotropic morphing skins. Journal of Intelligent Material Systems and Structures, 2015. v. 26, n. 5, p. 599-613, 2015. ISSN 1045-389X. Disponível em: <http://jim.sagepub.com/cgi/doi/10.1177/1045389X14554132>.

RADENSKI, A. Python first. ACM SIGCSE Bulletin, 2006. v. 38, n. 3, p. 197, 2006. ISSN 00978418. Disponível em: <http://portal.acm.org/citation.cfm?doid=1140123$.1140177>$.

RAFAEL, E.; TALAVERA, V.; CARLOS, S. Sistema evolutivo eficiente para aprendizagem estrutural de redes Bayesianas. Tese (Doutorado) - Universidade de $S\{\tilde{a}\} o$ Paulo, 2012.

RAY, S.; TURI, R. Determination of number of clusters in k-means clustering and application in colour image segmentation. Proceedings of the 4th international conference on advances in pattern recognition and digital techniques, 1999. p. 137-143, 1999. Disponível em: <http://www.csse.monash.edu.au/ roset/papers/cal99$. \mathrm{p}>$.

ROBINSON, R. W. Counting unlabeled acyclic digraphs. In: Combinatorial Mathematics V. [s.n.], 1977. v. 622, p. 28-43. ISBN 978-3-540-08524-9. Disponível em: $<$ http://dx.doi.org/10.1007/bfb0069178>.

RODGERS, D. P. Improvements in multiprocessor system design. 1985. 225-231 p.

ROKACH, L.; MAIMON, O. Clustering methods. In: MAIMON, O.; ROKACH, L. (Ed.). Data mining and knowledge discovery handbook. [S.l.]: Springer US, 2005. p. 321-352. ISBN 0387244352.

ROSENBERG, A.; HIRSCHBERG, J. V-measure: A conditional entropy-based external cluster evaluation measure. In: Proceedings of the 2007 Joint Conference on Empirical Methods in Natural Language Processing and Computational Natural Language Learning. [s.n.], 2007. v. 1, n. June, p. 410-420. Disponível em: $<$ http://acl.ldc.upenn.edu/D/D07/D07-1043.pdf>.

ROUSSEEUW, P. J. Silhouettes-a graphical aid to the interpretation and validation of cluster analysis. Journal of computational and applied mathematics, 1987. Elsevier, v. 20, p. 53-65, 1987.

SHANNON, C. A mathematical theory of communication. ACM SIGMOBILE Mobile ComThe Bell System Technical Journalputing and ..., 1948. ACM, v. 27, n. July 1948, p. 379-423, 1948. ISSN 07246811. Disponível em: $<$ http://dl.acm.org/citation.cfm?id=584093>.

SILVA, M. d. S. e-Processo: um passo para a gestao pela qualidade. 2006. Disponível em: <http://www.esaf.fazenda.gov.br/assuntos/premios/premios-1/ premios/pasta-premio-de-criatividade-e-inovacao-da-rfb/ monografias-premiadas-20133o-premio-schoentag-2004/5o-premio-schontag-2006>.

SPELLMAN, P. T.; SHERLOCK, G.; ZHANG, M. Q.; R, V.; ANDERS, K.; EISEN, M. B.; BROWN, P. O.; FUTCHER, B. Comprehensive identification of cell cycle-regulated genes of the yeast Saccharomyces cerevisiae by microarray hybridization. 
Molecular Biology of the Cell, 1998. v. 9, n. December 1998, p. 3273-3297, 1998. ISSN 1059-1524 (Print).

STOMMEL, M.; HERZOG, O.; XU, W. L. A quantitative evaluation of the conceptual consistency of visual words and visual vocabularies. Journal of Visual Communication and Image Representation, 2015. v. 28, p. 120-129, 2015. ISSN 10959076. Disponível em: <http://www.sciencedirect.com/science/article/pii/S1047320314001965>.

SUN, S.; ZHANG, C.; YU, G. A Bayesian network approach to traffic flow forecasting. IEEE Transactions on Intelligent Transportation Systems, 2006. v. 7, n. 1, p. 124-133, 2006. ISSN 15249050. Disponível em: <http://www.oldenbourg-link.com/doi/pdf/10.1524/auto.2001.49.11.505\backslashnhttp://ieeexplore.ieee.org/xpls/abs\_all.jsp?arnumber $=1603>$.

THORLUND, K.; ZAFARI, Z.; DRUYTS, E.; MILLS, E. J.; SADATSAFAVI, M. The impact of incorporating Bayesian network meta-analysis in cost-effectiveness analysis a case study of pharmacotherapies for moderate to severe COPD. Cost effectiveness and resource allocation : $\mathbf{C} / \mathbf{E}, 2014$. v. 12, n. 1, p. 8, 2014 . ISSN 1478-7547. Disponível em: <http://www.resource-allocation.com/content/12/1/8>.

TSAMARDINOS, I.; BROWN, L. E.; ALIFERIS, C. F. The max-min hill-climbing Bayesian network structure learning algorithm. Machine Learning, 2006. v. 65, n. 1, p. 31-78, 2006. ISSN 08856125. Disponível em: <http://link.springer.com/10.1007/s10994006-6889-7>.

VELIKOVA, M.; Van Scheltinga, J. T.; LUCAS, P. J. F.; SPAANDERMAN, M. Exploiting causal functional relationships in Bayesian network modelling for personalised healthcare. In: International Journal of Approximate Reasoning. [S.l.: s.n.], 2014. v. 55, n. 1 PART 1, p. 59-73. ISBN 0888-613X. ISSN 0888613X.

VILLANUEVA, E.; MACIEL, C. D. Efficient methods for learning Bayesian network super-structures. Neurocomputing, 2014. v. 123, p. 3-12, 2014. ISSN 09252312.

VINH, N. X. Information Theoretic Measures for Clusterings Comparison : Variants , Properties, Normalization and Correction for Chance. In: ACM. Proceedings of the 26th Annual International Conference on Machine Learning. [S.l.], 2010. v. 11, p. $2837-2854$.

Information Theoretic Measures for Clusterings Comparison : Variants , Properties, Normalization and Correction for Chance. The Journal of Machine Learning Research, 2010. JMLR. org, v. 11, p. 2837-2854, 2010.

WONG, A. a.; READ, S. J. 2011 ASA guideline on the management of patients with extracranial carotid and vertebral artery disease. A report of the American College of Cardiology Foundation and American Heart Association Task F. London: Mendeley Ltd., 2011. e54-130 p. Disponível em: $<$ http://www.ncbi.nlm.nih.gov/pubmed/17515473>.

ZOU, M. A new dynamic Bayesian network (DBN) approach for identifying gene regulatory networks from time course microarray data. Bioinformatics, 2005. v. 21, n. 1, p. 71-79, 2005. Disponível em: <http://bioinformatics.oxfordjournals.org/cgi/content/abstract/21/1/71>. 